Article

\title{
Muraymycin Nucleoside Antibiotics: Structure- Activity Relationship for Variations in the Nucleoside Unit
}

\author{
Anna Heib \$, Giuliana Niro $\$$, Stefanie C. Weck, Stefan Koppermann and Christian Ducho *(1) \\ Department of Pharmacy, Pharmaceutical and Medicinal Chemistry, Saarland University, Campus C2 3 , \\ 66123 Saarbrücken, Germany; s9aahei2@stud.uni-saarland.de (A.H.); giuliana.niro@uni-saarland.de (G.N.); \\ stefanie.weck@uni-saarland.de (S.C.W.); stefan.koppermann@uni-saarland.de (S.K.) \\ * Correspondence: christian.ducho@uni-saarland.de; Tel.: +49-(0)681-302-70343 \\ $\S$ These authors contributed equally to this work. \\ Academic Editors: Katherine Seley-Radtke and Theodore K. Dayie \\ Received: 14 November 2019; Accepted: 12 December 2019; Published: 19 December 2019

\begin{abstract}
Muraymycins are a subclass of naturally occurring nucleoside antibiotics with promising antibacterial activity. They inhibit the bacterial enzyme translocase I (MraY), a clinically yet unexploited target mediating an essential intracellular step of bacterial peptidoglycan biosynthesis. Several structurally simplified muraymycin analogues have already been synthesized for structure-activity relationship (SAR) studies. We now report on novel derivatives with unprecedented variations in the nucleoside unit. For the synthesis of these new muraymycin analogues, we employed a bipartite approach facilitating the introduction of different nucleosyl amino acid motifs. This also included thymidine- and 5-fluorouridine-derived nucleoside core structures. Using an in vitro assay for MraY activity, it was found that the introduction of substituents in the 5-position of the pyrimidine nucleobase led to a significant loss of inhibitory activity towards MraY. The loss of nucleobase aromaticity (by reduction of the uracil C5-C6 double bond) resulted in a ca. tenfold decrease in inhibitory potency. In contrast, removal of the $2^{\prime}$-hydroxy group furnished retained activity, thus demonstrating that modifications of the ribose moiety might be well-tolerated. Overall, these new SAR insights will guide the future design of novel muraymycin analogues for their potential development towards antibacterial drug candidates.
\end{abstract}

Keywords: antibiotics; natural products; nucleoside analogues; structure-activity relationships

\section{Introduction}

The increasing number of bacterial infections with strains that are resistant against established antibiotics are a major challenge in current and future clinical healthcare [1,2]. For the development of new antimicrobial drug candidates, cross resistances with established antibiotics are a central concern. Therefore, novel targets and yet unexploited modes of action need to be identified [3]. A promising target not yet addressed by clinically established classes of antibiotics is the bacterial enzyme MraY (translocase I) which mediates a key step in the intracellular stages of bacterial cell wall biosynthesis [4-6]. MraY catalyzes the first membrane-associated step in the cytosolic stage of peptidoglycan synthesis, i.e., the formation of the membrane-bound intermediate lipid I by reaction of UDP-MurNAc pentapeptide ('Park's nucleotide') with the isoprenoid membrane anchor undecaprenyl phosphate (Scheme 1) [7-13]. 


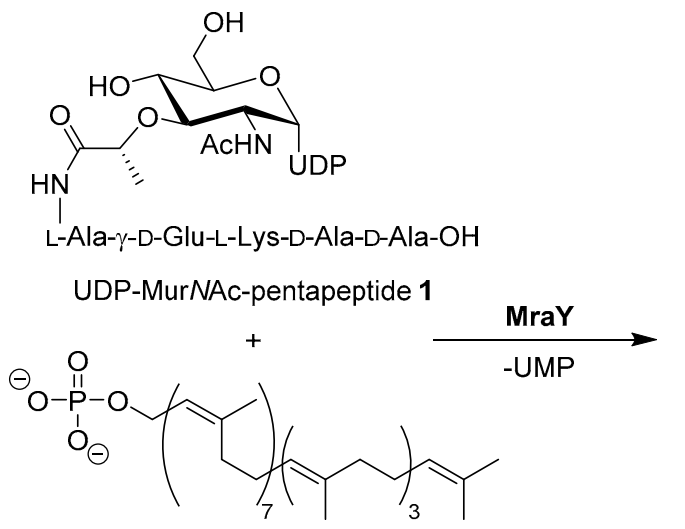

undecaprenyl phosphate 2

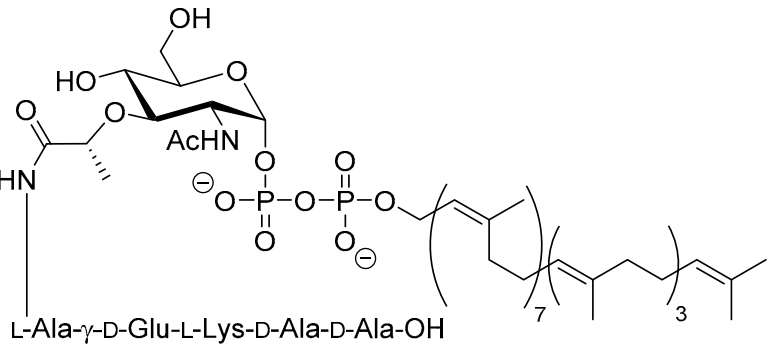

lipid I 3

Scheme 1. Reaction of Park's nucleotide 1 with undecaprenyl phosphate 2 yielding lipid I 3, catalyzed by MraY (translocase I). UDP = uridine diphosphate, UMP = uridine monophosphate. The exact composition of the pentapeptide moiety varies among different bacteria [12].

Nucleoside antibiotics are naturally produced secondary metabolites acting as MraY inhibitors. Several subclasses such as muraymycins, mureidomycins, tunicamycins, liposidomycins, and capuramycins have been reported [13-16]. Our research on nucleoside antibiotics mainly focusses on muraymycins which were isolated from Streptomyces sp. as a set of 19 structurally varying natural products [13,17]. Recently, several new members of this subclass have been reported [18]. Muraymycins can be divided into four groups (A-D, Figure 1). They share a joint backbone structure, i.e., a uridine-derived nucleosyl amino acid ('glycyluridine', GlyU) motif and a urea-containing peptide moiety, but vary in the substitution pattern at the central L-leucine unit and in the presence of aminoribosyl substituents in the $5^{\prime}$-position.

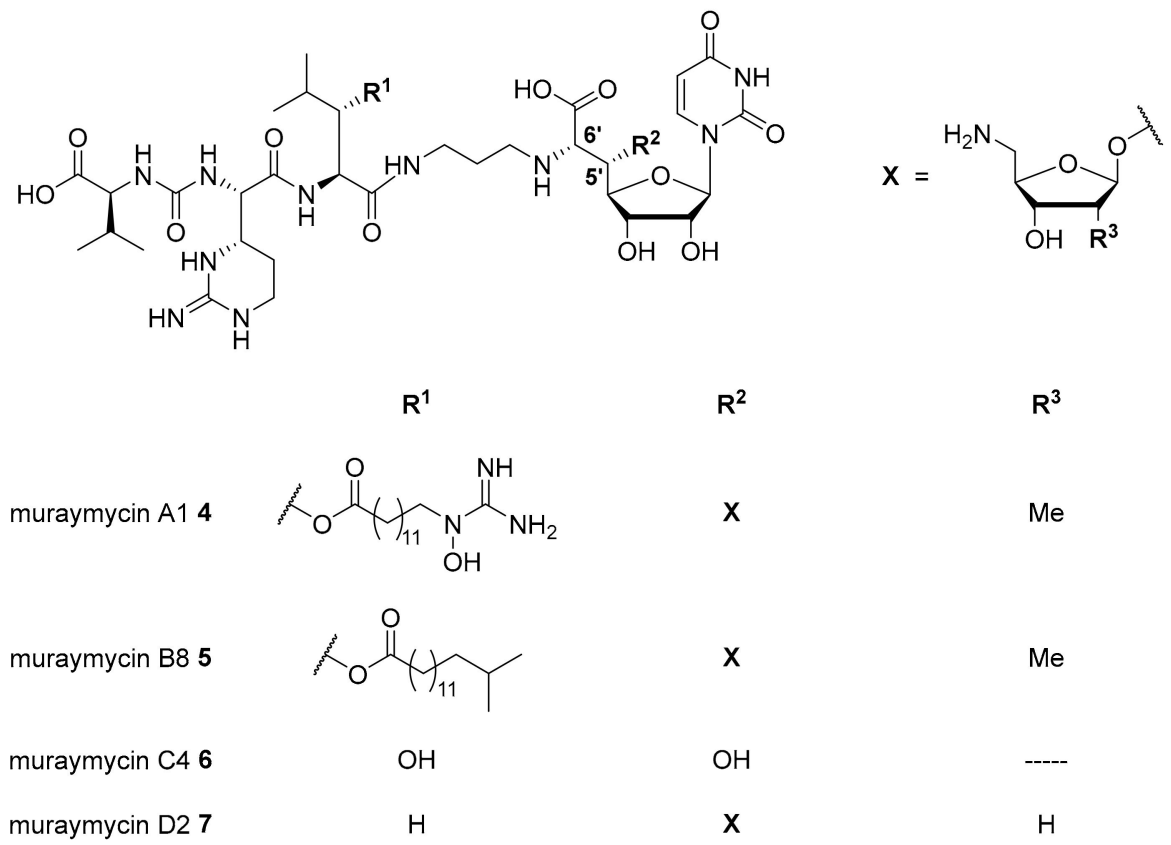

Figure 1. Structures of selected naturally occurring muraymycins 4-7 [18-20].

In the A- and B-series (e.g., muraymycins A1 4 and B8 5, Figure 1), lipophilic side chains are present which are connected to the backbone as fatty acid esters of $\beta$-hydroxylated L-leucine. Such motifs are not found in the C- and D-series congeners (e.g., muraymycins C4 6 and D2 7, Figure 1). Different aminoribosyl substituents ( $X$ in Figure 1$)$ at the GlyU core structure are present in most 
naturally occurring muraymycins. Structures containing hydroxy groups in the 5'-position (e.g., 6) are discussed to be hydrolysis products formed in the isolation and purification process of the natural products [19-21].

In 2016, an X-ray co-crystal structure of the natural product muraymycin D2 7 in complex with MraY from Aquifex aeolicus was reported by Chung et al. [22,23]. These structural insights into the target interaction of muraymycins allowed an identification of possible key interactions which were used to rationalize the design of synthetic muraymycin analogues for SAR studies [24]. A comparison of the aforementioned co-crystal structure with the previously reported crystal structure of the ligand-free apo enzyme [25] revealed a large conformational change due to inhibitor binding, hinting to a pronounced conformational plasticity of MraY. In this context, the formation of a well-defined binding pocket for the uridine-derived GlyU moiety was observed (Figure 2). This was regarded as one of the main reasons for the high binding affinity of naturally occurring nucleoside antibiotics despite their structural deviation from the natural substrate, i.e., UDP-MurNAc pentapeptide 1 [22,23,25]. Very recently, a more comprehensive model for MraY binding of diverse classes of nucleoside antibiotics, again based on X-ray crystallographic studies, has been reported [26].

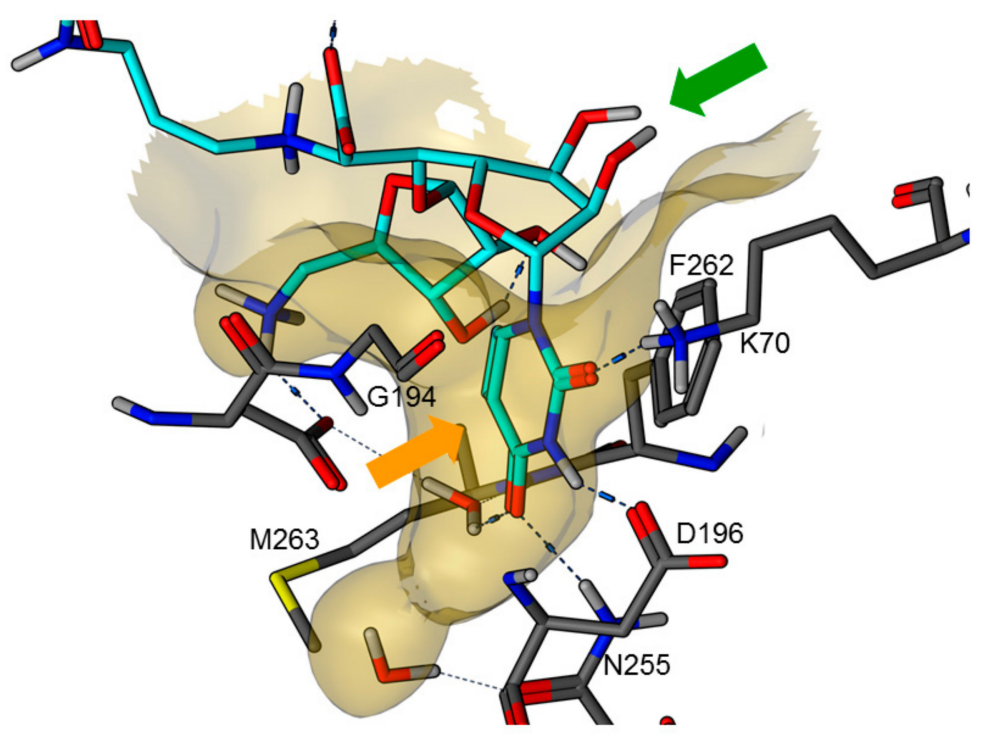

Figure 2. X-ray co-crystal structure of MraY from Aquifex aeolicus in complex with muraymycin D2 7 (PDB 5CKR) [22,23]: protein-inhibitor interactions at the GlyU binding site (hydrocarbon scaffold of inhibitor 7 in light blue; orange arrow: well-defined uracil binding pocket; green arrow: ribose moiety of the uridine-derived GlyU unit showing no significant interactions of 2'-OH and $3^{\prime}-\mathrm{OH}$ ).

Synthetic access to the naturally occurring muraymycins is challenging due to structural features such as the non-proteinogenic amino acid L-epicapreomycidine, the aminoribosylated GlyU moiety and the (3S)-3-hydroxy-L-leucine unit. Total syntheses of some naturally occurring muraymycins have been reported though [13,27-29], and synthetic routes towards crucial structural motifs have been developed [30-33]. Both for potential applications and for more straightforward SAR studies, several simplified muraymycin analogues have been designed [34-38]. By comparison of different natural products and synthetic analogues with long alkyl side chains, it was shown that increased lipophilicity improves antibacterial activities (MIC values), but has only a minor effect on MraY inhibition $[17,20,39,40]$. This is probably owed to an improved cellular uptake of lipophilically decorated muraymycins. Through design of simplified analogues, the terminal urea dipeptide motif [40] as well as the $5^{\prime}$-O-aminoribosyl substituent [21,39] were identified to mediate key interactions in MraY inhibition. However, synthetically obtained 5'-defunctionalized ('5'-deoxy') muraymycin C4 that was reported by our group [38] was found to still inhibit MraY in the nM range, even though most naturally occurring muramycins are MraY inhibitors with $\mathrm{pM}$ activities [39]. The replacement of 
(3S)-3-hydroxy-L-leucine with L-leucine resulted in a 25-fold loss of activity [41], but that implied that such simplified analogues may still be employed in SAR studies. The exact structure of the amino acid side chains in the urea dipeptide moiety seems to only have limited impact on MraY inhibition [21]. These findings led to the design of simplified analogues containing L-lysine instead of L-epicapreomycidine (e.g., analogue 8, Figure 3, MraY inhibition: $\mathrm{IC}_{50}=2.5 \mu \mathrm{M}$ ), thus further reducing synthetic effort [24]. Regarding the stereochemistry of the nucleoside moiety, the naturally occurring $\left(6^{\prime} S\right)$-configuration was found to be preferred. If a $5^{\prime}$-hydroxy group was present, at least either $C-5^{\prime}$ or C- $6^{\prime}$ needed to have their naturally occurring configuration in order to retain good inhibitory activity towards MraY in vitro [41].

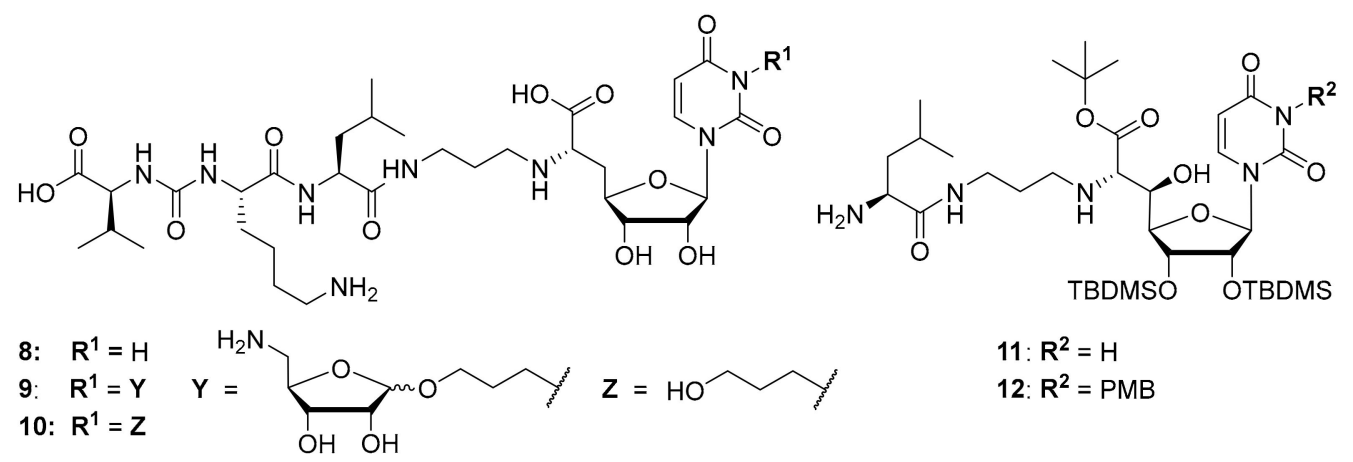

Figure 3. Structures of previously reported 5'-deoxy muraymycin analogues 8-10 [24] and the previously reported protecting group-containing analogues 11 and 12 (PMB = p-methoxybenzyl, TBDMS = tert-butyldimethylsilyl) [34].

It was also attempted to synthesize and study analogues bearing the aminoribosyl substituent ( $\mathbf{X}$ in Figure 1) at different positions of the muraymycin scaffold. This led to compounds $\mathbf{9}$ and $\mathbf{1 0}$ (with 10 serving as a reference, Figure 3) which were modified at the N-3 position of the uracil base. However, these analogues showed no inhibitory activity against MraY [24]. Remarkably, previously reported simplified analogues $\mathbf{1 1}$ and $\mathbf{1 2}$ (which still contained synthetic TBDMS and, in case of 12, PMB protecting groups, Figure 3) had been described to be antibacterially active MraY inhibitors, in spite of the modification of the uracil base in compound 12 [34].

Overall, the X-ray co-crystal structure (Figure 2) and the results with analogues $\mathbf{9}$ and $\mathbf{1 0}$ (Figure 3) suggest that some structural variations in the muraymycin nucleoside moiety might significantly hamper MraY inhibition. This is particularly the case for modifications of the uracil base with respect to the well-defined uracil binding pocket of MraY (Figure 2, orange arrow). In contrast, binding of the GlyU ribose moiety appears to be far less specific, with the X-ray co-crystal structure showing no significant interactions of the $2^{\prime}-\mathrm{OH}$ and $3^{\prime}-\mathrm{OH}$ groups (Figure 2, green arrow). However, the pronounced conformational plasticity of MraY (vide supra) might generally enable its adaptation to structural variations of inhibitors, which would be very hard to predict from the (inherently static) X-ray co-crystal structure. In this work, we have therefore decided to experimentally probe the SAR of the muraymycin nucleoside moiety by introducing structural changes to it which were supposed to be more subtle than the ones in analogues 9-12 (cf. Figure 3). These considerations have led to the design of the following target compounds (Scheme 2), which were based on the previously described 5 -defunctionalized muraymycin analogue 8 (vide supra): (i) a derivative 13 containing 5-fluorouracil as a nucleobase; (ii) $2^{\prime}$-deoxy analogue 14; (iii) thymidine-derived analogue 15 . This would enable us to systematically study both the influence of different C-5 substituents of the pyrimidine base (including the potential electronic effect of fluorine) and the significance of the $2^{\prime}$-functionalization of the ribose moiety. Furthermore, we have also envisioned to investigate a fourth target structure to evaluate the relevance of nucleobase aromaticity, i.e., derivative $\mathbf{1 6}$ having non-aromatic 5,6-dihydrouracil as a nucleobase (Scheme 2). Overall, target structures 13-16 were chosen based on the rationale that 
multiple SAR insights (regarding C-5-substitution, ribose modification, and nucleobase aromaticity) should be obtained with reasonable synthetic effort.

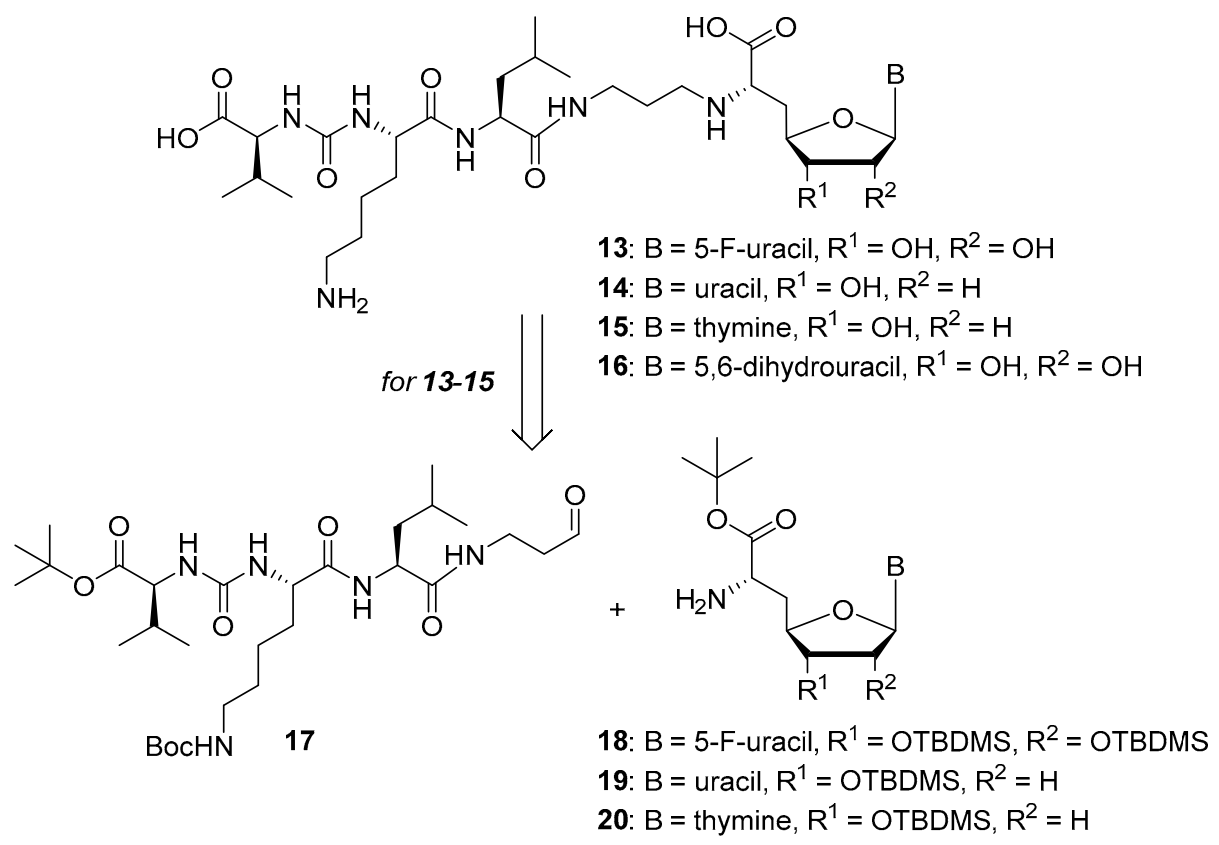

Scheme 2. Target structures 13-16 of this study and retrosynthetic strategy for 13-15.

\section{Results}

\subsection{Synthesis of Muraymycin Analogues}

We had previously described different solution-phase syntheses of muraymycin analogues, either based on a tripartite [38] or a bipartite [41] strategy. However, we have recently reported a novel synthetic approach towards muraymycin analogues, based on solid-phase peptide synthesis (SPPS) to construct a building block for the complete peptide unit [42]. We have decided to apply this new strategy for the synthesis of target structures 13-15 (Scheme 2). Thus, these muraymycin analogues should be accessible by reductive amination of the peptide-derived aldehyde $\mathbf{1 7}$ with different nucleosyl amino acids 18-20, to be followed by global acidic deprotection. The protected peptide building block 17 was readily accessible using our novel SPPS method as described [42], leaving the main synthetic challenge to be the stereoselective preparation of nucleosyl amino acids 18-20. For the synthesis of 5,6-dihydrouracil derivative 16, we have used a solution-phase route (vide infra) as this compound had already been prepared prior to the recent development of the SPPS-based method.

The synthesis of nucleosyl amino acids 18-20 was performed in analogy to the previously reported stereocontrolled synthesis of other uridine-derived 5'-deoxy nucleosyl amino acids (Scheme 3) [31]. Commercially available nucleosides 5-fluorouridine 21, 2'-deoxyuridine 22 and thymidine 23 were fully TBDMS-protected to give persilylated nucleosides 24-26 (yields 62\%-97\%). The protocols for subsequent selective 5'-O-desilylation had to be modified with respect to the different nucleoside structures. Thus, for 5-fluorouridine derivative 24, deprotection towards product 27 with aqueous TFA [43] proceeded with good yield (69\%) and regioselectivity. For 25 and 26, however, reduced steric differentiation of the $3^{\prime}$ - and $5^{\prime}$-positions (due to the absence of a $2^{\prime}$-O-TBDMS moiety adjacent to the $3^{\prime}$-position) led to poor selectivity under similar conditions. Therefore, an alternative method using milder acidic conditions [44] was applied: Hydrochloric acid was generated in situ by reaction of acetyl chloride with methanol at lower temperatures. This protocol furnished 5'-O-desilylated products $\mathbf{2 8}$ and $\mathbf{2 9}$ in yields of $65 \%$ and 59\%, respectively. Nucleosides 27-29 were then oxidized to the corresponding $5^{\prime}$-aldehydes 30-32 in 92\% to quantitative yields. Subsequent Wittig-Horner reaction of 
these aldehydes with phosphonate 33 [31] gave Z-configured didehydro nucleosyl amino acids 34-36. For 35 and 36, this transformation proceeded with good yields of $72 \%$ and $77 \%$, respectively. In the case of the 5-fluorouridine derivative 34, a low yield of $14 \%$ was obtained (Scheme 3). This was attributed to the increased acidity of the 5-fluorouracil imide 3-NH, caused by the electron-withdrawing fluorine substituent. Hence, the imide is supposed to (at least partially) protonate the phosphonate anion, thus resulting in incomplete conversion and potentially also partial decomposition of unconverted aldehyde 30. Using an excess of KHMDS to avoid this side reaction resulted in a loss of stereoselectivity, probably due to base-mediated isomerization of the $C-5^{\prime}-C 6^{\prime}$ double bond (reactions not shown). We had studied before if $3-N$-protection is a viable option for this synthetic route, but results were disappointing mainly due to difficult deprotection reactions [31]. Hence, no further optimization of the synthesis of $\mathbf{3 4}$ was attempted and it was decided instead to proceed with the obtained material. For all didehydro nucleosyl amino acids 34-36, the assignment of the Z-stereochemistry of the C-5'-C6' double bond was based on precedent [31] and ${ }^{1} \mathrm{H}$ NMR spectroscopic data (i.e., characteristic chemical shifts of the $\left.5^{\prime}-\mathrm{H}[31]\right)$.
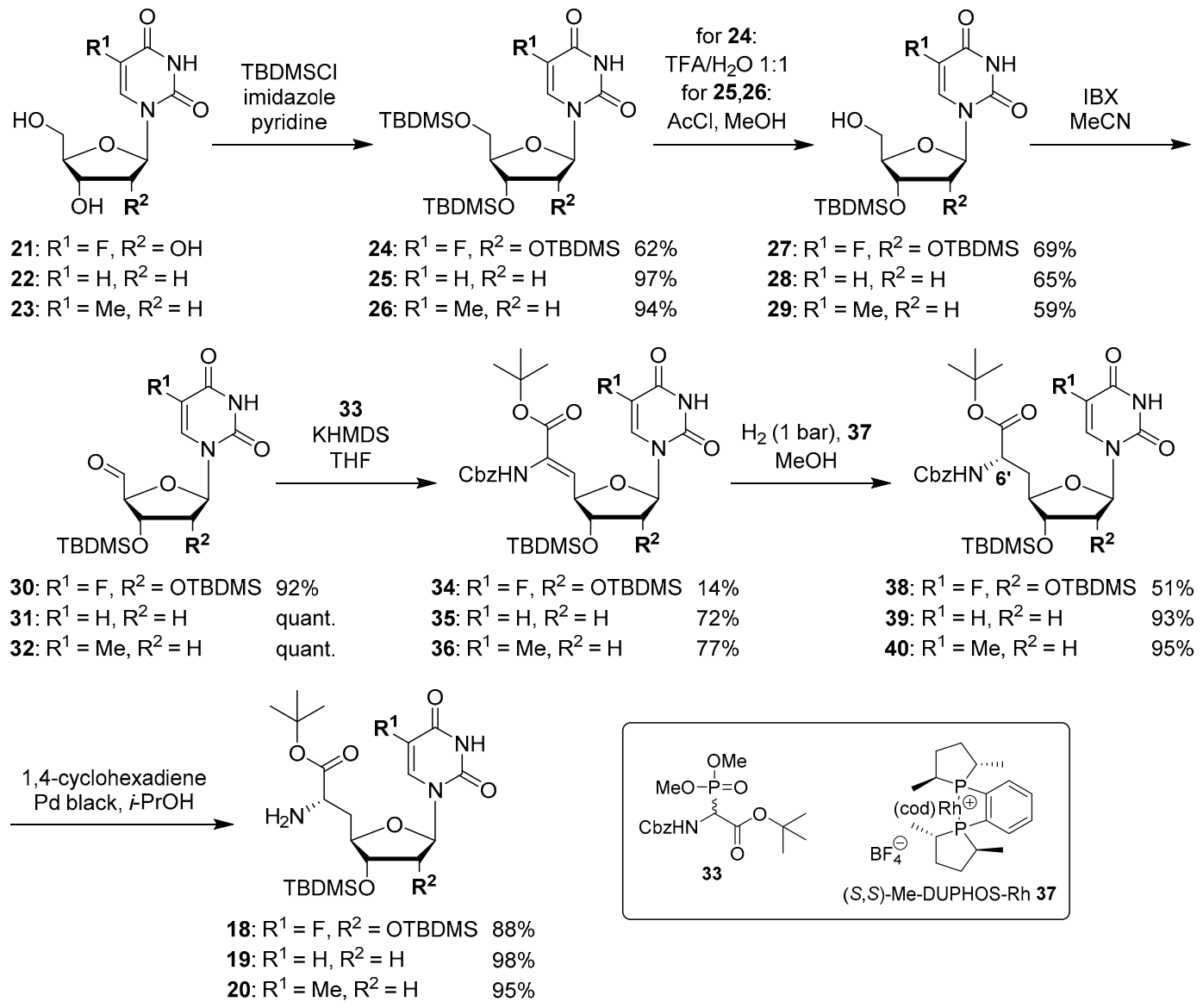

Scheme 3. Stereocontrolled synthesis of $\left(6^{\prime} S\right)$-configured nucleosyl amino acids 18-20.

The next step was the asymmetric hydrogenation of 34-36 using the chiral (S,S)-Me-DUPHOS-Rh(I) catalyst $37[31,45]$ (Scheme 3). It had been proven before that this catalyst selectively furnishes L-amino acids from Z-didehydro amino acid precursors [31,46,47], thus giving rise to the formation of $\mathrm{N}$-Cbz-protected $\left(6^{\prime} S\right)$-configured nucleosyl amino acids 38-40 in yields of $51 \%-95 \%$. The formation of the unwanted $\left(6^{\prime} R\right)$-epimer was not observed in any of these reactions. Finally, $\mathrm{Cbz}$ deprotection under transfer hydrogenation conditions (to avoid reduction of the pyrimidine C-5-C-6 double bond [31]) afforded (6'S)-nucleosyl amino acids 18-20 in yields of 88\%-98\% (Scheme 3).

The synthesis of the peptide-aldehyde unit 17, based on a solid phase-supported approach, has been performed as recently reported [42]. Thus, the stage was set for the preparation of target 
structures 13-15 (Scheme 4). Nucleosyl amino acids 18-20 were connected with peptide-aldehyde 17 by reductive amination. This transformation had been described before as a key step in the synthesis of muraymycin analogues $[24,31,38]$. Subsequent global acidic deprotection using $80 \%$ aqueous TFA and HPLC purification afforded target compounds 13-15 as their bis-TFA salts in 13\%-25\% yields over two steps from 18-20 (Scheme 4).

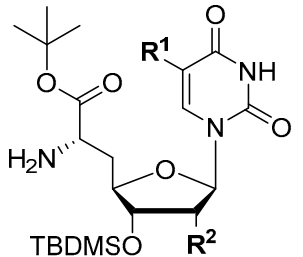

18: $R^{1}=F, R^{2}=$ OTBDMS

19: $R^{1}=H, R^{2}=H$

20: $R^{1}=M e, R^{2}=H$
1) $17, \mathrm{MS} 3 \AA$, THF then $\mathrm{NaBH}(\mathrm{OAc})_{3}$ Amberlyst ${ }^{\mathrm{TM}}$, THF 2) $\mathrm{TFA} / \mathrm{H}_{2} \mathrm{O} 4: 1$

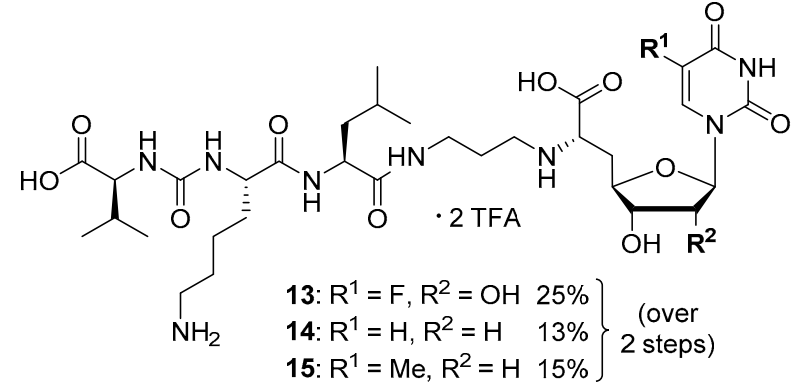

Scheme 4. Synthesis of target structures 13-15.

For the synthesis of target compound 16 containing 5,6-dihydrouracil as a nucleobase, our previously developed solution-phase tripartite approach was applied [13,38]. The nucleosyl amino acid building block was prepared by hydrogenation of 41 [31] to give concomitant Cbz cleavage and reduction of the uracil-C5-C6 double bond, affording 42 in 96\% yield (Scheme 5). This reduction of the uracil nucleobase can otherwise be observed as a side reaction during the hydrogenolytic deprotection of nucleosyl amino acids [31].
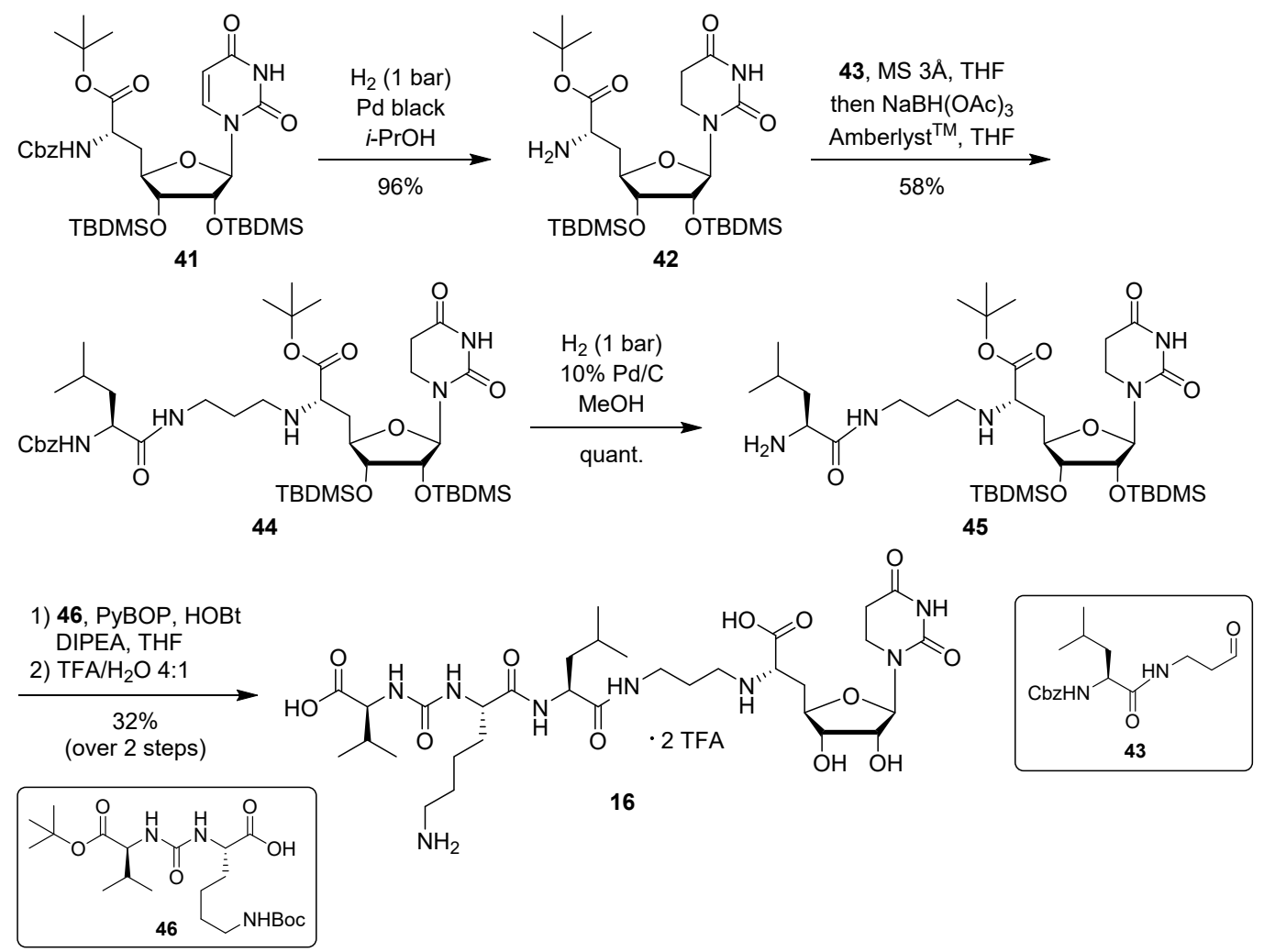

Scheme 5. Synthesis of target structure 16.

Introduction of the propyl linker and the leucine moiety was achieved by reductive amination of 42 with aldehyde 43 [24,34], furnishing 44 in 58\% yield (Scheme 5). After hydrogenolytic Cbz cleavage (product 45, quantitative yield), urea dipeptide building block 46 [24,41] was employed in a peptide 
coupling step to construct the full-length muraymycin scaffold. This was followed by global acidic deprotection and HPLC purification to give target compound 16 (as its bis-TFA salt) in $32 \%$ yield over two steps from 45 (Scheme 5).

\subsection{Biological Evaluation}

Target structures 13-16 were tested for their inhibitory potential towards the bacterial target enzyme MraY in vitro. For these studies, we used an established fluorescence-based assay for MraY activity, which employs a dansylated version of Park's nucleotide $\mathbf{1}$ and MraY from S. aureus (heterologously overexpressed in E. coli) [18,39,48-52]. The obtained inhibitory activities (IC 50 values, also see Supplementary Materials Figures S1-S4, for measured data and inhibition curves) are listed in Table 1, including the potency of previously reported reference compound 8 [24,41]. As target structures 13 and 15 turned out to be nearly inactive as MraY inhibitors in the relevant concentration range $(\leq 100 \mu \mathrm{M})$, we also tested them at a significantly higher concentration $(1 \mathrm{mM}$, Table 1$)$. Muraymycin analogues 13-16 were also investigated for their antibacterial activities in cellulo against $E$. coli, but were inactive (MIC $>50 \mu \mathrm{g} / \mathrm{mL}$ ).

Table 1. In vitro inhibitory activities of muraymycin analogues 13-16 against MraY from S. aureus.

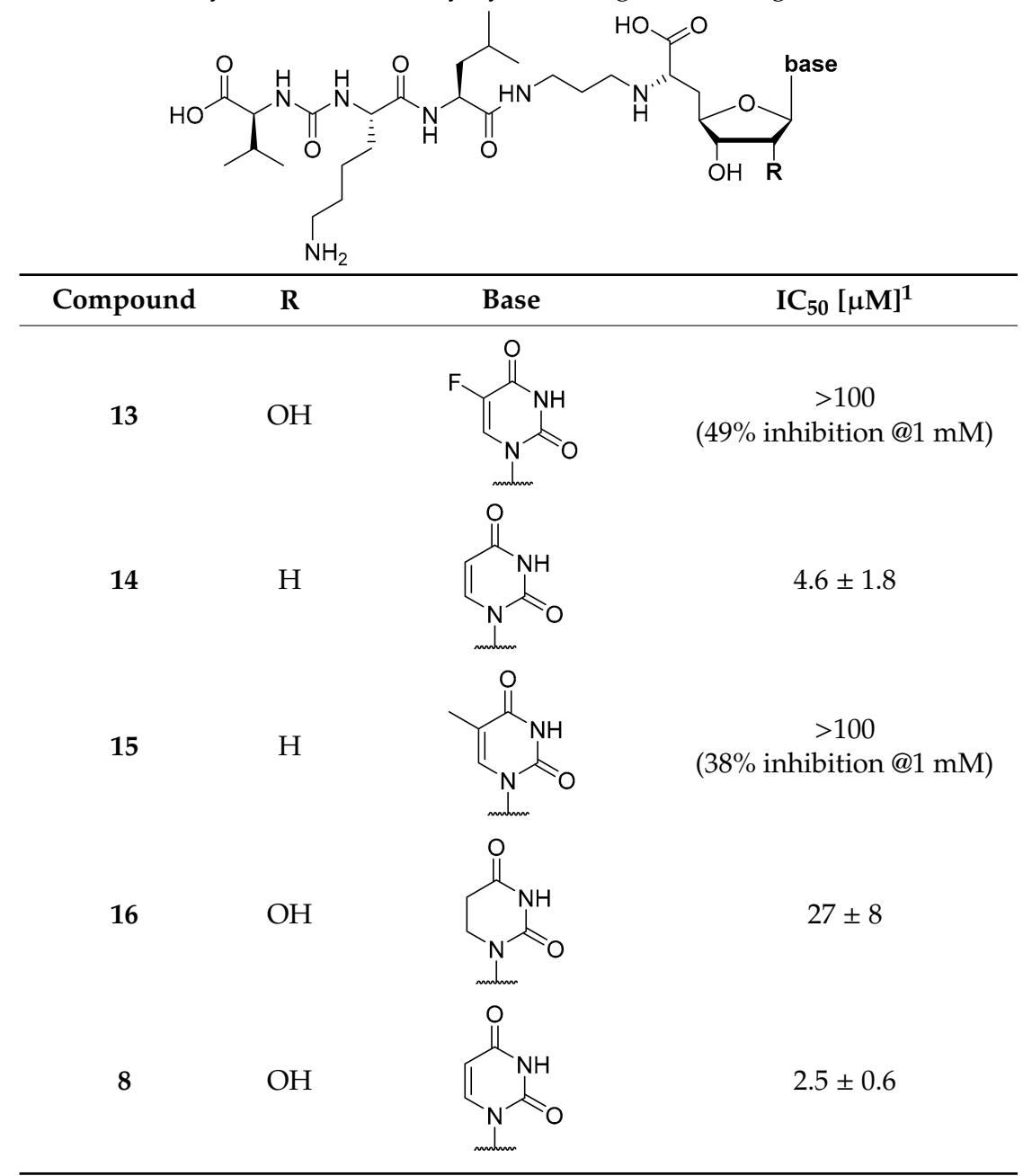

${ }^{1}$ A crude membrane preparation of MraY from S. aureus, heterologously overexpressed in E. coli, was used. Measurements for significantly active compounds $\left(\mathrm{IC}_{50}<100 \mu \mathrm{M}\right)$ were carried out in triplicates, for weakly active compounds $\left(\mathrm{IC}_{50}>100 \mu \mathrm{M}\right)$ in duplicates. Data for significantly active compounds are given as mean value \pm standard deviation. For weakly active compounds, percentage of inhibition at $1 \mathrm{mM}$ is also listed. 


\section{Discussion}

The synthesis of the target structures 13-16 was successfully accomplished. For 13-15, we have applied a recently reported novel approach which is based on the solid phase-supported synthesis of the peptide-aldehyde unit 17, which was then connected with a nucleosyl amino acid building block 18-20 (Scheme 2) [42]. Thus, we mainly had to focus on the preparation of 18-20, which was performed using an established route with Wittig-Horner reaction and subsequent asymmetric hydrogenation as key steps for the stereoselective construction of the amino acid motif [31]. It was thus demonstrated that this protocol is applicable for the introduction of different nucleoside core structures. In contrast to this bipartite strategy, target compound $\mathbf{1 6}$ was prepared using our previously employed solution-phase tripartite approach $[13,38]$. This enabled a direct comparison of both routes. With respect to the late-stage introduction of the nucleosyl amino acid moiety, the solid phase-supported bipartite synthesis (Schemes 3 and 4) appears to be superior and more efficient for studies on analogues with varying nucleoside structures.

The in vitro assay for inhibitory activities of 13-16 towards the bacterial target protein MraY provided highly interesting, unprecedented SAR insights. Compound $\mathbf{1 3}$ differs from reference compound 8 only in the formal substitution of the uracil-5-H with a fluorine atom. Nevertheless, this minor structural alteration leads to a nearly complete loss of inhibitory activity (Table 1). In contrast, the comparison of 2'-deoxyuridine-derived analogue 14 with 8 reveals a full retention of inhibitory activity (within the error margin of the assay). This suggests that structural variations in the ribose moiety appear to be much better tolerated than nucleobase modifications. Accordingly, when an additional 5-methyl substituent was formally introduced into the structure of 14 (i.e., thymidine analogue 15), the inhibitory activity was nearly completely lost again. The only partially tolerated modification of the pyrimidine base studied in this work was the reduction of the C5-C6 double bond, as $\mathbf{1 6}$ was only ca. tenfold less active than $\mathbf{8 .}$

These results are in good agreement with the insights obtained from the X-ray crystal structure of MraY from Aquifex aeolicus in complex with muraymycin D2 7 [22,23] (vide supra, Figure 2). The well-defined binding pocket for the uracil base indeed seems to preclude the introduction of substituents into this moiety. In the case of 5-fluoro substitution, it is not fully clear though if the loss of inhibitory activity is a result of steric hindrance or electronic effects (with respect to the strong electron-withdrawing nature of fluorine). Key interactions in the uracil binding pocket include hydrogen bonding with Lys70, Asp196, and Asn255 (Figure 2). The formation and/or strength of these hydrogen bonds might be hampered by the electron deficiency of the 5-fluorouracil moiety. The non-aromatic nucleobase in analogue $\mathbf{1 6}$ is probably not sterically hindered, but cannot undergo the same $\pi-\pi$ interaction with Phe262 as uracil, thus resulting in a moderate loss of activity. However, the retention of inhibitory activity for $2^{\prime}$-deoxy congener $\mathbf{1 4}$ could also be predicted from the X-ray crystal structure as it had indicated no obvious interaction of the 2 '-hydroxy group (vide supra, Figure 2). Overall, our findings demonstrate that X-ray crystal structures of MraY-inhibitor complexes appear to be excellent starting points for the structure-based design of new inhibitors, at the very least with respect to variations in the uridine-derived core unit.

The lack of antibacterial activities of target structures 13-16 in cellulo was expected. With respect to their potential to inhibit MraY, analogues 14 and 16 were the only candidates for showing antibacterial activity anyway. As part of our previous work on muraymycins, we had shown that there might be a 'threshold' of inhibitory activity towards MraY for observing antibacterial potency in cellulo, concluding that a low-nM (or stronger) inhibitory potency against MraY might be a prerequisite for sufficient antibacterial activity [24,41]. As $\mathbf{1 4}$ and 16 were not within this activity range as MraY inhibitors, their non-activity in cellulo was in good agreement with this hypothesis. It should be pointed out that the main goal of this work was to obtain new SAR insights on MraY inhibition and not to optimize muraymycin analogues for improved antibacterial potencies. The latter can probably be achieved at a later stage by making such muraymycin analogues more lipophilic, as their polar scaffold surely impairs cellular uptake. 


\section{Materials and Methods}

\subsection{Synthesis of Muraymycin Analogues}

General methods: All chemicals were purchased from standard suppliers. Reactions involving oxygen and/or moisture sensitive reagents were carried out under an atmosphere of nitrogen or argon using anhydrous solvents. Anhydrous solvents were obtained in the following manner: THF and MeCN were dried with a solvent purification system (MBRAUN MB SPS 800). Pyridine and $i$-PrOH were dried over $\mathrm{CaH}_{2}$ and distilled. $\mathrm{MeOH}$ was dried over activated molecular sieves $(3 \AA)$ and degassed. All of the thus obtained solvents were stored over molecular sieves ( $4 \AA$; in case of $\mathrm{MeOH} 3$ $\AA)$. All other solvents were of technical quality and distilled prior to use, and deionized water was used throughout. Column chromatography was carried out on silica gel 60 (0.040-0.063 mm, 230-400 mesh ASTM, VWR) under flash conditions except where indicated. TLC was performed on aluminum plates precoated with silica gel $60 \mathrm{~F}_{254}$ (VWR). Visualization of the spots was carried out using UV light $(254 \mathrm{~nm})$ and/or staining under heating $\left(\mathrm{H}_{2} \mathrm{SO}_{4}\right.$ staining solution: $4 \mathrm{~g}$ vanillin, $25 \mathrm{~mL}$ conc. $\mathrm{H}_{2} \mathrm{SO}_{4}$, $80 \mathrm{~mL} \mathrm{AcOH}$ and $680 \mathrm{~mL} \mathrm{MeOH} ; \mathrm{KMnO}_{4}$ staining solution: $1 \mathrm{~g} \mathrm{KMnO}_{4}, 6 \mathrm{~g} \mathrm{~K} \mathrm{KO}_{3}$ and $1.5 \mathrm{~mL}$ 1.25 M NaOH solution, all dissolved in $100 \mathrm{~mL} \mathrm{H}_{2} \mathrm{O}$; ninhydrin staining solution: $0.3 \mathrm{~g}$ ninhydrin, $3 \mathrm{~mL} \mathrm{AcOH}$ and $100 \mathrm{~mL}$ 1-butanol; bromocresol green staining solution: $0.1 \mathrm{~g}$ bromocresol green, $500 \mathrm{~mL}$ EtOH, $5 \mathrm{~mL}$ 0.1 M aqueous $\mathrm{NaOH}$ solution). Semipreparative HPLC was performed on a VWR-Hitachi system equipped with an L-2300 pump, an L-2200 autosampler, an L-2300 column oven $\left(24^{\circ} \mathrm{C}\right)$, an L-2455 Diode Array Detector (DAD) and a LiChroCart ${ }^{\mathrm{TM}}$ column $(10 \times 250 \mathrm{~mm})$ containing reversed phase silica gel Nucleodur ${ }^{\mathrm{TM}} 100-5 \mathrm{C} 18 \mathrm{ec}(10 \mu \mathrm{m})$ purchased from Macherey-Nagel. Method 1: eluent A water (+0.1\% TFA), eluent B MeCN (+0.1\% TFA); 0-15 min gradient of B (10\%-20\%), $15-25$ min gradient of B (20\%-40\%), 25-32 min gradient of B (40\%-100\%), 32-40 min 100\% B, 40-41 min gradient of B (100\%-30\%), 41-45 min 30\% B; flow $2 \mathrm{~mL} / \mathrm{min}$. Method 2: eluent A water $(+0.1 \%$ TFA), eluent B MeCN (+0.1\% TFA); 0-15 min gradient of B (20\%-30\%), 15-25 min gradient of B $(30 \%-40 \%), 25-32 \mathrm{~min}$ gradient of B (40\%-80\%), 32-40 min 80\% B, 40-41 min gradient of B (80\%-30\%), 41-45 min 30\% B; flow $2 \mathrm{~mL} / \mathrm{min}$. Method 3: eluent A water, eluent B MeCN, 0-25 min gradient of B (5\%-50\%), 25-40 min gradient of B (50\%-100\%), 40-45 min 100\% B, 45-50 min gradient of B (100\%-5\%), flow $5 \mathrm{~mL} / \mathrm{min} .500 \mathrm{MHz}-{ }^{1} \mathrm{H}, 126 \mathrm{MHz}^{-13} \mathrm{C}$, as well as $202 \mathrm{MHz}^{31} \mathrm{P}$ NMR spectra were recorded on a Bruker UltraShield ${ }^{\mathrm{TM}}-500$ spectrometer. $376 \mathrm{MHz}^{-19} \mathrm{~F}$ NMR spectra were recorded on a Bruker UltraShield ${ }^{\mathrm{TM}}-400$ spectrometer. $300 \mathrm{MHz}^{-1} \mathrm{H}$ and $76 \mathrm{MHz}-{ }^{13} \mathrm{C} \mathrm{NMR}$ spectra were recorded on a Bruker Fourier 300 spectrometer. All ${ }^{13} \mathrm{C}$ and ${ }^{19} \mathrm{~F}$ NMR spectra are ${ }^{1} \mathrm{H}$-decoupled. All spectra were recorded at room temperature except where indicated and were referenced internally to solvent reference frequencies wherever possible. Chemical shifts $(\delta)$ are quoted in ppm and coupling constants $(J)$ are reported in Hz. Assignment of signals was carried out using H,H-COSY, HSQC, and HMBC spectra obtained on the spectrometers mentioned above. The numbering of atoms of muraymycin target structures is depicted in the Supplementary Materials Figure S5. Mass spectra were measured on a Finnigan Surveyor MSQ Plus mass spectrometer. For ESI measurements in the positive mode, solutions in $\mathrm{MeOH}$ were used. High resolution mass spectra were measured on a Thermo Scientific Q Exactive Orbitrap mass spectrometer with ESI ionization mode and on a Finnigan sectorfield mass spectrometer type MAT 95S with chemical ionization (CI).

5-Fluorouridine-derived muraymycin analogue (13): Nucleosyl amino acid ester 18 (35 mg, $58 \mu \mathrm{mol})$ was dissolved in THF ( $3 \mathrm{~mL})$, and a solution of aldehyde 17 [42] (46 $\mathrm{mg}, 75 \mu \mathrm{mol})$ in THF ( $3 \mathrm{~mL}$ ) was added. The reaction mixture was stirred over molecular sieve ( $3 \AA$ ) at rt for $24 \mathrm{~h}$. $\mathrm{NaBH}(\mathrm{OAc})_{3}(33 \mathrm{mg}, 0.16 \mathrm{mmol})$ and Amberlyst $15^{\mathrm{TM}}(3.4 \mathrm{mg}, 11 \mu \mathrm{mol})$ were added and stirring was continued at $\mathrm{rt}$ for $24 \mathrm{~h}$. The reaction mixture was filtered and the residue was washed with EtOAc $(150 \mathrm{~mL})$. The combined filtrates were washed with sat. $\mathrm{NaHCO}_{3}$ solution $(100 \mathrm{~mL})$ and brine $(50$ $\mathrm{mL})$. The aqueous layer was extracted with EtOAc $(3 \times 100 \mathrm{~mL})$. The combined organics were dried over $\mathrm{Na}_{2} \mathrm{SO}_{4}$ and the solvent was evaporated under reduced pressure. The resultant crude product was purified by column chromatography $\left(98: 2 \rightarrow 95: 5, \mathrm{CH}_{2} \mathrm{Cl}_{2}-\mathrm{MeOH}\right)$ to give the fully protected 
muraymycin analogue as a colorless solid. This was dissolved in aq. TFA $(80 \%, 4.6 \mathrm{~mL})$ and stirred at $\mathrm{rt}$ for $24 \mathrm{~h}$. The reaction mixture was then diluted with water $(12 \mathrm{~mL})$ and the solvent was evaporated under reduced pressure. The resultant crude product was purified by semipreparative HPLC (method 1) to give 13 (bis-TFA salt) as a colorless foam (11 mg, 25\% over 2 steps from 18). ${ }^{1} \mathrm{H} \mathrm{NMR}(500 \mathrm{MHz}$, $\left.\mathrm{D}_{2} \mathrm{O}\right): \delta[\mathrm{ppm}]=0.83(\mathrm{~d}, J=6.0 \mathrm{~Hz}, 3 \mathrm{H}$, Leu-5-H), $0.88(\mathrm{~d}, J=5.7 \mathrm{~Hz}, 3 \mathrm{H}$, Leu-5-H), $0.89(\mathrm{~d}, J=6.9 \mathrm{~Hz}$, $3 \mathrm{H}$, Val-4-H), 0.93 (d, J = 6.9 Hz, 3H, Val-4-H), 1.33-1.48 (m, 2H, Lys-4-H), 1.50-1.70 (m, 6H, Lys-3-Ha , Lys-5-H, Leu-3-H, Leu-4-H), 1.73-1.87 (m, 1H, Lys-3-H $), 1.85-1.92$ (m, 2H, 2"-H), 2.10-2.16 (m, 1H,

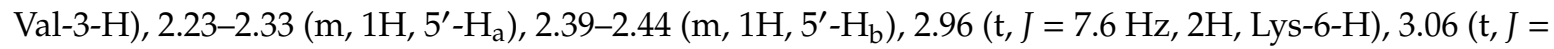
$\left.7.6 \mathrm{~Hz}, 2 \mathrm{H}, 1^{\prime \prime}-\mathrm{H}\right), 3.20-3.29\left(\mathrm{~m}, 2 \mathrm{H}, 3^{\prime \prime}-\mathrm{H}_{\mathrm{a}}, 3^{\prime \prime}-\mathrm{H}_{\mathrm{b}}\right), 3.85-3.90\left(\mathrm{~m}, 1 \mathrm{H}, 6^{\prime}-\mathrm{H}\right), 4.03(\mathrm{dd}, \mathrm{J}=12.3,6.3 \mathrm{~Hz}$, $\left.1 \mathrm{H}, 3^{\prime}-\mathrm{H}\right), 4.05(\mathrm{~d}, J=5.4 \mathrm{~Hz}, 1 \mathrm{H}, \mathrm{Val}-2-\mathrm{H}), 4.09$ (dd, J = 8.5, $\left.5.4 \mathrm{~Hz}, 1 \mathrm{H}, \mathrm{Lys}-2-\mathrm{H}\right), 4.14$ (ddd, $J=9.8,6.3$, $\left.2.8 \mathrm{~Hz}, 1 \mathrm{H}, 4^{\prime}-\mathrm{H}\right), 4.23(\mathrm{dd}, J=10.1,5.0 \mathrm{~Hz}, 1 \mathrm{H}, \mathrm{Leu}-2-\mathrm{H}), 4.35\left(\mathrm{dd}, J=5.7,3.8 \mathrm{~Hz}, 1 \mathrm{H}, 2^{\prime}-\mathrm{H}\right), 5.73(\mathrm{~d}, J=$ $\left.3.8 \mathrm{~Hz}, 1 \mathrm{H}, 1^{\prime}-\mathrm{H}\right), 7.81(\mathrm{~d}, J=6.3 \mathrm{~Hz}, 1 \mathrm{H}, 6-\mathrm{H}) .{ }^{13} \mathrm{C}$ NMR $\left(126 \mathrm{MHz}, \mathrm{D}_{2} \mathrm{O}\right): \delta$ [ppm] = $17.02($ Leu-C-5), 18.55 (Leu-C-5), 20.70 (Val-C-4), 22.08 (Lys-C-4), 22.15 (Val-C-4), 24.44 (Lys-C-5), 25.70 (C-2”), 26.31 (Leu-C-4), 30.02 (Val-C-3), 30.83 (Lys-C-3), 32.91 (C-5'), 36.01 (C-3’), 39.28 (Lys-C-6), 39.55 (Leu-C-3), 44.36 (C-1”), 52.65 (Leu-C-2), 54.11 (Lys-C-2), 58.95 (Val-C-2), 59.70 (C-6'), 72.83 (C-2'), 72.89 (C-3'), $79.96\left(\mathrm{C}-4^{\prime}\right), 91.38\left(\mathrm{C}-1^{\prime}\right), 116.45\left(\mathrm{~d}, J_{\mathrm{CF}}=291.4 \mathrm{~Hz}, \mathrm{TFA}-\mathrm{CF}_{3}\right), 126.45\left(\mathrm{~d}, J_{\mathrm{CF}}=34.8 \mathrm{~Hz}, \mathrm{C}-6\right), 140.76(\mathrm{~d}$, $\left.J_{\mathrm{CF}}=233.7 \mathrm{~Hz}, \mathrm{C}-5\right), 150.02(\mathrm{C}-2), 159.36$ (urea-C=O), $159.55(\mathrm{C}-4), 163.07$ (d, $\left.J_{\mathrm{CF}}=35.8 \mathrm{~Hz}, \mathrm{TFA}-\mathrm{COO}\right)$, 172.02 (C-7'), 174.98 (Leu-C-1), 175.48 (Lys-C-1), 176.80 (Val-C-1). ${ }^{19}$ F NMR (376 MHz, D 2 ): $\delta$ [ppm] $=-166.24(1 \mathrm{~F}, 5-\mathrm{F}),-75.59\left(6 \mathrm{~F}, \mathrm{TFA}-\mathrm{CF}_{3}\right) . \mathrm{MS}\left(\mathrm{ESI}^{+}\right): m / z=761.5[\mathrm{M}+\mathrm{H}]^{+}$. HRMS $\left(\mathrm{ESI}^{+}\right):$calcd.: $^{2}$ $761.3840[\mathrm{M}+\mathrm{H}]^{+}, 783.3659[\mathrm{M}+\mathrm{Na}]^{+}$, found: 761.3843, 783.3646. HPLC (semipreparative): $t_{\mathrm{R}}=24.2$ $\min (\operatorname{method} 1)$.

2'-Deoxyuridine-derived muraymycin analogue (14): Nucleosyl amino acid ester 19 (12.6 mg, $27.6 \mu \mathrm{mol})$ was dissolved in THF $(1.7 \mathrm{~mL})$, and a solution of aldehyde 17 [42] (17 mg, $28 \mu \mathrm{mol})$ in THF (1.7 mL) was added. The reaction mixture was stirred over molecular sieve ( $3 \AA$ ) at rt for $24 \mathrm{~h}$. $\mathrm{NaBH}(\mathrm{OAc})_{3}(12.3 \mathrm{mg}, 58.0 \mu \mathrm{mol})$ and Amberlyst $15^{\mathrm{TM}}(1.9 \mathrm{mg}, 5.5 \mu \mathrm{mol})$ were added and stirring was continued at $\mathrm{rt}$ for $24 \mathrm{~h}$. The reaction mixture was filtered and the residue was washed with EtOAc $(150 \mathrm{~mL})$. The combined filtrates were washed with sat. $\mathrm{NaHCO}_{3}$ solution $(100 \mathrm{~mL})$ and brine $(50 \mathrm{~mL})$. The aqueous layer was extracted with EtOAc $(3 \times 100 \mathrm{~mL})$. The combined organics were dried over $\mathrm{Na}_{2} \mathrm{SO}_{4}$ and the solvent was evaporated under reduced pressure. The resultant crude product was purified by column chromatography $\left(98: 2 \rightarrow 96: 4 \rightarrow 95: 5, \mathrm{CH}_{2} \mathrm{Cl}_{2}-\mathrm{MeOH}\right)$ to give the fully protected muraymycin analogue as a colorless solid. This was dissolved in aq. TFA $(80 \%, 1.3 \mathrm{~mL})$ and stirred at $\mathrm{rt}$ for $24 \mathrm{~h}$. The reaction mixture was then diluted with water $(12 \mathrm{~mL})$ and the solvent was evaporated under reduced pressure. The resultant crude product was purified by semipreparative HPLC (method 1) to give 14 (bis-TFA salt) as a colorless foam $\left(3.5 \mathrm{mg}, 13 \%\right.$ over 2 steps from 19). ${ }^{1} \mathrm{H} \mathrm{NMR}(500 \mathrm{MHz}$, $\left.\mathrm{D}_{2} \mathrm{O}\right): \delta[\mathrm{ppm}]=0.84(\mathrm{~d}, J=6.0 \mathrm{~Hz}, 3 \mathrm{H}$, Leu-5-H), $0.89(\mathrm{~d}, J=6.0 \mathrm{~Hz}, 3 \mathrm{H}$, Leu-5-H), $0.90(\mathrm{~d}, J=6.6 \mathrm{~Hz}$, 3H, Val-4-H), 0.93 (d, J = 6.9 Hz, 3H, Val-4-H), 1.35-1.46 (m, 2H, Lys-4-H), 1.50-1.69 (m, 6H, Lys-3-Ha, Lys-5-H, Leu-3-H, Leu-4-H), 1.72-1.80 (m, 1H, Lys-3-Hb), 1.85-1.91 (m, 2H, 2"-H), 2.10-2.17 (m, 1H, Val-3-H), $2.20\left(\mathrm{ddd}, J=15.1,10.4,6.0 \mathrm{~Hz}, 1 \mathrm{H}, 5^{\prime}-\mathrm{H}_{\mathrm{a}}\right), 2.33\left(\mathrm{ddd}, J=14.5,7.3,5.7 \mathrm{~Hz}, 1 \mathrm{H}, 2^{\prime}-\mathrm{H}_{\mathrm{a}}\right), 2.38$ $\left(\mathrm{ddd}, J=14.8,6.9,2.8 \mathrm{~Hz} 1 \mathrm{H}, 5^{\prime}-\mathrm{H}_{\mathrm{b}}\right), 2.45-2.51\left(\mathrm{~m}, 1 \mathrm{H}, 2^{\prime}-\mathrm{H}_{\mathrm{b}}\right), 2.96(\mathrm{t}, J=7.6 \mathrm{~Hz}, 2 \mathrm{H}, \mathrm{Lys}-6-\mathrm{H}), 3.04$ $\left(\mathrm{t}, J=7.6 \mathrm{~Hz}, 2 \mathrm{H}, 1^{\prime \prime}-\mathrm{H}\right), 3.19-3.32\left(\mathrm{~m}, 2 \mathrm{H}, 3^{\prime \prime}-\mathrm{H}_{\mathrm{a}}, 3^{\prime \prime}-\mathrm{H}_{\mathrm{b}}\right), 3.88\left(\mathrm{t}, J=6.3 \mathrm{~Hz}, 1 \mathrm{H}, 6^{\prime}-\mathrm{H}\right), 4.03(\mathrm{ddd}, J$ $\left.=10.4,5.0,2.8 \mathrm{~Hz}, 1 \mathrm{H}, 4^{\prime}-\mathrm{H}\right), 4.05(\mathrm{~d}, J=5.4 \mathrm{~Hz}, 1 \mathrm{H}, \mathrm{Val}-2-\mathrm{H}), 4.09(\mathrm{dd}, J=8.8,5.7 \mathrm{~Hz}, 1 \mathrm{H}, \mathrm{Lys}-2-\mathrm{H})$, $4.23(\mathrm{dd}, J=9.8,4.7 \mathrm{~Hz}, 1 \mathrm{H}$, Leu-2-H), 4.28-4.32 (m, 1H, 3'-H), $5.85(\mathrm{~d}, J=8.2 \mathrm{~Hz}, 1 \mathrm{H}, 5-\mathrm{H}), 6.16(\mathrm{dd}$, $\left.J=6.6,6.6 \mathrm{~Hz}, 1 \mathrm{H}, 1^{\prime}-\mathrm{H}\right), 7.66(\mathrm{~d}, J=8.2 \mathrm{~Hz}, 1 \mathrm{H}, 6-\mathrm{H}) .{ }^{13} \mathrm{C} \mathrm{NMR}\left(126 \mathrm{MHz}, \mathrm{D}_{2} \mathrm{O}\right): \delta[\mathrm{ppm}]=17.03$ (Val-C-4), 18.56 (Val-C-4), 20.71 (Leu-C-4), 22.10 (Leu-C-4), 22.16 (Lys-C-4), 24.46 (Lys-C-5), 25.69 (C-2”), 26.32 (Leu-C-4), 30.02 (Val-C-3), 30.84 (Lys-C-3), 32.95 (C-5'), 35.99 (C-3”), 37.47 (C-2'), 39.29 (Lys-C-6), 39.56 (Leu-C-6), 44.25 (C-1"'), 52.65 (Leu-C-2), 54.13 (Lys-C-2), 58.95 (Val-C-2), 59.60 (C-6'), 73.53 (C-3'), $82.56\left(\mathrm{C}-4^{\prime}\right), 86.33\left(\mathrm{C}-1^{\prime}\right), 102.30$ (C-5), 142.87 (C-6), 151.51 (C-2), 159.56 (urea-C=O), 166.27 (C-4), 171.90 (C-7'), 174.97 (Leu-C-1), 175.48 (Lys-C-1), 176.79 (Val-C-1). ${ }^{19}$ F NMR (376 MHz, D 2 ): $\delta$ [ppm] = -75.59 (TFA-CF $)$. HRMS $\left(\mathrm{ESI}^{+}\right)$: calcd.: $727.3985[\mathrm{M}+\mathrm{H}]^{+}$, found: 727.3966. HPLC (semipreparative): $\mathrm{t}_{\mathrm{R}}=$ $25.9 \mathrm{~min}(\operatorname{method} 1)$. 
Thymidine-derived muraymycin analogue (15): Nucleosyl amino acid ester 20 (25 mg, $53 \mu \mathrm{mol})$ was dissolved in THF ( $3 \mathrm{~mL})$, and a solution of aldehyde 17 [42] (42 mg, $68 \mu \mathrm{mol})$ in THF (3 mL) was added. The reaction mixture was stirred over molecular sieve $(3 \AA)$ at $\mathrm{rt}$ for $24 \mathrm{~h}$. $\mathrm{NaBH}(\mathrm{OAc})_{3}(23 \mathrm{mg}$, $0.11 \mathrm{mmol})$ and Amberlyst $15^{\mathrm{TM}}(3.5 \mathrm{mg}, 11 \mu \mathrm{mol})$ were added and stirring was continued at $\mathrm{rt}$ for 24 h. The reaction mixture was filtered and the residue was washed with EtOAc $(150 \mathrm{~mL})$. The combined filtrates were washed with sat. $\mathrm{NaHCO}_{3}$ solution $(100 \mathrm{~mL})$ and brine $(50 \mathrm{~mL})$. The aqueous layer was extracted with EtOAc $(3 \times 100 \mathrm{~mL})$. The combined organics were dried over $\mathrm{Na}_{2} \mathrm{SO}_{4}$ and the solvent was evaporated under reduced pressure. The resultant crude product was purified by column chromatography $\left(98: 2 \rightarrow 95: 5, \mathrm{CH}_{2} \mathrm{Cl}_{2}-\mathrm{MeOH}\right)$ to give the fully protected muraymycin analogue as a colorless solid. This was dissolved in aq. TFA $(80 \%, 6.5 \mathrm{~mL})$ and stirred at $\mathrm{rt}$ for $24 \mathrm{~h}$. The reaction mixture was then diluted with water $(12 \mathrm{~mL})$ and the solvent was evaporated under reduced pressure. The resultant crude product was purified by semipreparative HPLC (method 2) to give 15 (bis-TFA salt) as a colorless foam $(9.0 \mathrm{mg}, 15 \%$ over 2 steps from 20$) .{ }^{1} \mathrm{H}$ NMR $\left(500 \mathrm{MHz}, \mathrm{D}_{2} \mathrm{O}\right): \delta$ [ppm] $=0.83$ $(\mathrm{d}, J=6.0 \mathrm{~Hz}, 3 \mathrm{H}$, Leu-5-H), 0.88 (d, $J=5.7 \mathrm{~Hz}, 3 \mathrm{H}, \mathrm{Leu}-5-\mathrm{H}), 0.89$ (d, $J=6.6 \mathrm{~Hz}, 3 \mathrm{H}, \mathrm{Val}-4-\mathrm{H}), 0.93$ (d, $J=6.9$ Hz, 3H, Val-4-H), 1.31-1.45 (m, 2H, Lys-4-H), 1.50-1.68 (m, 6H, Lys-3-Ha, Lys-5-H, Leu-3-H, Leu-4-H), 1.73-1.76 (m, 1H, Lys-3-H ${ }_{\mathrm{b}}$ ), 1.85-1.90 (m, 2H, 2"-H), 1.86 (s, 3H, 7-H), 2.10-2.16 (m, 1H, Val-3-H), 2.20-2.25 (m, 1H, 5'- $\left.\mathrm{H}_{\mathrm{a}}\right), 2.30\left(\mathrm{ddd}, J=14.2,6.9,5.0 \mathrm{~Hz}, 1 \mathrm{H}, 2^{\prime}-\mathrm{H}_{\mathrm{a}}\right), 2.39-2.44\left(\mathrm{~m}, 1 \mathrm{H}, 5^{\prime}-\mathrm{H}_{\mathrm{b}}\right)$, 2.46-2.51 (m, 1H, 2'- $\left.\mathrm{H}_{\mathrm{b}}\right), 2.96(\mathrm{t}, J=7.6 \mathrm{~Hz}, 2 \mathrm{H}, \mathrm{Lys}-6-\mathrm{H}), 3.06\left(\mathrm{t}, J=7.3 \mathrm{~Hz}, 2 \mathrm{H}, 1^{\prime \prime}-\mathrm{H}\right), 3.20-3.29(\mathrm{~m}$, 2H, 3"-H), 3.94-3.97 (m, 1H, 6'-H), $4.02\left(\mathrm{ddd}, J=10.4,4.7,2.8 \mathrm{~Hz}, 1 \mathrm{H}, 4^{\prime}-\mathrm{H}\right), 4.05(\mathrm{~d}, J=5.4 \mathrm{~Hz}, 1 \mathrm{H}$, Val-2-H), 4.05-4.10 (dd, $J=8.5,5.4$ Hz, 1H, Lys-2-H), 4.21 (dd, $J=9.8,4.7$ Hz, 1H, Leu-2-H), 4.30-4.33 $\left(\mathrm{m}, 1 \mathrm{H}, 3^{\prime}-\mathrm{H}\right), 6.16\left(\mathrm{dd}, J=6.6,6.6 \mathrm{~Hz}, 1 \mathrm{H}, 1^{\prime}-\mathrm{H}\right), 7.44(\mathrm{~s}, 1 \mathrm{H}, 6-\mathrm{H}) .{ }^{13} \mathrm{C}$ NMR $\left(126 \mathrm{MHz}, \mathrm{D}_{2} \mathrm{O}\right): \delta[\mathrm{ppm}]$ = 11.57 (C-7), 17.02 (Val-C-4), 18.54 (Val-C-4), 20.70 (Leu-C-4), 22.09 (Leu-C-4), 22.16 (Lys-C-4), 24.45 (Lys-C-5), 25.67 (C-2”), 26.32 (Leu-C-4), 30.00 (Val-C-3), 30.82 (Lys-C-3), 32.73 (C-5'), 35.96 (C-3”), 37.24 (C-2'), 39.28 (Lys-C-6), 39.55 (Leu-C-6), 44.19 (C-1"), 52.62 (Leu-C-2), 54.15 (Lys-C-2), 58.91 (Val-C-2), $59.16\left(\mathrm{C}-6^{\prime}\right), 73.16\left(\mathrm{C}-3^{\prime}\right), 82.30\left(\mathrm{C}-4^{\prime}\right), 85.96\left(\mathrm{C}-1^{\prime}\right), 111.52(\mathrm{C}-5), 116.41\left(\mathrm{~d}, J_{\mathrm{CF}}=291.4 \mathrm{~Hz}, \mathrm{TFA}_{-} \mathrm{CF}_{3}\right)$, 138.34 (C-6), 151.65 (C-2), 159.56 (urea-C=O), 163.05 (d, J $J_{C F}=35.7$ Hz, TFA-COO), 166.51 (C-4), 171.57 $\left(\mathrm{C}-7^{\prime}\right), 174.95$ (Leu-C-1), 175.46 (Lys-C-1), 176.73 (Val-C-1). ${ }^{19}$ F NMR (376 MHz, D O): $\delta$ [ppm] = -75.59 $\left(\mathrm{TFA}_{-} \mathrm{CF}_{3}\right) . \mathrm{MS}\left(\mathrm{ESI}^{+}\right): \mathrm{m} / z=741.5[\mathrm{M}+\mathrm{H}]^{+}, 763.5[\mathrm{M}+\mathrm{Na}]^{+}$. HRMS $\left(\mathrm{ESI}^{+}\right):$calcd.: $741.4141[\mathrm{M}+$ $\mathrm{H}^{+}$, found: 741.4122. HPLC (semipreparative): $t_{\mathrm{R}}=13.9 \min (\operatorname{method} 2)$.

5,6-Dihydrouridine-derived muraymycin analogue (16): Protected urea dipeptide 46 [24,41] (15.5 mg, $34.8 \mu \mathrm{mol})$ was dissolved in THF (5 mL), and 1-hydroxybenzotriazole (HOBt, $4.9 \mathrm{mg}, 36$ $\mu \mathrm{mol})$, benzotriazole-1-yl-oxytripyrrolidinophosphonium hexafluorophosphate (PyBOB, 18.7 mg, 35.9 $\mu \mathrm{mol})$ and DIPEA $(12.2 \mu \mathrm{L}, 71.8 \mu \mathrm{mol})$ were added. The reaction mixture was stirred at $\mathrm{rt}$ for $30 \mathrm{~min}$. After cooling to $0{ }^{\circ} \mathrm{C}$, a solution of 5,6-dihydrouridine derivative 45 (25.2 $\left.\mathrm{mg}, 33.2 \mu \mathrm{mol}\right)$ in THF (7 $\mathrm{mL}$ ) was added. The reaction mixture was stirred at $0{ }^{\circ} \mathrm{C}$ for $30 \mathrm{~min}$ and at $\mathrm{rt}$ for $3 \mathrm{~h}$. The solvent was evaporated under reduced pressure, and the resultant crude product was purified by column chromatography $\left(98: 2 \rightarrow 95: 5, \mathrm{CH}_{2} \mathrm{Cl}_{2}-\mathrm{MeOH}\right)$ to give the fully protected muraymycin analogue. This was dissolved in aq. TFA $(80 \%, 5 \mathrm{~mL})$ and stirred at $\mathrm{rt}$ for $24 \mathrm{~h}$. The reaction mixture was then diluted with water $(15 \mathrm{~mL})$ and the solvent was evaporated under reduced pressure. The resultant crude product was purified by semipreparative HPLC (method 3) to give $\mathbf{1 6}$ (bis-TFA salt) as a colorless solid (7.9 mg, 32\% over 2 steps from 45$).{ }^{1} \mathrm{H}$ NMR $\left(500 \mathrm{MHz}, \mathrm{D}_{2} \mathrm{O}, 15^{\circ} \mathrm{C}\right): \delta[\mathrm{ppm}]=0.79(\mathrm{~d}, J=5.0$ $\mathrm{Hz}, 3 \mathrm{H}, \mathrm{Leu}-5-\mathrm{H}), 0.82-0.87$ (m, 6H, Leu-5-H, Val-4-H), 0.89 (d, J = 6.4 Hz, 3H, Val-4-H), 1.31-1.41 (m, 2H, Lys-4-H), 1.44-1.56 (m, 3H, Leu-3-H, Leu-4-H), 1.56-1.66 (m, 2H, Lys-5-H), 1.67-1.76 (m, 2H,

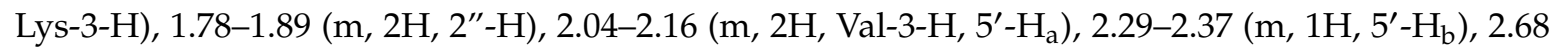
$(\mathrm{t}, J=6.5 \mathrm{~Hz}, 2 \mathrm{H}, 5-\mathrm{H}), 2.89-2.94(\mathrm{~m}, 2 \mathrm{H}, \mathrm{Lys}-6-\mathrm{H}), 2.98-3.04\left(\mathrm{~m}, 2 \mathrm{H}, 1^{\prime \prime}-\mathrm{H}\right), 3.16-3.25\left(\mathrm{~m}, 2 \mathrm{H}, 3^{\prime \prime}-\mathrm{H}\right)$, $3.45(\mathrm{t}, J=6.5 \mathrm{~Hz}, 2 \mathrm{H}, 6-\mathrm{H}), 3.84-3.88\left(\mathrm{~m}, 1 \mathrm{H}, 6^{\prime}-\mathrm{H}\right), 3.89-3.95\left(\mathrm{~m}, 1 \mathrm{H}, 3^{\prime}-\mathrm{H}\right), 3.96-4.09$ (m, 3H, 4' $-\mathrm{H}$, Lys-2-H, Val-2-H), 4.12-4.22 (m, 1H, Leu-2-H), 4.25 (dd, J = 5.3, 4.9 Hz, 1H, 2'-H), 5.67 (d, J = 4.9 Hz, $\left.1 \mathrm{H}, 1^{\prime}-\mathrm{H}\right) .{ }^{13} \mathrm{C}$ NMR $\left(126 \mathrm{MHz}, \mathrm{D}_{2} \mathrm{O}\right): \delta$ [ppm] = 17.04 (Val-C-4), 18.56 (Val-C-4), 20.72 (Leu-C-5), 22.10 (Lys-C-4), 22.16 (Leu-C-5), 24.46 (Leu-C-4), 25.69 (C-2”), 26.32 (Lys-C-5), 30.01 (Val-C-3), 30.21 (C-5), 30.83 (Lys-C-3), 33.04 (C-5'), 36.00 (C-3”), 37.56 (C-6), 39.30 (Lys-C-6), 39.60 (Leu-C-3), 44.31 (C-1”), 
52.65 (Leu-C-2), 54.11 (Lys-C-2), 58.95 (Val-C-2), 59.42 (C-6'), $70.50\left(\mathrm{C}-2^{\prime}\right), 73.30\left(\mathrm{C}-3^{\prime}\right), 79.07$ (C-4'), $89.51\left(\mathrm{C}-1^{\prime}\right), 116.47\left(\mathrm{q}, J_{\mathrm{CF}}=291.4 \mathrm{~Hz}, \mathrm{TFA}-\mathrm{CF}_{3}\right), 154.45(\mathrm{C}-2), 159.58\left(\right.$ urea-C=O), $163.10\left(\mathrm{q}, J_{\mathrm{CF}}=35.6\right.$ Hz, TFA-COO), 171.47 (C-7'), 173.75 (C-4), 174.99 (Lys-C-1), 175.46 (Leu-C-1), 176.78 (Val-C-1). ${ }^{19} \mathrm{~F}$ NMR $\left(376 \mathrm{MHz}, \mathrm{D}_{2} \mathrm{O}\right): \delta[\mathrm{ppm}]=-76.04\left(\mathrm{TFA}^{-C_{3}}\right) . \mathrm{HRMS}\left(\mathrm{ESI}^{+}\right)$: calcd.: $745.4090[\mathrm{M}+\mathrm{H}]^{+}$, found: 745.4074. HPLC (semipreparative): $t_{R}=5.9 \min (\operatorname{method} 3)$.

(6'S)-5-Fluorouridinyl amino acid tert-butyl ester (18): Cbz-protected nucleosyl amino acid ester $38(25 \mathrm{mg}, 34 \mu \mathrm{mol})$ was dissolved in $i-\mathrm{PrOH}(2 \mathrm{~mL}) .1,4$-Cyclohexadiene $(31 \mu \mathrm{L}, 0.34 \mathrm{mmol})$ and $\mathrm{Pd}$ black ( $4 \mathrm{mg}, 38 \mu \mathrm{mol})$ were added and the reaction mixture was stirred at $\mathrm{rt}$ for $3 \mathrm{~h}$. After filtration through a syringe filter and washing the filter with EtOAc $(3 \times 5 \mathrm{~mL})$, the solvent of the combined filtrates was evaporated under reduced pressure to give 18 as a colorless foam $(18 \mathrm{mg}, 88 \%) .{ }^{1} \mathrm{H} \mathrm{NMR}$ $\left(500 \mathrm{MHz}, \mathrm{CDCl}_{3}\right): \delta[\mathrm{ppm}]=0.08\left(\mathrm{~s}, 6 \mathrm{H}, \mathrm{Si}\left(\mathrm{CH}_{3}\right)_{2} \mathrm{C}\left(\mathrm{CH}_{3}\right)_{3}\right), 0.12\left(\mathrm{~s}, 6 \mathrm{H}, \mathrm{Si}\left(\mathrm{C}_{3}\right)_{2} \mathrm{C}\left(\mathrm{CH}_{3}\right)_{3}\right), 0.90(\mathrm{~s}, 9 \mathrm{H}$, $\left.\mathrm{Si}\left(\mathrm{CH}_{3}\right)_{2} \mathrm{C}\left(\mathrm{CH}_{3}\right)_{3}\right), 0.91\left(\mathrm{~s}, 9 \mathrm{H}, \mathrm{Si}\left(\mathrm{CH}_{3}\right)_{2} \mathrm{C}\left(\mathrm{CH}_{3}\right)_{3}\right), 1.47\left(\mathrm{~s}, 9 \mathrm{H}, \mathrm{COOC}\left(\mathrm{CH}_{3}\right)_{3}\right), 1.86$ (ddd, J = 17.0, 10.4, $\left.6.3 \mathrm{~Hz}, 1 \mathrm{H}, 5^{\prime}-\mathrm{H}_{\mathrm{a}}\right), 2.18\left(\mathrm{ddd}, J=14.2,6.3,2.8 \mathrm{~Hz}, 1 \mathrm{H}, 5^{\prime}-\mathrm{H}_{\mathrm{b}}\right), 3.63\left(\mathrm{dd}, J=6.3,6.3 \mathrm{~Hz}, 1 \mathrm{H}, 6^{\prime}-\mathrm{H}\right), 3.67(\mathrm{dd}$, $\left.J=6.6,4.1 \mathrm{~Hz}, 1 \mathrm{H}, 3^{\prime}-\mathrm{H}\right), 4.16\left(\mathrm{dd}, J=4.1,2.8 \mathrm{~Hz}, 1 \mathrm{H}, 2^{\prime}-\mathrm{H}\right), 4.21\left(\mathrm{ddd}, J=10.7,6.6,2.9 \mathrm{~Hz}, 1 \mathrm{H}, 4^{\prime}-\mathrm{H}\right)$, $5.63\left(\mathrm{~d}, J=1.9 \mathrm{~Hz}, 1 \mathrm{H}, 1^{\prime}-\mathrm{H}\right), 7.58\left(\mathrm{~d}, J_{\mathrm{HF}}=6.0 \mathrm{~Hz}, 1 \mathrm{H}, 6-\mathrm{H}\right) .{ }^{13} \mathrm{C} \mathrm{NMR}\left(126 \mathrm{MHz}, \mathrm{CDCl}_{3}\right): \delta[\mathrm{ppm}]=$

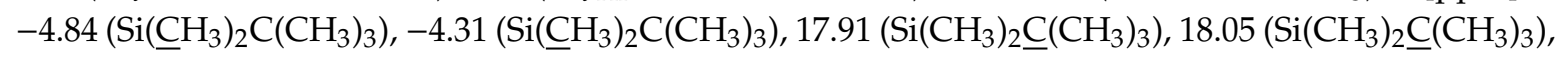
$25.76\left(\mathrm{Si}\left(\mathrm{CH}_{3}\right)_{2} \mathrm{C}\left(\underline{\mathrm{CH}}_{3}\right)_{3}\right), 25.84\left(\mathrm{Si}\left(\mathrm{CH}_{3}\right)_{2} \mathrm{C}\left(\underline{\mathrm{CH}}_{3}\right)_{3}\right), 27.98\left(\mathrm{COOC}\left(\underline{\mathrm{CH}}_{3}\right)_{3}\right), 37.80\left(\mathrm{C}-5^{\prime}\right), 53.18\left(\mathrm{C}-6^{\prime}\right)$, $75.01\left(\mathrm{C}-2^{\prime}\right), 75.19\left(\mathrm{C}-3^{\prime}\right), 81.34\left(\mathrm{C}-4^{\prime}\right), 81.74\left(\mathrm{COOC}\left(\mathrm{CH}_{3}\right)_{3}\right), 91.56\left(\mathrm{C}-1^{\prime}\right), 124.26\left(\mathrm{~d}, J_{\mathrm{CF}}=34.8 \mathrm{~Hz}, \mathrm{C}-6\right)$, $140.4\left(\mathrm{~d}, J_{\mathrm{CF}}=237.4 \mathrm{~Hz}, \mathrm{C}-5\right), 148.55(\mathrm{C}-2), 156.82\left(\mathrm{~d}, J_{\mathrm{CF}}=26.6 \mathrm{~Hz}, \mathrm{C}-4\right) .{ }^{19} \mathrm{~F}$ NMR $\left(376 \mathrm{MHz}, \mathrm{CDCl}_{3}\right)$ : -164.54. MS $\left(\mathrm{ESI}^{+}\right): \mathrm{m} / z=604.4[\mathrm{M}+\mathrm{H}]^{+}, 626.4[\mathrm{M}+\mathrm{Na}]^{+}$. HRMS $\left(\mathrm{ESI}^{+}\right)$: calcd.: $604.3244[\mathrm{M}+\mathrm{H}]^{+}$, 626.3064 [M + Na] $]^{+}$, found: 604.3232, 626.3051. TLC: $R_{\mathrm{f}}=0.31\left(95: 5, \mathrm{CH}_{2} \mathrm{Cl}_{2}-\mathrm{MeOH}\right)$.

(6'S)-2'-Deoxyuridinyl amino acid tert-butyl ester (19): Cbz-protected nucleosyl amino acid ester $39(50 \mathrm{mg}, 85 \mu \mathrm{mol})$ was dissolved in $i-\mathrm{PrOH}(5 \mathrm{~mL}) .1,4-C y c l o h e x a d i e n e ~(80 \mu \mathrm{L}, 0.85 \mathrm{mmol})$ and $\mathrm{Pd}$ black $(\sim 4 \mathrm{mg}, 38 \mu \mathrm{mol})$ were added and the reaction mixture was stirred at $\mathrm{rt}$ for $1.5 \mathrm{~h}$. After filtration through a syringe filter and washing the filter with EtOAc $(3 \times 10 \mathrm{~mL})$, the solvent of the combined filtrates was evaporated under reduced pressure to give 19 as a colorless foam ( $38 \mathrm{mg}, 98 \%) .{ }^{1} \mathrm{H}$ NMR $\left(500 \mathrm{MHz}, \mathrm{CDCl}_{3}\right): \delta[\mathrm{ppm}]=0.08\left(\mathrm{~s}, 6 \mathrm{H}, \mathrm{Si}\left(\mathrm{C}_{3}\right)_{2} \mathrm{C}\left(\mathrm{CH}_{3}\right)_{3}\right), 0.89\left(\mathrm{~s}, 9 \mathrm{H}, \mathrm{Si}\left(\mathrm{CH}_{3}\right)_{2} \mathrm{C}\left(\mathrm{CH}_{3}\right)_{3}\right), 1.47(\mathrm{~s}, 9 \mathrm{H}$, $\left.\operatorname{COOC}\left(\underline{\mathrm{C}}_{3}\right)_{3}\right), 1.84\left(\mathrm{ddd}, J=14.2,9.5,6.9 \mathrm{~Hz}, 1 \mathrm{H}, 5^{\prime}-\mathrm{H}_{\mathrm{a}}\right), 2.11-2.17\left(\mathrm{~m}, 2 \mathrm{H}, 2^{\prime}-\mathrm{H}_{\mathrm{a}}, 5^{\prime}-\mathrm{H}_{\mathrm{b}}\right), 2.30(\mathrm{ddd}, J=$ 13.6, 6.6, $\left.5.4 \mathrm{~Hz}, 1 \mathrm{H}, 2^{\prime}-\mathrm{H}_{\mathrm{b}}\right), 3.57\left(\mathrm{dd}, J=6.3,6.3 \mathrm{~Hz}, 1 \mathrm{H}, 6^{\prime}-\mathrm{H}\right), 3.95\left(\mathrm{ddd}, J=9.1,5.0,3.5 \mathrm{~Hz}, 1 \mathrm{H}, 4^{\prime}-\mathrm{H}\right)$, $4.11\left(\mathrm{dd}, J=12.0,5.0 \mathrm{~Hz}, 1 \mathrm{H}, 3^{\prime}-\mathrm{H}\right), 5.76(\mathrm{~d}, J=7.9 \mathrm{~Hz}, 1 \mathrm{H}, 5-\mathrm{H}), 6.16\left(\mathrm{dd}, J=6.0,6.0 \mathrm{~Hz}, 1 \mathrm{H}, 1^{\prime}-\mathrm{H}\right)$, $7.44(\mathrm{~d}, J=8.2 \mathrm{~Hz}, 1 \mathrm{H}, 6-\mathrm{H}) .{ }^{13} \mathrm{C} \mathrm{NMR}\left(126 \mathrm{MHz}, \mathrm{CDCl}_{3}\right): \delta[\mathrm{ppm}]=-4.71\left(\mathrm{Si}\left(\mathrm{CH}_{3}\right)_{2} \mathrm{C}\left(\mathrm{CH}_{3}\right)_{3}\right), 17.90$ $\left(\mathrm{Si}\left(\mathrm{CH}_{3}\right)_{2} \underline{\mathrm{C}}\left(\mathrm{CH}_{3}\right)_{3}\right), 25.66\left(\mathrm{Si}\left(\mathrm{CH}_{3}\right)_{2} \mathrm{C}\left(\underline{\mathrm{CH}}_{3}\right)_{3}\right), 28.00\left(\mathrm{COOC}\left(\mathrm{CH}_{3}\right)_{3}\right), 37.85\left(\mathrm{C}-5^{\prime}\right), 40.58\left(\mathrm{C}-2^{\prime}\right), 53.09$ $\left(\mathrm{C}-6^{\prime}\right), 74.89\left(\mathrm{C}-3^{\prime}\right), 81.65\left(\mathrm{COOC}\left(\mathrm{CH}_{3}\right)_{3}\right), 84.28\left(\mathrm{C}-4^{\prime}\right), 85.25\left(\mathrm{C}-1^{\prime}\right), 102.55(\mathrm{C}-5), 139.88(\mathrm{C}-6), 149.90$ (C-2), $162.86(\mathrm{C}-4), 173.81\left(\mathrm{C}-7^{\prime}\right) . \mathrm{MS}\left(\mathrm{ESI}^{+}\right): \mathrm{m} / \mathrm{z}=456.1[\mathrm{M}+\mathrm{H}]^{+}, 478.2[\mathrm{M}+\mathrm{Na}]^{+}$. HRMS $\left(\mathrm{ESI}^{+}\right)$: calcd.: $456.2524[\mathrm{M}+\mathrm{H}]^{+}$, found: 456.2498 .

(6'S)-Thymidinyl amino acid tert-butyl ester (20): Cbz-protected nucleosyl amino acid ester 40 (50 $\mathrm{mg}, 83 \mu \mathrm{mol})$ was dissolved in $i$ - $\mathrm{PrOH}(5 \mathrm{~mL})$. 1,4-Cyclohexadiene $(77 \mu \mathrm{L}, 0.82 \mathrm{mmol})$ and Pd black $(\sim 4$ $\mathrm{mg}, 38 \mu \mathrm{mol})$ were added and the reaction mixture was stirred at $\mathrm{rt}$ for $2.5 \mathrm{~h}$. After filtration through a syringe filter and washing the filter with EtOAc $(3 \times 10 \mathrm{~mL})$, the solvent of the combined filtrates was evaporated under reduced pressure to give 20 as a colorless foam $(37 \mathrm{mg}, 95 \%) .{ }^{1} \mathrm{H} \mathrm{NMR} \mathrm{(500}$ $\left.\mathrm{MHz}, \mathrm{CDCl}_{3}\right): \delta[\mathrm{ppm}]=0.09\left(\mathrm{~s}, 6 \mathrm{H}, \mathrm{Si}\left(\mathrm{C}_{3}\right)_{2} \mathrm{C}\left(\mathrm{CH}_{3}\right)_{3}\right), 0.90\left(\mathrm{~s}, 9 \mathrm{H}, \mathrm{Si}\left(\mathrm{CH}_{3}\right)_{2} \mathrm{C}\left(\mathrm{CH}_{3}\right)_{3}\right), 1.47(\mathrm{~s}, 9 \mathrm{H}$, $\left.\operatorname{COOC}\left(\mathrm{CH}_{3}\right)_{3}\right), 1.95(\mathrm{~d}, J=1.1 \mathrm{~Hz}, 3 \mathrm{H}, 7-\mathrm{H}), 1.86\left(\mathrm{ddd}, J=16.1,9.3,6.9 \mathrm{~Hz}, 1 \mathrm{H}, 5^{\prime}-\mathrm{H}_{\mathrm{a}}\right), 2.13-2.18(\mathrm{~m}$, $\left.2 \mathrm{H}, 2^{\prime}-\mathrm{H}_{\mathrm{a}}, 5^{\prime}-\mathrm{H}_{\mathrm{b}}\right), 2.26\left(\mathrm{ddd}, J=13.6,6.7,5.0 \mathrm{~Hz}, 1 \mathrm{H}, 2^{\prime}-\mathrm{H}_{\mathrm{b}}\right), 3.58\left(\mathrm{dd}, J=6.4,6.4 \mathrm{~Hz}, 1 \mathrm{H}, 6^{\prime}-\mathrm{H}\right), 3.93$ $\left(\mathrm{ddd}, J=9.2,4.9,4.0 \mathrm{~Hz}, 1 \mathrm{H}, 4^{\prime}-\mathrm{H}\right), 4.13\left(\mathrm{dd}, J=12.1,5.0 \mathrm{~Hz}, 1 \mathrm{H}, 3^{\prime}-\mathrm{H}\right), 6.17(\mathrm{dd}, J=6.5,6.5 \mathrm{~Hz}, 1 \mathrm{H}$, $\left.1^{\prime}-\mathrm{H}\right), 7.20(\mathrm{~d}, J=1.1 \mathrm{~Hz}, 1 \mathrm{H}, 6-\mathrm{H}) .{ }^{13} \mathrm{C} \mathrm{NMR}\left(126 \mathrm{MHz}, \mathrm{CDCl}_{3}\right): \delta[\mathrm{ppm}]=-4.71\left(\mathrm{Si}\left(\mathrm{CH}_{3}\right)_{2} \mathrm{C}\left(\mathrm{CH}_{3}\right)_{3}\right)$, $12.58(\mathrm{C}-7), 17.90\left(\mathrm{Si}^{\left(\mathrm{CH}_{3}\right)_{2}} \underline{\mathrm{C}}\left(\mathrm{CH}_{3}\right)_{3}\right), 25.67\left(\mathrm{Si}\left(\mathrm{CH}_{3}\right)_{2} \mathrm{C}\left(\underline{\mathrm{CH}}_{3}\right)_{3}\right), 27.98\left(\mathrm{COOC}\left(\underline{\mathrm{CH}}_{3}\right)_{3}\right), 37.86\left(\mathrm{C}-5^{\prime}\right), 40.33$ $\left(\mathrm{C}-2^{\prime}\right), 53.10\left(\mathrm{C}-6^{\prime}\right), 75.00\left(\mathrm{C}-3^{\prime}\right), 81.57\left(\mathrm{COOC}\left(\mathrm{CH}_{3}\right)_{3}\right), 84.04\left(\mathrm{C}-4^{\prime}\right), 84.87\left(\mathrm{C}-1^{\prime}\right), 111.07(\mathrm{C}-5), 135.63$ (C-6), $149.97(\mathrm{C}-2), 163.43(\mathrm{C}-4), 173.88\left(\mathrm{C}-7^{\prime}\right) . \mathrm{MS}\left(\mathrm{ESI}^{+}\right): \mathrm{m} / \mathrm{z}=470.1[\mathrm{M}+\mathrm{H}]^{+}, 492.3[\mathrm{M}+\mathrm{Na}]^{+}$. HRMS $\left(\mathrm{ESI}^{+}\right)$: calcd.: $470.2681[\mathrm{M}+\mathrm{H}]^{+}$, found: 470.2658 . 
$2^{\prime}, 3^{\prime}, 5^{\prime}$-Tris-O-TBDMS-5-fluorouridine (24): 5-Fluorouridine 21 (2.00 g, $\left.7.62 \mathrm{mmol}\right)$ was coevaporated with dry pyridine $(2 \times 14 \mathrm{~mL})$. Pyridine $(26 \mathrm{~mL})$, imidazole $(1.56 \mathrm{~g}, 22.8 \mathrm{mmol})$ and TBDMSCl $(5.74$ $\mathrm{g}$, $38.1 \mathrm{mmol}$ ) were added and the reaction mixture was stirred at $\mathrm{rt}$ for $4 \mathrm{~d}$. Water $(90 \mathrm{~mL})$ was then added at $0{ }^{\circ} \mathrm{C}$. The solvent was evaporated under reduced pressure, the resultant colorless residue was dissolved in EtOAc $(100 \mathrm{~mL})$ and washed with sat. $\mathrm{NaHCO}_{3}$ solution $(3 \times 100 \mathrm{~mL})$ and brine $(2$ $\times 20 \mathrm{~mL}$ ). The organic layer was dried over $\mathrm{Na}_{2} \mathrm{SO}_{4}$ and the solvent was evaporated under reduced pressure. The resultant crude product was purified by column chromatography (7:3, petroleum ether-EtOAc) to give 24 as a colorless foam $(2.87 \mathrm{~g}, 62 \%) .{ }^{1} \mathrm{H}$ NMR $\left(500 \mathrm{MHz}, \mathrm{CDCl}_{3}\right): \delta[\mathrm{ppm}]=0.07$ (s, 6H, Si $\left.\left(\underline{\mathrm{C}}_{3}\right)_{2} \mathrm{C}\left(\mathrm{CH}_{3}\right)_{3}\right), 0.09$ (s, 6H, Si $\left.\left(\underline{\mathrm{C}}_{3}\right)_{2} \mathrm{C}\left(\mathrm{CH}_{3}\right)_{3}\right), 0.16$ (s, 6H, Si $\left.\left(\mathrm{C}_{3}\right)_{2} \mathrm{C}\left(\mathrm{CH}_{3}\right)_{3}\right), 0.89(\mathrm{~s}, 9 \mathrm{H}$, $\left.\mathrm{Si}\left(\mathrm{CH}_{3}\right)_{2} \mathrm{C}\left(\mathrm{C}_{3}\right)_{3}\right), 0.92$ (s, 9H, $\left.\mathrm{Si}\left(\mathrm{CH}_{3}\right)_{2} \mathrm{C}\left(\underline{\mathrm{C}}_{3}\right)_{3}\right), 0.97$ (s, 9H, Si $\left.\left(\mathrm{CH}_{3}\right)_{2} \mathrm{C}\left(\underline{\mathrm{C}}_{3}\right)_{3}\right), 3.77(\mathrm{dd}, J=11.7$, $\left.1.0 \mathrm{~Hz}, 1 \mathrm{H}, 5^{\prime}-\mathrm{H}_{\mathrm{a}}\right), 4.01\left(\mathrm{dd}, J=11.7,1.2 \mathrm{~Hz}, 1 \mathrm{H}, 5^{\prime}-\mathrm{H}_{\mathrm{b}}\right), 4.06-4.10\left(\mathrm{~m}, 3 \mathrm{H}, 2^{\prime}-\mathrm{H}, 3^{\prime}-\mathrm{H}, 4^{\prime}-\mathrm{H}\right), 5.89(\mathrm{dd}$, $\left.J=4.1,1.2 \mathrm{~Hz}, 1 \mathrm{H}, 1^{\prime}-\mathrm{H}\right), 8.18\left(\mathrm{~d}, J_{\mathrm{HF}}=6.3 \mathrm{~Hz}, 1 \mathrm{H}, 6-\mathrm{H}\right), 8.73(\mathrm{bs}, 1 \mathrm{H}, 3-\mathrm{NH}) .{ }^{13} \mathrm{C} \mathrm{NMR}(126 \mathrm{MHz}$, $\left.\mathrm{CDCl}_{3}\right): \delta[\mathrm{ppm}]=-5.54\left(\mathrm{Si}\left(\mathrm{CH}_{3}\right)_{2} \mathrm{C}\left(\mathrm{CH}_{3}\right)_{3}\right),-4.81\left(\mathrm{Si}\left(\mathrm{CH}_{3}\right)_{2} \mathrm{C}\left(\mathrm{CH}_{3}\right)_{3}\right),-3.94\left(\mathrm{Si}\left(\mathrm{CH}_{3}\right)_{2} \mathrm{C}\left(\mathrm{CH}_{3}\right)_{3}\right), 17.92$ $\left(\mathrm{Si}\left(\mathrm{CH}_{3}\right)_{2} \mathrm{C}\left(\mathrm{CH}_{3}\right)_{3}\right), 18.05\left(\mathrm{Si}\left(\mathrm{CH}_{3}\right)_{2} \underline{\mathrm{C}}\left(\mathrm{CH}_{3}\right)_{3}\right), 18.61\left(\mathrm{Si}\left(\mathrm{CH}_{3}\right)_{2} \underline{\mathrm{C}}\left(\mathrm{CH}_{3}\right)_{3}\right), 25.70\left(\mathrm{Si}\left(\mathrm{CH}_{3}\right)_{2} \mathrm{C}\left(\mathrm{CH}_{3}\right)_{3}\right), 25.79$ $\left(\mathrm{Si}\left(\mathrm{CH}_{3}\right)_{2} \mathrm{C}\left(\mathrm{CH}_{3}\right)_{3}\right), 26.06\left(\mathrm{Si}\left(\mathrm{CH}_{3}\right)_{2} \mathrm{C}\left(\mathrm{CH}_{3}\right)_{3}\right), 62.15\left(\mathrm{C}-5^{\prime}\right), 71.16\left(\mathrm{C}-3^{\prime}\right), 76.12\left(\mathrm{C}-4^{\prime}\right), 85.11\left(\mathrm{C}-2^{\prime}\right), 88.78$ $\left(\mathrm{C}-1^{\prime}\right), 124.41\left(\mathrm{~d}, J_{\mathrm{CF}}=33.9 \mathrm{~Hz}, \mathrm{C}-6\right), 140.37\left(\mathrm{~d}, J_{\mathrm{CF}}=236.4 \mathrm{~Hz}, \mathrm{C}-5\right), 148.65(\mathrm{C}-2), 156.67\left(\mathrm{~d}, J_{\mathrm{CF}}=26.6\right.$ $\mathrm{Hz}, \mathrm{C}-4) .{ }^{19} \mathrm{~F} \mathrm{NMR}\left(376 \mathrm{MHz}, \mathrm{CDCl}_{3}\right): \delta[\mathrm{ppm}]=-164.60 . \mathrm{MS}\left(\mathrm{ESI}^{-}\right): m / z=605.3[\mathrm{M}+\mathrm{H}]^{+}, 627.3$ $[\mathrm{M}+\mathrm{Na}]^{+}$. HRMS $(\mathrm{ESI})^{+}$: calcd.: $605.3268[\mathrm{M}+\mathrm{H}]^{+}$, found: 605.3261 . TLC: $R_{\mathrm{f}}=0.85(1: 1$, petroleum ether-EtOAc).

$3^{\prime}, 5^{\prime}$-Bis-O-TBDMS-2'-deoxyuridine (25): 2'-Deoxyuridine $22(5.09 \mathrm{~g}, 22.3 \mathrm{mmol})$ was coevaporated with dry pyridine $(2 \times 40 \mathrm{~mL})$. Pyridine $(75 \mathrm{~mL})$, imidazole $(4.58 \mathrm{~g}, 66.9 \mathrm{mmol})$ and TBDMSCl $(10.1 \mathrm{~g}$, $66.9 \mathrm{mmol})$ were added and the reaction mixture was stirred at $\mathrm{rt}$ for $31 \mathrm{~h}$. Water $(50 \mathrm{~mL})$ was then added at $0{ }^{\circ} \mathrm{C}$. The solvent was evaporated under reduced pressure, the resultant colorless residue was dissolved in EtOAc $(250 \mathrm{~mL})$ and washed with sat. $\mathrm{NaHCO}_{3}$ solution $(3 \times 125 \mathrm{~mL})$ and brine $(50 \mathrm{~mL})$. The organic layer was dried over $\mathrm{Na}_{2} \mathrm{SO}_{4}$ and the solvent was evaporated under reduced pressure. The resultant crude product was purified by column chromatography $(3: 2$, petroleum ether-EtOAc) to give 25 as a colorless solid $(9.90 \mathrm{~g}, 97 \%) .{ }^{1} \mathrm{H} \mathrm{NMR}\left(300 \mathrm{MHz}, \mathrm{CDCl}_{3}\right): \delta[\mathrm{ppm}]=0.08$ (s, 3H, Si $\left.\left(\underline{\mathrm{C}}_{3}\right)_{2} \mathrm{C}\left(\mathrm{CH}_{3}\right)_{3}\right), 0.09$ (s, 3H, Si $\left.\left(\underline{\mathrm{C}}_{3}\right)_{2} \mathrm{C}\left(\mathrm{CH}_{3}\right)_{3}\right), 0.11\left(\mathrm{~s}, 3 \mathrm{H}, \mathrm{Si}\left(\mathrm{CH}_{3}\right)_{2} \mathrm{C}\left(\mathrm{CH}_{3}\right)_{3}\right), 0.11(\mathrm{~s}, 3 \mathrm{H}$, $\left.\mathrm{Si}\left(\mathrm{C}_{3}\right)_{2} \mathrm{C}\left(\mathrm{CH}_{3}\right)_{3}\right), 0.90$ (s, 9H, $\left.\mathrm{Si}\left(\mathrm{CH}_{3}\right)_{2} \mathrm{C}\left(\mathrm{C}_{3}\right)_{3}\right), 0.98$ (s, 9H, Si $\left.\left(\mathrm{CH}_{3}\right)_{2} \mathrm{C}\left(\underline{\mathrm{CH}}_{3}\right)_{3}\right), 2.07$ (ddd, J = 13.2, $\left.6.2,6.2 \mathrm{~Hz}, 1 \mathrm{H}, 2^{\prime}-\mathrm{H}_{\mathrm{a}}\right), 2.33\left(\mathrm{ddd}, J=13.2,6.2,4.2 \mathrm{~Hz}, 1 \mathrm{H}, 2^{\prime}-\mathrm{H}_{\mathrm{b}}\right), 3.77\left(\mathrm{dd}, J=11.3,2.5 \mathrm{~Hz}, 1 \mathrm{H}, 5^{\prime}-\mathrm{H}_{\mathrm{a}}\right)$, $3.90\left(\mathrm{dd}, J=11.3,2.5 \mathrm{~Hz}, 1 \mathrm{H}, 5^{\prime}-\mathrm{H}_{\mathrm{b}}\right), 3.92-3.94\left(\mathrm{~m}, 1 \mathrm{H}, 4^{\prime}-\mathrm{H}\right), 4.42\left(\mathrm{ddd}, J=6.0,6.0,3.8 \mathrm{~Hz}, 1 \mathrm{H}, 3^{\prime}-\mathrm{H}\right)$, $5.68(\mathrm{~d}, J=8.0 \mathrm{~Hz}, 1 \mathrm{H}, 5-\mathrm{H}), 6.29\left(\mathrm{dd}, J=6.2,6.2 \mathrm{~Hz}, 1 \mathrm{H}, 1^{\prime}-\mathrm{H}\right), 7.47(\mathrm{~d}, J=8.0 \mathrm{~Hz}, 1 \mathrm{H}, 6-\mathrm{H}), 8.16(\mathrm{~s}, 1 \mathrm{H}$, 3-NH). ${ }^{13} \mathrm{C} \mathrm{NMR}\left(126 \mathrm{MHz}, \mathrm{CDCl}_{3}\right): \delta[\mathrm{ppm}]=-5.43\left(\mathrm{Si}\left(\mathrm{CH}_{3}\right)_{2} \mathrm{C}\left(\mathrm{CH}_{3}\right)_{3}\right),-5.36\left(\mathrm{Si}\left(\mathrm{CH}_{3}\right)_{2} \mathrm{C}\left(\mathrm{CH}_{3}\right)_{3}\right)$, $-4.72\left(\mathrm{Si}\left(\mathrm{CH}_{3}\right)_{2} \mathrm{C}\left(\mathrm{CH}_{3}\right)_{3}\right),-4.47\left(\mathrm{Si}\left(\mathrm{CH}_{3}\right)_{2} \mathrm{C}\left(\mathrm{CH}_{3}\right)_{3}\right), 18.12\left(\mathrm{Si}\left(\mathrm{CH}_{3}\right)_{2} \underline{\mathrm{C}}\left(\mathrm{CH}_{3}\right)_{3}\right), 18.50\left(\mathrm{Si}\left(\mathrm{CH}_{3}\right)_{2} \underline{\mathrm{C}}\left(\mathrm{CH}_{3}\right)_{3}\right)$, $25.86\left(\mathrm{Si}\left(\overline{\mathrm{CH}}_{3}\right)_{2} \mathrm{C}\left(\mathrm{CH}_{3}\right)_{3}\right), 26.02\left(\mathrm{Si}\left(\overline{\mathrm{CH}}_{3}\right)_{2} \mathrm{C}\left(\mathrm{CH}_{3}\right)_{3}\right), 42.00\left(\mathrm{C}-2^{\prime}\right), 62.60\left(\mathrm{C}-5^{\prime}\right), 71.38\left(\mathrm{C}-3^{\prime}\right), 85.35\left(\mathrm{C}-1^{\prime}\right)$, 87.94 (C-4'), 102.25 (C-5), 140.34 (C-6), 150.10 (C-2), 162.95 (C-4). HRMS (CI): calcd.: 457.2549 [M + H] ${ }^{+}$, found: 457.2538. TLC: $R_{\mathrm{f}}=0.40\left(1: 1, \mathrm{CH}_{2} \mathrm{Cl}_{2}\right.$-EtOAc).

$3^{\prime}, 5^{\prime}$-Bis-O-TBDMS-thymidine (26): Thymidine 23 (5.40 g, $\left.22.3 \mathrm{mmol}\right)$ was coevaporated with dry pyridine $(2 \times 22 \mathrm{~mL})$. Pyridine $(50 \mathrm{~mL})$, imidazole $(3.88 \mathrm{~g}, 57.0 \mathrm{mmol})$ and TBDMSCl $(8.43 \mathrm{~g}$, $56.0 \mathrm{mmol})$ were added and the reaction mixture was stirred at $\mathrm{rt}$ for $48 \mathrm{~h}$. Water $(50 \mathrm{~mL})$ was then added at $0{ }^{\circ} \mathrm{C}$. The solvent was evaporated under reduced pressure, the resultant colorless residue was dissolved in EtOAc $(250 \mathrm{~mL})$ and washed with sat. $\mathrm{NaHCO}_{3}$ solution $(3 \times 125 \mathrm{~mL})$ and brine $(50 \mathrm{~mL})$. The organic layer was dried over $\mathrm{Na}_{2} \mathrm{SO}_{4}$ and the solvent was evaporated under reduced pressure. The resultant crude product was purified by column chromatography (3:1, petroleum ether-EtOAc) to give 26 as a colorless solid $(9.81 \mathrm{~g}, 94 \%) .{ }^{1} \mathrm{H} \mathrm{NMR}\left(300 \mathrm{MHz}, \mathrm{CDCl}_{3}\right): \delta[\mathrm{ppm}]=$ 0.08 (s, 3H, Si $\left.\left(\underline{\mathrm{C}}_{3}\right)_{2} \mathrm{C}\left(\mathrm{CH}_{3}\right)_{3}\right), 0.08$ (s, 3H, Si $\left.\left(\mathrm{CH}_{3}\right)_{2} \mathrm{C}\left(\mathrm{CH}_{3}\right)_{3}\right), 0.11\left(\mathrm{~s}, 3 \mathrm{H}, \mathrm{Si}\left(\mathrm{CH}_{3}\right)_{2} \mathrm{C}\left(\mathrm{CH}_{3}\right)_{3}\right), 0.11$ (s, 3H, Si( $\left.\left.\underline{\mathrm{CH}}_{3}\right)_{2} \mathrm{C}\left(\mathrm{CH}_{3}\right)_{3}\right), 0.90$ (s, 9H, Si $\left.\left(\mathrm{CH}_{3}\right)_{2} \mathrm{C}\left(\mathrm{C}_{3}\right)_{3}\right), 0.93$ (s, 9H, Si $\left.\left(\mathrm{CH}_{3}\right)_{2} \mathrm{C}\left(\mathrm{C}_{3}\right)_{3}\right), 1.92(\mathrm{~d}, J=$ $0.8 \mathrm{~Hz}, 3 \mathrm{H}, 7-\mathrm{H}), 1.95-2.05\left(\mathrm{~m}, 1 \mathrm{H}, 2^{\prime}-\mathrm{H}_{\mathrm{a}}\right), 2.25\left(\mathrm{ddd}, J=13.1,5.8,2.5 \mathrm{~Hz}, 1 \mathrm{H}, 2^{\prime}-\mathrm{H}_{\mathrm{b}}\right) 3.76(\mathrm{dd}, J=$ $\left.11.4,2.5 \mathrm{~Hz}, 1 \mathrm{H}, 5^{\prime}-\mathrm{H}_{\mathrm{a}}\right), 3.87\left(\mathrm{dd}, J=11.4,2.5 \mathrm{~Hz}, 1 \mathrm{H}, 5^{\prime}-\mathrm{H}_{\mathrm{b}}\right), 3.94\left(\mathrm{dd}, J=2.5,2.5 \mathrm{~Hz}, 1 \mathrm{H}, 4^{\prime}-\mathrm{H}\right)$, $4.41\left(\mathrm{ddd}, J=5.8,2.5,2.5 \mathrm{~Hz}, 1 \mathrm{H}, 3^{\prime}-\mathrm{H}\right), 6.33\left(\mathrm{dd}, J=8.0,5.8 \mathrm{~Hz}, 1 \mathrm{H}, 1^{\prime}-\mathrm{H}\right), 7.47(\mathrm{~d}, J=0.8 \mathrm{~Hz}$, 
1H, 6-H), $8.03(\mathrm{~s}, 1 \mathrm{H}, 3-\mathrm{NH}) .{ }^{13} \mathrm{C}$ NMR $\left(126 \mathrm{MHz}, \mathrm{CDCl}_{3}\right): \delta[\mathrm{ppm}]=-5.29\left(\mathrm{Si}\left(\mathrm{CH}_{3}\right)_{2} \mathrm{C}\left(\mathrm{CH}_{3}\right)_{3}\right)$, $-5.20\left(\mathrm{Si}\left(\mathrm{CH}_{3}\right)_{2} \mathrm{C}\left(\mathrm{CH}_{3}\right)_{3}\right),-4.67\left(\mathrm{Si}\left(\mathrm{CH}_{3}\right)_{2} \mathrm{C}\left(\mathrm{CH}_{3}\right)_{3}\right),-4.48\left(\mathrm{Si}\left(\mathrm{CH}_{3}\right)_{2} \mathrm{C}\left(\mathrm{CH}_{3}\right)_{3}\right), 12.68(\mathrm{C}-7), 18.17$ $\left.\left(\mathrm{Si}\left(\mathrm{CH}_{3}\right)_{2} \underline{\mathrm{C}}\left(\mathrm{CH}_{3}\right)_{3}\right), 18.57\left(\mathrm{Si}\left(\mathrm{CH}_{3}\right)_{2} \underline{\mathrm{C}}\left(\mathrm{CH}_{3}\right)_{3}\right), 25.90\left(\mathrm{Si}\left(\mathrm{CH}_{3}\right)_{2} \mathrm{C}(\underline{\mathrm{CH}})_{3}\right)_{3}\right), 26.09\left(\mathrm{Si}\left(\mathrm{CH}_{3}\right)_{2} \mathrm{C}\left(\mathrm{CH}_{3}\right)_{3}\right), 41.53$ (C-2'), 63.16 (C-5'), 72.45 (C-3'), 85.00 (C-1'), 88.01 (C-4'), 110.93 (C-5), 135.64 (C-6), 150.17 (C-2), 163.52 (C-4). HRMS (CI): calcd.: $471.2705[\mathrm{M}+\mathrm{H}]^{+}$, found: 471.2694. TLC: $R_{\mathrm{f}}=0.29$ (1:1, $\mathrm{CH}_{2} \mathrm{Cl}_{2}$-EtOAc).

$2^{\prime}, 3^{\prime}$-Bis-O-TBDMS-5-fluorouridine (27): 2', 3', 5' -Tris-O-TBDMS-5-fluorouridine 24 (1.09 g, 1.80 $\mathrm{mmol})$ was dissolved in THF $(22 \mathrm{~mL})$ and aq. TFA $(50 \%, 5.4 \mathrm{~mL})$ was added slowly at $0{ }^{\circ} \mathrm{C}$ over $40 \mathrm{~min}$. The reaction mixture was stirred at $0^{\circ} \mathrm{C}$ for $5.5 \mathrm{~h}$. After conversion was sufficient according to TLC, sat. $\mathrm{NaHCO}_{3}$ solution $(70 \mathrm{~mL})$ was added until $\mathrm{pH} 8$ was reached. The aqueous layer was extracted with EtOAc $(3 \times 70 \mathrm{~mL})$ and the combined organics were dried over $\mathrm{Na}_{2} \mathrm{SO}_{4}$. The solvent was evaporated under reduced pressure, and the resultant crude product was purified by column chromatography (7:3, petroleum ether-EtOAc) to give 27 as a colorless foam $(610 \mathrm{mg}, 69 \%) .{ }^{1} \mathrm{H}$ NMR $\left(500 \mathrm{MHz}, \mathrm{CDCl}_{3}\right)$ : $\delta[\mathrm{ppm}]=0.09\left(\mathrm{~s}, 6 \mathrm{H}, \mathrm{Si}\left(\mathrm{CH}_{3}\right)_{2} \mathrm{C}\left(\mathrm{CH}_{3}\right)_{3}\right), 0.10\left(\mathrm{~s}, 6 \mathrm{H}, \mathrm{Si}\left(\mathrm{CH}_{3}\right)_{2} \mathrm{C}\left(\mathrm{CH}_{3}\right)_{3}\right), 0.90\left(\mathrm{~s}, 9 \mathrm{H}, \mathrm{Si}\left(\mathrm{CH}_{3}\right)_{2} \mathrm{C}\left(\mathrm{CH}_{3}\right)_{3}\right)$, $0.92\left(\mathrm{~s}, 9 \mathrm{H}, \mathrm{Si}\left(\mathrm{CH}_{3}\right)_{2} \mathrm{C}\left(\mathrm{CH}_{3}\right)_{3}\right), 2.45\left(\mathrm{bs}, 1 \mathrm{H}, 5^{\prime}-\mathrm{OH}\right), 3.80\left(\mathrm{ddd}, J=11.9,5.0,1.9 \mathrm{~Hz}, 1 \mathrm{H}, 5^{\prime}-\mathrm{H}_{\mathrm{a}}\right), 4.04$ $\left(\mathrm{ddd}, J=11.6,2.2 \mathrm{~Hz}, 1 \mathrm{H}, 5^{\prime}-\mathrm{H}_{\mathrm{b}}\right), 4.11\left(\mathrm{~d}, J=5.0 \mathrm{~Hz}, 1 \mathrm{H}, 4^{\prime}-\mathrm{H}\right), 4.16\left(\mathrm{dd}, J=4.7,4.4 \mathrm{~Hz}, 1 \mathrm{H}, 3^{\prime}-\mathrm{H}\right), 4.34$ $\left(\mathrm{dd}, J=4.7,4.4 \mathrm{~Hz}, 1 \mathrm{H}, 2^{\prime}-\mathrm{H}\right), 5.60\left(\mathrm{~d}, J=6.0 \mathrm{~Hz}, 1 \mathrm{H}, 1^{\prime}-\mathrm{H}\right), 8.12\left(\mathrm{~d}, J_{\mathrm{HF}}=6.6 \mathrm{~Hz}, 1 \mathrm{H}, 6-\mathrm{H}\right), 9.00(\mathrm{bs}, 1 \mathrm{H}$, 3-NH). ${ }^{13} \mathrm{C} \mathrm{NMR}\left(126 \mathrm{MHz}, \mathrm{CDCl}_{3}\right): \delta[\mathrm{ppm}]=-4.84\left(\mathrm{Si}\left(\mathrm{CH}_{3}\right)_{2} \mathrm{C}\left(\mathrm{CH}_{3}\right)_{3}\right),-4.55\left(\mathrm{Si}\left(\underline{\mathrm{CH}}_{3}\right)_{2} \mathrm{C}\left(\mathrm{CH}_{3}\right)_{3}\right)$, $17.95\left(\mathrm{Si}\left(\mathrm{CH}_{3}\right)_{2} \underline{\mathrm{C}}\left(\mathrm{CH}_{3}\right)_{3}\right), 18.05\left(\mathrm{Si}\left(\mathrm{CH}_{3}\right)_{2} \underline{\mathrm{C}}\left(\mathrm{CH}_{3}\right)_{3}\right), 25.75\left(\mathrm{Si}\left(\mathrm{CH}_{3}\right)_{2} \mathrm{C}\left(\mathrm{CH}_{3}\right)_{3}\right), 25.80\left(\mathrm{Si}\left(\mathrm{CH}_{3}\right)_{2} \mathrm{C}\left(\underline{\mathrm{CH}}_{3}\right)_{3}\right)$, $60.89\left(\mathrm{C}-5^{\prime}\right), 70.76\left(\mathrm{C}-4^{\prime}\right), 74.87\left(\mathrm{C}-2^{\prime}\right), 84.88\left(\mathrm{C}-3^{\prime}\right), 91.89\left(\mathrm{C}-1^{\prime}\right), 126.12\left(\mathrm{~d}, J_{\mathrm{CF}}=34.8 \mathrm{~Hz}, \mathrm{C}-6\right), 139.29$ (d, $\left.J_{\mathrm{CF}}=236.4 \mathrm{~Hz}, \mathrm{C}-5\right), 148.76(\mathrm{C}-2), 156.78\left(\mathrm{~d}, J_{\mathrm{CF}}=26.6 \mathrm{~Hz}, \mathrm{C}-4\right) .{ }^{19} \mathrm{~F} \mathrm{NMR}\left(376 \mathrm{MHz}, \mathrm{CDCl}_{3}\right): \delta[\mathrm{ppm}]$ $=-165.47 . \mathrm{MS}\left(\mathrm{ESI}^{+}\right): \mathrm{m} / \mathrm{z}=513.2[\mathrm{M}+\mathrm{Na}]^{+}$. HRMS $\left(\mathrm{ESI}^{+}\right):$calcd.: $491.2403[\mathrm{M}+\mathrm{H}]^{+}, 513.2223[\mathrm{M}+$ $\mathrm{Na}^{+}$, found: $491.2392,513.2210$. TLC: $R_{\mathrm{f}}=0.19$ (7:3, petroleum ether-EtOAc).

3'-O-TBDMS-2'-deoxyuridine (28): 3', 5'-Bis-O-TBDMS-2'-deoxyuridine 25 (7.09 g, 15.5 mmol) was dissolved in $\mathrm{MeOH}(200 \mathrm{~mL})$ and cooled to $-10^{\circ} \mathrm{C}$. Acetyl chloride $(273 \mu \mathrm{L}, 3.84 \mathrm{mmol})$ was added slowly at this temperature. The mixture was warmed to $0{ }^{\circ} \mathrm{C}$ and stirred at this temperature for $2.5 \mathrm{~h}$. After conversion was sufficient according to TLC, sat. $\mathrm{NaHCO}_{3}$ solution $(150 \mathrm{~mL})$ was added and the mixture was stirred for $15 \mathrm{~min}$. Then EtOAc $(300 \mathrm{~mL})$, water $(100 \mathrm{~mL})$ and brine $(200 \mathrm{~mL})$ were added. The organic layer was washed with sat. $\mathrm{NaHCO}_{3}$ solution $(100 \mathrm{~mL})$, brine $(2 \times 100 \mathrm{~mL})$ and water $(100$ $\mathrm{mL}$ ) and dried over $\mathrm{Na}_{2} \mathrm{SO}_{4}$. The solvent was evaporated under reduced pressure, and the resultant crude product was purified by column chromatography (3:2, petroleum ether-EtOAc $\rightarrow 7: 3$, petroleum ether-EtOAc $\rightarrow$ EtOAc) to give 28 as a colorless solid $(3.47 \mathrm{~g}, 65 \%) .{ }^{1} \mathrm{H} \mathrm{NMR}\left(500 \mathrm{MHz}, \mathrm{CDCl}_{3}\right): \delta[\mathrm{ppm}]$ $=0.08\left(\mathrm{~s}, 6 \mathrm{H}, \mathrm{Si}\left(\mathrm{CH}_{3}\right)_{2} \mathrm{C}\left(\mathrm{CH}_{3}\right)_{3}\right), 0.89\left(\mathrm{~s}, 9 \mathrm{H}, \mathrm{Si}\left(\mathrm{CH}_{3}\right)_{2} \mathrm{C}\left(\mathrm{CH}_{3}\right)_{3}\right), 2.26-2.30\left(\mathrm{~m}, 2 \mathrm{H}, 2^{\prime}-\mathrm{H}\right), 2.51(\mathrm{dd}, J=$ $\left.4.6,4.6 \mathrm{~Hz}, 1 \mathrm{H}, 5^{\prime}-\mathrm{OH}\right), 3.76\left(\mathrm{ddd}, J=11.6,5.8,3.2 \mathrm{~Hz}, 1 \mathrm{H}, 5^{\prime}-\mathrm{H}_{\mathrm{a}}\right), 3.89-3.91\left(\mathrm{~m}, 1 \mathrm{H}, 5^{\prime}-\mathrm{H}_{\mathrm{b}}\right), 3.92-3.94$ $\left(\mathrm{m}, 1 \mathrm{H}, 4^{\prime}-\mathrm{H}\right), 4.48\left(\mathrm{ddd}, J=5.9,4.2,4.2 \mathrm{~Hz}, 1 \mathrm{H}, 3^{\prime}-\mathrm{H}\right), 5.73(\mathrm{~d}, J=8.1 \mathrm{~Hz}, 1 \mathrm{H}, 5-\mathrm{H}), 6.18(\mathrm{dd}, J=6.6,6.6$ $\left.\mathrm{Hz}, 1 \mathrm{H}, 1^{\prime}-\mathrm{H}\right), 7.68(\mathrm{~d}, J=8.1 \mathrm{~Hz}, 1 \mathrm{H}, 6-\mathrm{H}), 9.33(\mathrm{~s}, 1 \mathrm{H}, 3-\mathrm{NH}) .{ }^{13} \mathrm{C}$ NMR $\left(126 \mathrm{MHz}, \mathrm{CDCl}_{3}\right): \delta[\mathrm{ppm}]=$

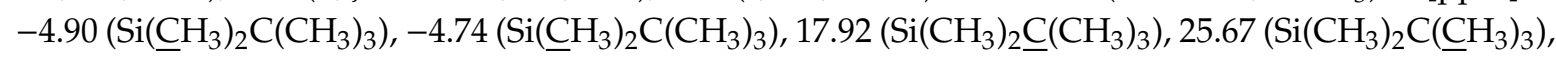
$40.87\left(\mathrm{C}-2^{\prime}\right), 61.73\left(\mathrm{C}-5^{\prime}\right), 71.38\left(\mathrm{C}-3^{\prime}\right), 86.60\left(\mathrm{C}-1^{\prime}\right), 87.61\left(\mathrm{C}-4^{\prime}\right), 102.40$ (C-5), 141.15 (C-6), 150.30 (C-2), $163.56(\mathrm{C}-4)$. HRMS (CI): calcd.: $343.1684[\mathrm{M}+\mathrm{H}]^{+}$, found: 343.1687. TLC: $R_{\mathrm{f}}=0.44$ (EtOAc).

3'-O-TBDMS-thymidine (29): 3', $5^{\prime}$-Bis-O-TBDMS-thymidine 26 (7.02 g, $\left.14.9 \mathrm{mmol}\right)$ was dissolved in $\mathrm{MeOH}(340 \mathrm{~mL})$ and cooled to $-10^{\circ} \mathrm{C}$. Acetyl chloride $(265 \mu \mathrm{L}, 3.73 \mathrm{mmol})$ was added slowly at this temperature. The mixture was warmed to $0{ }^{\circ} \mathrm{C}$ and stirred at this temperature for $3.5 \mathrm{~h}$. After conversion was sufficient according to TLC, sat. $\mathrm{NaHCO}_{3}$ solution $(150 \mathrm{~mL})$ was added and the mixture was stirred for $15 \mathrm{~min}$. Then EtOAc $(300 \mathrm{~mL})$, water $(100 \mathrm{~mL})$ and brine $(400 \mathrm{~mL})$ were added. The organic layer was washed with sat. $\mathrm{NaHCO}_{3}$ solution $(2 \times 100 \mathrm{~mL})$, water $(100 \mathrm{~mL})$ and brine $(100$ $\mathrm{mL}$ ) and dried over $\mathrm{Na}_{2} \mathrm{SO}_{4}$. The solvent was evaporated under reduced pressure, and the resultant crude product was purified by column chromatography (1:1, petroleum ether-EtOAc) to give 29 as a colorless solid $(3.21 \mathrm{~g}, 59 \%) .{ }^{1} \mathrm{H}$ NMR $\left(500 \mathrm{MHz}, \mathrm{CDCl}_{3}\right): \delta[\mathrm{ppm}]=0.09\left(\mathrm{~s}, 6 \mathrm{H}, \mathrm{Si}\left(\mathrm{C}_{3}\right)_{2} \mathrm{C}\left(\mathrm{CH}_{3}\right)_{3}\right)$, $0.90\left(\mathrm{~s}, 9 \mathrm{H}, \mathrm{Si}\left(\mathrm{CH}_{3}\right)_{2} \mathrm{C}\left(\mathrm{CH}_{3}\right)_{3}\right), 1.92(\mathrm{~d}, J=1.1 \mathrm{~Hz}, 3 \mathrm{H}, 7-\mathrm{H}), 2.22\left(\mathrm{ddd}, J=13.3,6.4,3.8 \mathrm{~Hz}, 1 \mathrm{H}, 2^{\prime}-\mathrm{H}_{\mathrm{a}}\right)$, 2.33-2.42 (m, 1H, $\left.2^{\prime}-\mathrm{H}_{\mathrm{b}}\right), 2.60\left(\mathrm{brs}, 1 \mathrm{H}, 5^{\prime}-\mathrm{OH}\right), 3.76\left(\mathrm{ddd}, J=12.4,6.5,3.5 \mathrm{~Hz}, 1 \mathrm{H}, 5^{\prime}-\mathrm{H}_{\mathrm{a}}\right), 3.90-3.95$ $\left(\mathrm{m}, 2 \mathrm{H}, 4^{\prime}-\mathrm{H}, 5^{\prime}-\mathrm{H}_{\mathrm{b}}\right), 4.48-4.52\left(\mathrm{~m}, 1 \mathrm{H}, 3^{\prime}-\mathrm{H}\right), 6.14\left(\mathrm{dd}, J=6.8,6.8 \mathrm{~Hz}, 1 \mathrm{H}, 1^{\prime}-\mathrm{H}\right), 7.36(\mathrm{~d}, J=1.1 \mathrm{~Hz}$, 
1H, 6-H), $8.63(\mathrm{~s}, 1 \mathrm{H}, 3-\mathrm{NH}) .{ }^{13} \mathrm{C} \mathrm{NMR}\left(126 \mathrm{MHz}, \mathrm{CDCl}_{3}\right): \delta[\mathrm{ppm}]=-4.87\left(\mathrm{Si}\left(\mathrm{CH}_{3}\right)_{2} \mathrm{C}\left(\mathrm{CH}_{3}\right)_{3}\right),-4.71$ $\left(\mathrm{Si}\left(\mathrm{CH}_{3}\right)_{2} \mathrm{C}\left(\mathrm{CH}_{3}\right)_{3}\right), 12.52(\mathrm{C}-7), 17.94\left(\mathrm{Si}\left(\mathrm{CH}_{3}\right)_{2} \mathrm{C}\left(\mathrm{CH}_{3}\right)_{3}\right), 25.70\left(\mathrm{Si}\left(\mathrm{CH}_{3}\right)_{2} \mathrm{C}\left(\underline{\mathrm{CH}}_{3}\right)_{3}\right), 40.41\left(\mathrm{C}-2^{\prime}\right), 62.05$ (C-5'), 71.60 (C-3'), 87.09 (C-1'), 87.56 (C-4'), 111.00 (C-5), 137.05 (C-6), 150.24 (C-2), 163.59 (C-4). HRMS (CI): calcd.: $357.1840[\mathrm{M}+\mathrm{H}]^{+}$, found: 357.1848 . TLC: $R_{\mathrm{f}}=0.35$ (1:1, petroleum ether-EtOAc).

2', 3'-Bis-O-TBDMS-5-fluorouridine-5'-aldehyde (30): 2', 3'-Bis-O-TBDMS-5-fluorouridine $27(992$ $\mathrm{mg}, 2.02 \mathrm{mmol})$ was dissolved in $\mathrm{MeCN}(21 \mathrm{~mL})$ and IBX $(1.19 \mathrm{~g}, 4.26 \mathrm{mmol})$ was added. The reaction mixture was stirred under reflux for $1.5 \mathrm{~h}$. After cooling to $0{ }^{\circ} \mathrm{C}$, stirring was continued for $30 \mathrm{~min}$. The reaction mixture was then filtered and the solid residue was washed with EtOAc $(6 \times 40 \mathrm{~mL})$. The solvent of the combined filtrates was evaporated under reduced pressure to give $\mathbf{3 0}$ as a colorless foam $(910 \mathrm{mg}, 92 \%)$. This material was used in the following step without further purification and characterization with respect to its limited stability. ${ }^{1} \mathrm{H} \mathrm{NMR}\left(500 \mathrm{MHz}, \mathrm{CDCl}_{3}\right): \delta[\mathrm{ppm}]=0.04$ (s, 6H, Si $\left.\left(\underline{\mathrm{CH}}_{3}\right)_{2} \mathrm{C}\left(\mathrm{CH}_{3}\right)_{3}\right), 0.14\left(\mathrm{~s}, 6 \mathrm{H}, \mathrm{Si}\left(\mathrm{C}_{3}\right)_{2} \mathrm{C}\left(\mathrm{CH}_{3}\right)_{3}\right), 0.89\left(\mathrm{~s}, 9 \mathrm{H}, \mathrm{Si}\left(\mathrm{CH}_{3}\right)_{2} \mathrm{C}\left(\mathrm{CH}_{3}\right)_{3}\right), 0.94(\mathrm{~s}, 9 \mathrm{H}$, $\left.\mathrm{Si}\left(\mathrm{CH}_{3}\right)_{2} \mathrm{C}\left(\mathrm{CH}_{3}\right)_{3}\right), 4.18\left(\mathrm{dd}, J=5.4,4.1 \mathrm{~Hz}, 1 \mathrm{H}, 4^{\prime}-\mathrm{H}\right), 4.21\left(\mathrm{dd}, J=4.1,4.1 \mathrm{~Hz}, 1 \mathrm{H}, 3^{\prime}-\mathrm{H}\right), 4.64(\mathrm{~d}, J=3.5$ $\left.\mathrm{Hz}, 1 \mathrm{H}, 2^{\prime}-\mathrm{H}\right), 5.82\left(\mathrm{dd}, J=5.4,1.0 \mathrm{~Hz}, 1 \mathrm{H}, 1^{\prime}-\mathrm{H}\right), 8.02\left(\mathrm{~d}, J_{\mathrm{HF}}=6.0 \mathrm{~Hz}, 1 \mathrm{H}, 6-\mathrm{H}\right), 8.53(\mathrm{brs}, 1 \mathrm{H}, 3-\mathrm{NH})$, $9.83\left(\mathrm{~s}, 1 \mathrm{H}, 5^{\prime}-\mathrm{H}\right)$.

3'-O-TBDMS-2'-deoxyuridine-5'-aldehyde (31): $3^{\prime}$-O-TBDMS-2'-deoxyuridine 28 (1.25 g, 3.66 $\mathrm{mmol})$ was dissolved in $\mathrm{MeCN}(35 \mathrm{~mL})$ and IBX $(2.56 \mathrm{~g}, 9.15 \mathrm{mmol})$ was added. The reaction mixture was stirred under reflux for $2 \mathrm{~h}$. After cooling to $0{ }^{\circ} \mathrm{C}$, stirring was continued for $30 \mathrm{~min}$. The reaction mixture was then filtered and the solid residue was washed with EtOAc $(3 \times 50 \mathrm{~mL})$. The solvent of the combined filtrates was evaporated under reduced pressure to give 31 as a colorless foam (1.25 g, quant.). This material was used in the following step without further purification and characterization with respect to its limited stability. ${ }^{1} \mathrm{H}$ NMR $\left(500 \mathrm{MHz}, \mathrm{CDCl}_{3}\right): \delta[\mathrm{ppm}]=0.13\left(\mathrm{~s}, 3 \mathrm{H}, \mathrm{Si}\left(\mathrm{C}_{3}\right)_{2} \mathrm{C}\left(\mathrm{CH}_{3}\right)_{3}\right)$, $0.14\left(\mathrm{~s}, 3 \mathrm{H}, \mathrm{Si}\left(\mathrm{CH}_{3}\right)_{2} \mathrm{C}\left(\mathrm{CH}_{3}\right)_{3}\right), 0.91\left(\mathrm{~s}, 9 \mathrm{H}, \mathrm{Si}\left(\mathrm{CH}_{3}\right)_{2} \mathrm{C}\left(\mathrm{C}_{3}\right)_{3}\right), 1.97-2.03\left(\mathrm{~m}, 1 \mathrm{H}, 2^{\prime}-\mathrm{H}_{\mathrm{a}}\right), 2.37$ (ddd, $J=$ 13.6, $\left.5.8,2.2 \mathrm{~Hz}, 1 \mathrm{H}, 2^{\prime}-\mathrm{H}_{\mathrm{b}}\right), 4.52\left(\mathrm{~d}, J=2.0 \mathrm{~Hz}, 1 \mathrm{H}, 4^{\prime}-\mathrm{H}\right), 4.64-4.68\left(\mathrm{~m}, 1 \mathrm{H}, 3^{\prime}-\mathrm{H}\right), 5.81(\mathrm{~d}, J=8.2 \mathrm{~Hz}$, $1 \mathrm{H}, 5-\mathrm{H}), 6.31\left(\mathrm{dd}, J=8.1,5.8 \mathrm{~Hz}, 1 \mathrm{H}, 1^{\prime}-\mathrm{H}\right), 7.85(\mathrm{~d}, J=8.2 \mathrm{~Hz}, 1 \mathrm{H}, 6-\mathrm{H}), 9.26(\mathrm{brs}, 1 \mathrm{H}, 3-\mathrm{NH}), 9.75(\mathrm{~s}$, $\left.1 \mathrm{H}, 5^{\prime}-\mathrm{H}\right)$.

3'-O-TBDMS-thymidine-5'-aldehyde (32): 3'-O-TBDMS-thymidine 29 (1.32 g, $3.70 \mathrm{mmol})$ was dissolved in MeCN $(35 \mathrm{~mL})$ and IBX $(2.59 \mathrm{~g}, 9.25 \mathrm{mmol})$ was added. The reaction mixture was stirred under reflux for $1 \mathrm{~h}$. After cooling to $0{ }^{\circ} \mathrm{C}$, stirring was continued for $30 \mathrm{~min}$. The reaction mixture was then filtered and the solid residue was washed with EtOAc $(3 \times 40 \mathrm{~mL})$. The solvent of the combined filtrates was evaporated under reduced pressure to give 32 as a colorless foam (1.31 g, quant.). This material was used in the following step without further purification and characterization with respect to its limited stability. ${ }^{1} \mathrm{H}$ NMR $\left(500 \mathrm{MHz}, \mathrm{CDCl}_{3}\right): \delta[\mathrm{ppm}]=0.15\left(\mathrm{~s}, 3 \mathrm{H}, \mathrm{Si}\left(\mathrm{C}_{3}\right)_{2} \mathrm{C}\left(\mathrm{CH}_{3}\right)_{3}\right), 0.16$ (s, $\left.3 \mathrm{H}, \mathrm{Si}\left(\mathrm{CH}_{3}\right)_{2} \mathrm{C}\left(\mathrm{CH}_{3}\right)_{3}\right), 0.94\left(\mathrm{~s}, 9 \mathrm{H}, \mathrm{Si}\left(\mathrm{CH}_{3}\right)_{2} \mathrm{C}\left(\mathrm{CH}_{3}\right)_{3}\right), 1.98(\mathrm{~d}, J=1.1 \mathrm{~Hz}, 3 \mathrm{H}, 7-\mathrm{H}), 2.03-2.12(\mathrm{~m}, 1 \mathrm{H}$, $\left.2^{\prime}-\mathrm{H}_{\mathrm{a}}\right), 2.34\left(\mathrm{ddd}, J=13.4,5.9,1.9 \mathrm{~Hz}, 1 \mathrm{H}, 2^{\prime}-\mathrm{H}_{\mathrm{b}}\right), 4.50\left(\mathrm{~d}, J=2.1 \mathrm{~Hz}, 1 \mathrm{H}, 4^{\prime}-\mathrm{H}\right), 4.69(\mathrm{ddd}, J=5.2,2.1$, $\left.1.9 \mathrm{~Hz}, 1 \mathrm{H}, 3^{\prime}-\mathrm{H}\right), 6.33\left(\mathrm{dd}, J=8.1,5.9 \mathrm{~Hz}, 1 \mathrm{H}, 1^{\prime}-\mathrm{H}\right), 7.59(\mathrm{~d}, J=1.1 \mathrm{~Hz}, 1 \mathrm{H}, 6-\mathrm{H}), 8.76(\mathrm{brs}, 1 \mathrm{H}, 3-\mathrm{NH})$, $9.78\left(\mathrm{~s}, 1 \mathrm{H}, 5^{\prime}-\mathrm{H}\right)$.

$\mathrm{Z}-6^{\prime}-\mathrm{N}-\mathrm{Cbz}-5^{\prime}, 6^{\prime}$-didehydro-5-fluorouridinyl amino acid tert-butyl ester (34): THF (8 mL) was added to a solution of KHMDS in toluene $(0.5 \mathrm{M}, 2.84 \mathrm{~mL}, 1.42 \mathrm{mmol})$. After cooling to $-86{ }^{\circ} \mathrm{C}$, a solution of phosphonate 33 [31] $(480 \mathrm{mg}, 1.42 \mathrm{mmol})$ in THF $(10 \mathrm{~mL})$ was added slowly at this temperature. The mixture was stirred at $-86^{\circ} \mathrm{C}$ for $30 \mathrm{~min}$. Subsequently, a solution of aldehyde 30 (900 $\mathrm{mg}, 1.85 \mathrm{mmol})$ in THF $(12 \mathrm{~mL})$ was added dropwise. Stirring was continued for $16 \mathrm{~h}$ while the solution was allowed to slowly warm to rt. After cooling to $10^{\circ} \mathrm{C}, \mathrm{MeOH}(3.2 \mathrm{~mL})$ was added. The mixture was diluted with EtOAc $(70 \mathrm{~mL})$ and washed with half-sat. $\mathrm{NaCl}$ solution $(2 \times 65 \mathrm{~mL})$. The organic layer was dried over $\mathrm{Na}_{2} \mathrm{SO}_{4}$ and the solvent was evaporated under reduced pressure. The resultant crude product was purified by threefold column chromatography $(7: 3$, petroleum ether-EtOAc and 3:1, petroleum ether-EtOAc, respectively) to give 34 (9:1 mixture of $Z$ and $E$ isomers as determined by ${ }^{1} \mathrm{H}$ NMR spectroscopy) as a colorless foam (184 mg, 14\%). Z-34: ${ }^{1} \mathrm{H}$ NMR $\left(500 \mathrm{MHz}, \mathrm{CDCl}_{3}\right): \delta$ [ppm] $=0.07\left(\mathrm{~s}, 6 \mathrm{H}, \mathrm{Si}\left(\mathrm{CH}_{3}\right)_{2} \mathrm{C}\left(\mathrm{CH}_{3}\right)_{3}\right), 0.12\left(\mathrm{~s}, 6 \mathrm{H}, \mathrm{Si}\left(\mathrm{CH}_{3}\right)_{2} \mathrm{C}\left(\mathrm{CH}_{3}\right)_{3}\right), 0.90\left(\mathrm{~s}, 9 \mathrm{H}, \mathrm{Si}\left(\mathrm{CH}_{3}\right)_{2} \mathrm{C}\left(\mathrm{C}_{3}\right)_{3}\right), 0.91$ $\left(\mathrm{s}, 9 \mathrm{H}, \mathrm{Si}\left(\mathrm{CH}_{3}\right)_{2} \mathrm{C}\left(\mathrm{C}_{3}\right)_{3}\right), 1.49\left(\mathrm{~s}, 9 \mathrm{H}, \mathrm{COOC}\left(\underline{\mathrm{C}}_{3}\right)_{3}\right), 3.90\left(\mathrm{dd}, J=3.8,3.8 \mathrm{~Hz}, 1 \mathrm{H}, 3^{\prime}-\mathrm{H}\right), 4.28(\mathrm{dd}, J=$ 
3.5, $\left.3.5 \mathrm{~Hz}, 1 \mathrm{H}, 2^{\prime}-\mathrm{H}\right), 4.92\left(\mathrm{dd}, J=7.0,7.0 \mathrm{~Hz}, 1 \mathrm{H}, 4^{\prime}-\mathrm{H}\right), 5.13-5.18\left(\mathrm{~m}, 2 \mathrm{H}, 1^{\prime \prime}-\mathrm{H}\right), 5.60(\mathrm{~d}, J=2.9 \mathrm{~Hz}$, $\left.1 \mathrm{H}, 1^{\prime}-\mathrm{H}\right), 6.24\left(\mathrm{~d}, J=7.8 \mathrm{~Hz}, 1 \mathrm{H}, 5^{\prime}-\mathrm{H}\right), 6.80\left(\mathrm{brs}, 1 \mathrm{H}, 6^{\prime}-\mathrm{NH}\right), 7.34-7.36\left(\mathrm{~m}, 5 \mathrm{H}\right.$, aryl-H), $7.39\left(\mathrm{~d}, J_{\mathrm{HF}}\right.$ $=6.0 \mathrm{~Hz}, 1 \mathrm{H}, 6-\mathrm{H}), 8.48\left(\mathrm{~d}, J_{\mathrm{HF}}=4.4 \mathrm{~Hz}, 1 \mathrm{H}, 3-\mathrm{NH}\right) .{ }^{13} \mathrm{C} \mathrm{NMR}\left(126 \mathrm{MHz}, \mathrm{CDCl}_{3}\right): \delta[\mathrm{ppm}]=-4.81$ $\left(\mathrm{Si}\left(\underline{\mathrm{CH}}_{3}\right)_{2} \mathrm{C}\left(\mathrm{CH}_{3}\right)_{3}\right),-4.47\left(\mathrm{Si}\left(\underline{\mathrm{CH}}_{3}\right)_{2} \mathrm{C}\left(\mathrm{CH}_{3}\right)_{3}\right), 18.02\left(\mathrm{Si}\left(\mathrm{CH}_{3}\right)_{2} \underline{\mathrm{C}}\left(\mathrm{CH}_{3}\right)_{3}\right), 18.10\left(\mathrm{Si}\left(\mathrm{CH}_{3}\right)_{2} \underline{\mathrm{C}}\left(\mathrm{CH}_{3}\right)_{3}\right), 25.75$ $\left(\mathrm{Si}\left(\mathrm{CH}_{3}\right)_{2} \mathrm{C}\left(\underline{\mathrm{CH}}_{3}\right)_{3}\right), 25.82\left(\mathrm{Si}\left(\mathrm{CH}_{3}\right)_{2} \mathrm{C}\left(\underline{\mathrm{CH}}_{3}\right)_{3}\right), 27.84\left(\mathrm{COOC}\left(\underline{\mathrm{CH}}_{3}\right)_{3}\right), 67.60\left(\mathrm{C}-1^{\prime \prime}\right), 74.90\left(\mathrm{C}-2^{\prime}\right), 76.03$ $\left(\mathrm{C}-3^{\prime}\right), 79.44\left(\mathrm{C}-4^{\prime}\right), 82.90\left(\mathrm{COOC}\left(\mathrm{CH}_{3}\right)_{3}\right), 92.21\left(\mathrm{C}-1^{\prime}\right), 124.28\left(\mathrm{C}-5^{\prime}\right), 124.55\left(\mathrm{~d}, J_{\mathrm{CF}}=34.8 \mathrm{~Hz}, \mathrm{C}-6\right)$, $128.20\left(\mathrm{C}-3^{\prime \prime} / \mathrm{C}-4^{\prime \prime}\right), 128.52\left(\mathrm{C}-3^{\prime \prime} / \mathrm{C}-4^{\prime \prime}\right), 131.28\left(\mathrm{C}-2^{\prime \prime}\right), 135.71\left(\mathrm{C}-5^{\prime \prime}\right), 140.26$ (d, J $\left.J_{\mathrm{CF}}=238.3 \mathrm{~Hz}, \mathrm{C}-5\right)$, $148.09(\mathrm{C}-2), 156.19\left(\mathrm{~d}, J_{\mathrm{CF}}=27.5 \mathrm{~Hz}, \mathrm{C}-4\right) .{ }^{19} \mathrm{~F} \mathrm{NMR}\left(376 \mathrm{MHz}, \mathrm{CDCl}_{3}\right): \delta[\mathrm{ppm}]=-164.45 . \mathrm{MS}$ $\left(\mathrm{ESI}^{+}\right): \mathrm{m} / z=736.4[\mathrm{M}+\mathrm{H}]^{+}, 758.5[\mathrm{M}+\mathrm{Na}]^{+}$. HRMS $\left(\mathrm{ESI}^{+}\right):$calcd.: $736.3455[\mathrm{M}+\mathrm{H}]^{+}, 758.3275[\mathrm{M}+$ $\mathrm{Na}]^{+}$, found: 736.3433, 758.3256. TLC: $R_{\mathrm{f}}=0.60$ (1:1, petroleum ether-EtOAc). E-29: ${ }^{1} \mathrm{H}$ NMR (500 $\left.\mathrm{MHz}, \mathrm{CDCl}_{3}\right): \delta[\mathrm{ppm}]=0.07\left(\mathrm{~s}, 6 \mathrm{H}, \mathrm{Si}\left(\mathrm{CH}_{3}\right)_{2} \mathrm{C}\left(\mathrm{CH}_{3}\right)_{3}\right), 0.12\left(\mathrm{~s}, 6 \mathrm{H}, \mathrm{Si}\left(\mathrm{CH}_{3}\right)_{2} \mathrm{C}\left(\mathrm{CH}_{3}\right)_{3}\right), 0.90(\mathrm{~s}, 9 \mathrm{H}$, $\left.\mathrm{Si}\left(\mathrm{CH}_{3}\right)_{2} \mathrm{C}\left(\mathrm{C}_{3}\right)_{3}\right), 0.91\left(\mathrm{~s}, 9 \mathrm{H}, \mathrm{Si}\left(\mathrm{CH}_{3}\right)_{2} \mathrm{C}\left(\underline{\mathrm{CH}}_{3}\right)_{3}\right), 1.49\left(\mathrm{~s}, 9 \mathrm{H}, \mathrm{COOC}\left(\mathrm{C}_{3}\right)_{3}\right), 3.84(\mathrm{dd}, J=5.7,4.1 \mathrm{~Hz}$, $\left.1 \mathrm{H}, 3^{\prime}-\mathrm{H}\right), 4.23\left(\mathrm{dd}, J=3.8,3.5 \mathrm{~Hz}, 1 \mathrm{H}, 2^{\prime}-\mathrm{H}\right), 5.16\left(\mathrm{~d}, J=1.3 \mathrm{~Hz}, 2 \mathrm{H}, 1^{\prime \prime}-\mathrm{H}\right), 5.46(\mathrm{dd}, J=9.8,6.0 \mathrm{~Hz}, 1 \mathrm{H}$, $\left.4^{\prime}-\mathrm{H}\right), 5.68\left(\mathrm{~d}, J=4.1 \mathrm{~Hz}, 1 \mathrm{H}, 1^{\prime}-\mathrm{H}\right), 6.86\left(\mathrm{~d}, J=9.5 \mathrm{~Hz}, 1 \mathrm{H}, 5^{\prime}-\mathrm{H}\right), 7.26-7.38\left(\mathrm{~m}, 5 \mathrm{H}\right.$, aryl-H), $7.55\left(\mathrm{~d}, J_{\mathrm{HF}}\right.$ $=6.3 \mathrm{~Hz}, 1 \mathrm{H}, 6-\mathrm{H}) \cdot{ }^{19} \mathrm{~F} \mathrm{NMR}\left(376 \mathrm{MHz}, \mathrm{CDCl}_{3}\right): \delta[\mathrm{ppm}]=-164.09 . \mathrm{MS}\left(\mathrm{ESI}^{+}\right): \mathrm{m} / z=736.4[\mathrm{M}+\mathrm{H}]^{+}$, $758.5[\mathrm{M}+\mathrm{Na}]^{+}$. TLC: $R_{\mathrm{f}}=0.66(1: 1$, petroleum ether-EtOAc).

$\mathrm{Z}-6^{\prime}-\mathrm{N}-\mathrm{Cbz}-5^{\prime}, 6^{\prime}$-didehydro-2' -deoxyuridinyl amino acid tert-butyl ester (35): KOt-Bu (460 mg, $4.06 \mathrm{mmol})$ was dissolved in THF $(15 \mathrm{~mL})$. After cooling to $-87^{\circ} \mathrm{C}$, a solution of phosphonate 33 [31] $(1.50 \mathrm{~g}, 4.02 \mathrm{mmol})$ in THF $(30 \mathrm{~mL})$ was added slowly at this temperature. The mixture was stirred at $-86^{\circ} \mathrm{C}$ for $30 \mathrm{~min}$. Subsequently, a solution of aldehyde $31(1.25 \mathrm{~g}, 3.66 \mathrm{mmol})$ in THF $(12 \mathrm{~mL})$ was added dropwise. Stirring was continued for $18.5 \mathrm{~h}$ while the solution was allowed to slowly warm to rt. After cooling to $0{ }^{\circ} \mathrm{C}, \mathrm{MeOH}(5 \mathrm{~mL})$ was added and the mixture was stirred for further $40 \mathrm{~min}$. It was then diluted with EtOAc $(150 \mathrm{~mL})$ and washed with half-sat. $\mathrm{NaCl}$ solution $(3 \times 100 \mathrm{~mL})$. The organic layer was dried over $\mathrm{Na}_{2} \mathrm{SO}_{4}$ and the solvent was evaporated under reduced pressure. The resultant crude product was purified by column chromatography (1:1, petroleum ether-EtOAc) to give 35 as a colorless foam $(1.54 \mathrm{~g}, 72 \%) .{ }^{1} \mathrm{H}$ NMR $\left(500 \mathrm{MHz}, \mathrm{CDCl}_{3}\right): \delta[\mathrm{ppm}]=0.08\left(\mathrm{~s}, 3 \mathrm{H}, \mathrm{Si}\left(\mathrm{C}_{3}\right)_{2} \mathrm{C}\left(\mathrm{CH}_{3}\right)_{3}\right)$, $0.09\left(\mathrm{~s}, 3 \mathrm{H}, \mathrm{Si}\left(\mathrm{CH}_{3}\right)_{2} \mathrm{C}\left(\mathrm{CH}_{3}\right)_{3}\right), 0.88\left(\mathrm{~s}, 9 \mathrm{H}, \mathrm{Si}\left(\mathrm{CH}_{3}\right)_{2} \mathrm{C}\left(\mathrm{C}_{3}\right)_{3}\right), 1.47$ (s, 9H, COOC$\left.\left(\mathrm{CH}_{3}\right)_{3}\right), 2.16$ (ddd, $J$ $\left.=13.6,6.2,6.2 \mathrm{~Hz}, 1 \mathrm{H}, 2^{\prime}-\mathrm{H}_{\mathrm{a}}\right), 2.41\left(\mathrm{ddd}, J=13.6,6.2,4.7 \mathrm{~Hz}, 1 \mathrm{H}, 2^{\prime}-\mathrm{H}_{\mathrm{b}}\right), 4.33(\mathrm{ddd}, J=6.2,4.7,4.6$ $\left.\mathrm{Hz}, 1 \mathrm{H}, 3^{\prime}-\mathrm{H}\right), 4.71\left(\mathrm{dd}, J=7.8,4.6 \mathrm{~Hz}, 1 \mathrm{H}, 4^{\prime}-\mathrm{H}\right), 5.14\left(\mathrm{~d}, J=4.0 \mathrm{~Hz}, 2 \mathrm{H}, 1^{\prime \prime}-\mathrm{H}\right), 5.73(\mathrm{dd}, J=8.1,2.2$ $\mathrm{Hz}, 1 \mathrm{H}, 5-\mathrm{H}), 6.13\left(\mathrm{~d}, J=7.8 \mathrm{~Hz}, 1 \mathrm{H}, 5^{\prime}-\mathrm{H}\right), 6.14\left(\mathrm{dd}, J=6.2,6.2 \mathrm{~Hz}, 1 \mathrm{H}, 1^{\prime}-\mathrm{H}\right), 6.78\left(\mathrm{~s}, 1 \mathrm{H}, 6^{\prime}-\mathrm{NH}\right)$, 7.29-7.40 (m, 6H, aryl-H, 6-H), 8.75 (brs, $1 \mathrm{H}, 3-\mathrm{NH}) .{ }^{13} \mathrm{C} \mathrm{NMR}\left(126 \mathrm{MHz}, \mathrm{CDCl}_{3}\right): \delta[\mathrm{ppm}]=-4.76$ $\left(\mathrm{Si}\left(\underline{\mathrm{CH}}_{3}\right)_{2} \mathrm{C}\left(\mathrm{CH}_{3}\right)_{3}\right),-4.64\left(\mathrm{Si}\left(\underline{C H}_{3}\right)_{2} \mathrm{C}\left(\mathrm{CH}_{3}\right)_{3}\right), 18.06\left(\mathrm{Si}_{\left(\mathrm{CH}_{3}\right)_{2}} \underline{\mathrm{C}}\left(\mathrm{CH}_{3}\right)_{3}\right), 25.81\left(\mathrm{Si}\left(\mathrm{CH}_{3}\right)_{2} \mathrm{C}\left(\underline{\mathrm{CH}}_{3}\right)_{3}\right), 28.03$ $\left(\mathrm{COOC}\left(\mathrm{CH}_{3}\right)_{3}\right), 40.88\left(\mathrm{C}-2^{\prime}\right), 67.75\left(\mathrm{C}-1^{\prime \prime}\right), 75.97\left(\mathrm{C}-3^{\prime}\right), 82.85\left(\mathrm{C}-4^{\prime}\right), 82.92\left(\mathrm{COOC}\left(\mathrm{CH}_{3}\right)_{3}\right), 86.69\left(\mathrm{C}-1^{\prime}\right)$, 102.60 (C-5), $124.91\left(\mathrm{C}-5^{\prime}\right), 128.40$ (C-3",C-7") 128.51 (C-5"), 128.68 (C-4", C-6"), 130.36 (C-6'), 135.85 (C-2"), 139.78 (C-6), 149.98 (C-2), 153.70 (Cbz-C=O), 162.83 (C-4), 171.13 (C-7'). HRMS (CI): calcd.: $588.2736[\mathrm{M}+\mathrm{H}]^{+}$, found: 588.2717. TLC: $R_{\mathrm{f}}=0.26$ (EtOAc).

$\mathrm{Z}-6^{\prime}-\mathrm{N}-\mathrm{Cbz}-5^{\prime}, 6^{\prime}$-didehydro-thymidinyl amino acid tert-butyl ester (36): KOt-Bu (466 mg, $4.06 \mathrm{mmol})$ was dissolved in THF $(35 \mathrm{~mL})$. After cooling to $-80^{\circ} \mathrm{C}$, a solution of phosphonate 33 [31] (1.52 $\mathrm{g}, 4.06 \mathrm{mmol})$ in THF ( $30 \mathrm{~mL})$ was added slowly at this temperature. The mixture was stirred at $-86^{\circ} \mathrm{C}$ for $30 \mathrm{~min}$. Subsequently, a solution of aldehyde $32(1.31 \mathrm{~g}, 3.70 \mathrm{mmol})$ in THF (12 $\mathrm{mL}$ ) was added dropwise. Stirring was continued for $21 \mathrm{~h}$ while the solution was allowed to slowly warm to rt. After cooling to $0{ }^{\circ} \mathrm{C}, \mathrm{MeOH}(5 \mathrm{~mL})$ was added. The mixture was diluted with EtOAc $(150$ $\mathrm{mL})$ and washed with half-sat. $\mathrm{NaCl}$ solution $(3 \times 100 \mathrm{~mL})$. The organic layer was dried over $\mathrm{Na}_{2} \mathrm{SO}_{4}$ and the solvent was removed under reduced pressure. The resultant crude product was purified by twofold column chromatography (3:2, petroleum ether-EtOAc) to give 36 (95:5 mixture of $Z$ and $E$ isomers as determined by ${ }^{1} \mathrm{H}$ NMR spectroscopy) as a colorless foam $(1.71 \mathrm{~g}, 77 \%) .{ }^{1} \mathrm{H}$ NMR (300 $\left.\mathrm{MHz}, \mathrm{CDCl}_{3}\right): \delta[\mathrm{ppm}]=0.09\left(\mathrm{~s}, 3 \mathrm{H}, \mathrm{Si}\left(\mathrm{C}_{3}\right)_{2} \mathrm{C}\left(\mathrm{CH}_{3}\right)_{3}\right), 0.09\left(\mathrm{~s}, 3 \mathrm{H}, \mathrm{Si}\left(\mathrm{CH}_{3}\right)_{2} \mathrm{C}\left(\mathrm{CH}_{3}\right)_{3}\right), 0.89(\mathrm{~s}, 9 \mathrm{H}$, $\left.\mathrm{Si}\left(\mathrm{CH}_{3}\right)_{2} \mathrm{C}\left(\mathrm{CH}_{3}\right)_{3}\right), 1.47\left(\mathrm{~s}, 9 \mathrm{H}, \mathrm{COOC}\left(\underline{\mathrm{CH}}_{3}\right)_{3}\right), 1.92(\mathrm{~s}, 3 \mathrm{H}, 7-\mathrm{H}), 2.16(\mathrm{ddd}, J=13.5,6.2,6.2 \mathrm{~Hz}, 1 \mathrm{H}$, $\left.2^{\prime}-\mathrm{H}_{\mathrm{a}}\right), 2.36\left(\mathrm{ddd}, J=13.5,6.2,4.7 \mathrm{~Hz}, 1 \mathrm{H}, 2^{\prime}-\mathrm{H}_{\mathrm{b}}\right), 4.35\left(\mathrm{ddd}, J=6.2,4.7,4.6 \mathrm{~Hz}, 1 \mathrm{H}, 3^{\prime}-\mathrm{H}\right), 4.70(\mathrm{dd}, J=$ $\left.7.8,4.6 \mathrm{~Hz}, 1 \mathrm{H}, 4^{\prime}-\mathrm{H}\right), 5.14\left(\mathrm{~d}, J=4.0 \mathrm{~Hz}, 2 \mathrm{H}, 1^{\prime \prime}-\mathrm{H}\right), 6.13\left(\mathrm{~d}, J=7.8 \mathrm{~Hz}, 1 \mathrm{H}, 5^{\prime}-\mathrm{H}\right), 6.14(\mathrm{dd}, J=6.2,6.2$ 
$\left.\mathrm{Hz}, 1 \mathrm{H}, 1^{\prime}-\mathrm{H}\right), 6.81\left(\mathrm{~s}, 1 \mathrm{H}, 6^{\prime}-\mathrm{NH}\right), 7.13(\mathrm{~s}, 1 \mathrm{H}, 6-\mathrm{H}), 7.29-7.40\left(\mathrm{~m}, 5 \mathrm{H}\right.$, aryl-H), $8.71(\mathrm{~s}, 1 \mathrm{H}, 3-\mathrm{NH}) .{ }^{13} \mathrm{C}$ NMR $\left.\left(126 \mathrm{MHz}, \mathrm{CDCl}_{3}\right): \delta[\mathrm{ppm}]=-4.76\left(\mathrm{Si}^{\left(\mathrm{CH}_{3}\right.}\right)_{2} \mathrm{C}\left(\mathrm{CH}_{3}\right)_{3}\right),-4.64\left(\mathrm{Si}\left(\mathrm{CH}_{3}\right)_{2} \mathrm{C}\left(\mathrm{CH}_{3}\right)_{3}\right), 12.78(\mathrm{C}-7)$, $18.05\left(\mathrm{Si}\left(\mathrm{CH}_{3}\right)_{2} \underline{\mathrm{C}}\left(\mathrm{CH}_{3}\right)_{3}\right), 25.81\left(\mathrm{Si}\left(\mathrm{CH}_{3}\right)_{2} \mathrm{C}\left(\underline{\mathrm{CH}}_{3}\right)_{3}\right), 28.02\left(\mathrm{COOC}\left(\mathrm{CH}_{3}\right)_{3}\right), 40.57\left(\mathrm{C}-2^{\prime}\right), 67.73\left(\mathrm{C}-1^{\prime \prime}\right)$, $76.13\left(\mathrm{C}-3^{\prime}\right), 82.85\left(\mathrm{COO} \underline{\mathrm{C}}\left(\mathrm{CH}_{3}\right)_{3}\right), 83.34\left(\mathrm{C}-4^{\prime}\right), 86.39\left(\mathrm{C}-1^{\prime}\right), 111.20(\mathrm{C}-5), 124.95\left(\mathrm{C}-5^{\prime}\right), 128.38\left(\mathrm{C}-3^{\prime \prime}\right.$, C-7"), 128.49 (C-5"), 128.68 (C-4", C-6"), 130.67 (C-6'), 135.61 (C-6), 135.86 (C-2"), 150.12 (C-2), 153.71 $(\mathrm{Cbz}-\mathrm{C}=\mathrm{O}), 162.91(\mathrm{C}-4), 163.67\left(\mathrm{C}-7^{\prime}\right)$. HRMS (CI): calcd.: $602.2892[\mathrm{M}+\mathrm{H}]^{+}$, found: 602.2888. TLC: $R_{\mathrm{f}}=0.31$ (55:45, petroleum ether-EtOAc).

(6'S)-6'-N-Cbz-5-fluorouridinyl amino acid tert-butyl ester (38): Under strict exclusion of oxygen, didehydro amino acid 34 (9:1 mixture of $Z$ and $E$ isomers, $280 \mathrm{mg}, 0.381 \mathrm{mmol})$ was dissolved in $\mathrm{MeOH}(13 \mathrm{~mL})$. After addition of $(S, S)$-Me-DUPHOS-Rh $37(\sim 8 \mathrm{mg}, 12 \mu \mathrm{mol})$, the solution was stirred under an $\mathrm{H}_{2}$ atmosphere ( $\sim 1$ bar) at $\mathrm{rt}$ for $6 \mathrm{~d}$. The reaction was monitored by ${ }^{1} \mathrm{H}$ NMR spectroscopy. Additional catalyst $37(\sim 4 \mathrm{mg}, 6 \mu \mathrm{mol})$ was added after further $5 \mathrm{~d}$ and $2 \mathrm{~d}$, respectively, until the conversion of starting material 34 was complete. The solvent was evaporated under reduced pressure, and the resultant crude product was purified by threefold column chromatography $(3: 1$, petroleum ether-EtOAc and 9:1, petroleum ether-EtOAc and $\mathrm{CH}_{2} \mathrm{Cl}_{2} \rightarrow 95: 5, \mathrm{CH}_{2} \mathrm{Cl}_{2}$-EtOAc, respectively) to give 38 as a colorless foam $(133 \mathrm{mg}, 51 \%) .{ }^{1} \mathrm{H}$ NMR $\left(500 \mathrm{MHz}, \mathrm{CDCl}_{3}\right): \delta[\mathrm{ppm}]=0.07\left(\mathrm{~s}, 6 \mathrm{H}, \mathrm{Si}\left(\mathrm{C}_{3}\right)_{2} \mathrm{C}\left(\mathrm{CH}_{3}\right)_{3}\right)$, $0.12\left(\mathrm{~s}, 6 \mathrm{H}, \mathrm{Si}\left(\mathrm{CH}_{3}\right)_{2} \mathrm{C}\left(\mathrm{CH}_{3}\right)_{3}\right), 0.89$ (s, 9H, Si $\left.\left(\mathrm{CH}_{3}\right)_{2} \mathrm{C}\left(\mathrm{CH}_{3}\right)_{3}\right), 0.91$ (s, 9H, $\left.\mathrm{Si}\left(\mathrm{CH}_{3}\right)_{2} \mathrm{C}\left(\mathrm{C}_{3}\right)_{3}\right), 1.46$ (s, $\left.9 \mathrm{H}, \mathrm{COOC}\left(\mathrm{C}_{3}\right)_{3}\right), 2.02\left(\mathrm{ddd}, J=14.2,8.2,3.8 \mathrm{~Hz}, 1 \mathrm{H}, 5^{\prime}-\overline{\mathrm{H}}_{\mathrm{a}}\right), 2.19\left(\mathrm{ddd}, J=14.2,8.2,2.2 \mathrm{~Hz}, 1 \mathrm{H}, 5^{\prime}-\mathrm{H}_{\mathrm{b}}\right)$, $3.63\left(\mathrm{dd}, J=6.0,4.1 \mathrm{~Hz}, 1 \mathrm{H}, 3^{\prime}-\mathrm{H}\right), 4.14\left(\mathrm{dd}, J=4.1,3.2 \mathrm{~Hz}, 1 \mathrm{H}, 2^{\prime}-\mathrm{H}\right), 4.25(\mathrm{ddd}, J=10.8,6.3,1.9 \mathrm{~Hz}$, $\left.1 \mathrm{H}, 4^{\prime}-\mathrm{H}\right), 4.45\left(\mathrm{ddd}, J=7.6,7.6,3.8 \mathrm{~Hz}, 1 \mathrm{H}, 6^{\prime}-\mathrm{H}\right), 5.12\left(\mathrm{~s}, 2 \mathrm{H}, 1^{\prime \prime}-\mathrm{H}\right), 5.61\left(\mathrm{~d}, J=6.9 \mathrm{~Hz}, 1 \mathrm{H}, 6^{\prime}-\mathrm{NH}\right)$, $5.62\left(\mathrm{~d},{ }^{3} J=1.9 \mathrm{~Hz}, 1 \mathrm{H}, 1^{\prime}-\mathrm{H}\right), 7.31-7.38(\mathrm{~m}, 5 \mathrm{H}, \operatorname{aryl}-\mathrm{H}), 7.84\left(\mathrm{~d}, J_{\mathrm{HF}}=6.0 \mathrm{~Hz}, 1 \mathrm{H}, 6-\mathrm{H}\right), 8.95(\mathrm{brs}, 1 \mathrm{H}$, 3-NH). ${ }^{13} \mathrm{C}$ NMR $\left(126 \mathrm{MHz}, \mathrm{CDCl}_{3}\right): \delta[\mathrm{ppm}]=-4.85\left(\mathrm{Si}\left(\mathrm{CH}_{3}\right)_{2} \mathrm{C}\left(\mathrm{CH}_{3}\right)_{3}\right),-4.33\left(\mathrm{Si}\left(\mathrm{CH}_{3}\right)_{2} \mathrm{C}\left(\mathrm{CH}_{3}\right)_{3}\right)$, $17.96\left(\mathrm{Si}\left(\mathrm{CH}_{3}\right)_{2} \underline{\mathrm{C}}\left(\mathrm{CH}_{3}\right)_{3}\right), 17.99\left(\mathrm{Si}\left(\mathrm{CH}_{3}\right)_{2} \underline{\mathrm{C}}\left(\mathrm{CH}_{3}\right)_{3}\right), 25.75\left(\mathrm{Si}\left(\mathrm{CH}_{3}\right)_{2} \mathrm{C}\left(\underline{\mathrm{CH}}_{3}\right)_{3}\right), 25.79\left(\mathrm{Si}\left(\mathrm{CH}_{3}\right)_{2} \mathrm{C}\left(\underline{\mathrm{CH}}_{3}\right)_{3}\right)$, $27.92\left(\mathrm{COOC}\left(\mathrm{C}_{3}\right)_{3}\right), 36.35\left(\mathrm{C}-5^{\prime}\right), 51.86\left(\mathrm{C}-6^{\prime}\right), 66.97\left(\mathrm{C}-1^{\prime \prime}\right), 75.15\left(\mathrm{C}-2^{\prime}\right), 75.24\left(\mathrm{C}-3^{\prime}\right), 80.24\left(\mathrm{C}-4^{\prime}\right)$, $82.98\left(\mathrm{COOC}\left(\mathrm{CH}_{3}\right)_{3}\right), 91.20\left(\mathrm{C}-1^{\prime}\right), 124.72\left(\mathrm{~d}, J_{\mathrm{CF}}=30.0 \mathrm{~Hz}, \mathrm{C}-6\right), 128.22\left(\mathrm{C}-3^{\prime \prime} / \mathrm{C}-4^{\prime \prime}\right), 128.26\left(\mathrm{C}-3^{\prime \prime} / \mathrm{C}-4^{\prime \prime}\right)$, $128.51\left(\mathrm{C}-2^{\prime \prime}\right), 139.51\left(\mathrm{C}-5^{\prime \prime}\right), 140.65\left(\mathrm{~d}, J_{\mathrm{CF}}=238.3 \mathrm{~Hz}, \mathrm{C}-5\right), 148.39(\mathrm{C}-2), 155.49\left(\mathrm{~d}, J_{\mathrm{CF}}=32.9 \mathrm{~Hz}, \mathrm{C}-4\right)$.

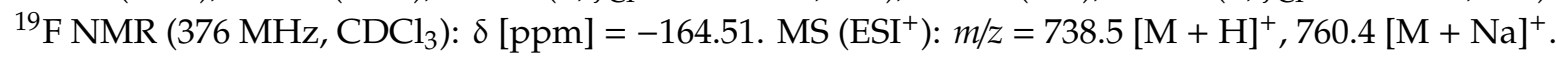
HRMS (ESI ${ }^{+}$): calcd.: $738.3612[\mathrm{M}+\mathrm{H}]^{+}, 760.3431[\mathrm{M}+\mathrm{Na}]^{+}$, found: 738.3594, 760.3413. TLC: $R_{\mathrm{f}}=$ 0.53 (1:1, petroleum ether-EtOAc).

(6' $\left.6^{\prime}\right)-6^{\prime}-\mathrm{N}-\mathrm{Cbz}-2^{\prime}$-deoxyuridinyl amino acid tert-butyl ester (39): Under strict exclusion of oxygen, didehydro amino acid $35(600 \mathrm{mg}, 1.02 \mathrm{mmol})$ was dissolved in $\mathrm{MeOH}(35 \mathrm{~mL})$. After addition of $(S, S)$-Me-DUPHOS-Rh $37(\sim 15 \mathrm{mg}, 21 \mu \mathrm{mol})$, the solution was stirred under an $\mathrm{H}_{2}$ atmosphere $(\sim 1$ bar) at $\mathrm{rt}$ for $4 \mathrm{~d}$. The reaction was monitored by ${ }^{1} \mathrm{H}$ NMR spectroscopy. Additional catalyst $37(\sim 4$ $\mathrm{mg}, 6 \mu \mathrm{mol}$ ) was added and stirring was continued for $2 \mathrm{~d}$ until the conversion of starting material 35 was complete. The solvent was evaporated under reduced pressure, and the resultant crude product was purified by column chromatography (3:2, petroleum ether-EtOAc) to give 39 as a colorless foam (562 mg, 93\%). ${ }^{1} \mathrm{H}$ NMR (500 MHz, CDCl 3 ): $\delta$ [ppm] $=0.05\left(\mathrm{~s}, 6 \mathrm{H}, \mathrm{Si}\left(\mathrm{C}_{3}\right)_{2} \mathrm{C}\left(\mathrm{CH}_{3}\right)_{3}\right), 0.89(\mathrm{~s}, 9 \mathrm{H}$, $\left.\mathrm{Si}\left(\mathrm{CH}_{3}\right)_{2} \mathrm{C}\left(\mathrm{CH}_{3}\right)_{3}\right), 1.43\left(\mathrm{~s}, 9 \mathrm{H}, \mathrm{COOC}\left(\mathrm{CH}_{3}\right)_{3}\right), 1.93-2.02\left(\mathrm{~m}, 1 \mathrm{H}, 5^{\prime}-\mathrm{H}_{\mathrm{a}}\right), 2.03-2.11\left(\mathrm{~m}, 1 \mathrm{H}, 2^{\prime}-\mathrm{H}_{\mathrm{a}}\right), 2.20$ $\left(\mathrm{ddd}, J=14.2,6.7,2.9 \mathrm{~Hz}, 1 \mathrm{H}, 5^{\prime}-\mathrm{H}_{\mathrm{b}}\right), 2.23-2.31\left(\mathrm{~m}, 1 \mathrm{H}, 2^{\prime}-\mathrm{H}_{\mathrm{b}}\right), 3.90-3.97\left(\mathrm{~m}, 1 \mathrm{H}, 4^{\prime}-\mathrm{H}\right), 4.05(\mathrm{dd}, J=10.8$, $\left.4.9 \mathrm{~Hz}, 1 \mathrm{H}, 3^{\prime}-\mathrm{H}\right), 4.41\left(\mathrm{dd}, J=11.6,6.7 \mathrm{~Hz}, 1 \mathrm{H}, 6^{\prime}-\mathrm{H}\right), 5.10\left(\mathrm{~s}, 2 \mathrm{H}, 1^{\prime \prime}-\mathrm{H}\right), 5.55\left(\mathrm{~d}, J=6.8 \mathrm{~Hz}, 1 \mathrm{H}, 6^{\prime}-\mathrm{NH}\right)$, $5.77(\mathrm{~d}, J=8.0 \mathrm{~Hz}, 1 \mathrm{H}, 5-\mathrm{H}), 6.14\left(\mathrm{dd}, J=6.1,6.1 \mathrm{~Hz}, 1 \mathrm{H}, 1^{\prime}-\mathrm{H}\right), 7.27-7.39(\mathrm{~m}, 5 \mathrm{H}, \operatorname{aryl}-\mathrm{H}), 7.54(\mathrm{~d}, J=$ $8.0 \mathrm{~Hz}, 1 \mathrm{H}, 6-\mathrm{H}), 8.92(\mathrm{~s}, 1 \mathrm{H}, 3-\mathrm{NH}) .{ }^{13} \mathrm{C} \mathrm{NMR}\left(126 \mathrm{MHz}, \mathrm{CDCl}_{3}\right): \delta[\mathrm{ppm}]=-4.74\left(\mathrm{Si}\left(\mathrm{CH}_{3}\right)_{2} \mathrm{C}\left(\mathrm{CH}_{3}\right)_{3}\right)$, $-4.48\left(\mathrm{Si}\left(\mathrm{CH}_{3}\right)_{2} \mathrm{C}\left(\mathrm{CH}_{3}\right)_{3}\right), 18.03\left(\mathrm{Si}\left(\mathrm{CH}_{3}\right)_{2} \underline{\mathrm{C}}\left(\mathrm{CH}_{3}\right)_{3}\right), 25.79\left(\mathrm{Si}\left(\mathrm{CH}_{3}\right)_{2} \mathrm{C}\left(\mathrm{CH}_{3}\right)_{3}\right), 28.06\left(\mathrm{COOC}\left(\underline{\mathrm{CH}}_{3}\right)_{3}\right)$, $36.14\left(\mathrm{C}-5^{\prime}\right), 40.64\left(\mathrm{C}-2^{\prime}\right), 52.23\left(\mathrm{C}-6^{\prime}\right), 67.09\left(\mathrm{C}-1^{\prime \prime}\right), 74.92\left(\mathrm{C}-3^{\prime}\right), 82.92\left(\mathrm{COOC}\left(\mathrm{CH}_{3}\right)_{3}\right), 83.31\left(\mathrm{C}-4^{\prime}\right), 85.63$ $\left(\mathrm{C}-1^{\prime}\right), 102.68$ (C-5), 128.30, 128.37, 128.67 (C-3", C-4", C-5", C-6", C-7"), 136.38 (C-2"), 140.35 (C-6), 150.15 (C-2), 155.69 (Cbz-C=O), 163.29 (C-4), 170.61 (C-7'). HRMS (CI): calcd.: 590.2892 [M + H] ${ }^{+}$, found: 590.2885. TLC: $R_{\mathrm{f}}=0.25$ (1:1, petroleum ether-EtOAc).

$\left(6^{\prime} S\right)-6^{\prime}-N$-Cbz-thymidinyl amino acid tert-butyl ester (40): Under strict exclusion of oxygen, didehydro amino acid $36(600 \mathrm{mg}, 0.997 \mathrm{mmol})$ was dissolved in $\mathrm{MeOH}(35 \mathrm{~mL})$. After addition of $(S, S)$-Me-DUPHOS-Rh $37(\sim 20 \mathrm{mg}, 28 \mu \mathrm{mol})$, the solution was stirred under an $\mathrm{H}_{2}$ atmosphere $(\sim 1$ 
bar) at $\mathrm{rt}$ for $7 \mathrm{~d}$. The reaction was monitored by ${ }^{1} \mathrm{H}$ NMR spectroscopy. After complete conversion of starting material 36, the solvent was evaporated under reduced pressure. The resultant crude product was purified by column chromatography (1:1, petroleum ether-EtOAc) to give 40 as a colorless foam (566 mg, 95\%). ${ }^{1} \mathrm{H} \mathrm{NMR}\left(500 \mathrm{MHz}, \mathrm{CDCl}_{3}\right): \delta[\mathrm{ppm}]=0.06\left(\mathrm{~s}, 6 \mathrm{H}, \mathrm{Si}\left(\mathrm{CH}_{3}\right)_{2} \mathrm{C}\left(\mathrm{CH}_{3}\right)_{3}\right), 0.88(\mathrm{~s}$, $\left.9 \mathrm{H}, \mathrm{Si}\left(\mathrm{CH}_{3}\right)_{2} \mathrm{C}\left(\mathrm{CH}_{3}\right)_{3}\right), 1.43\left(\mathrm{~s}, 9 \mathrm{H}, \mathrm{COOC}\left(\underline{\mathrm{CH}}_{3}\right)_{3}\right), 1.97(\mathrm{~s}, 3 \mathrm{H}, 7-\mathrm{H}), 1.99-2.09\left(\mathrm{~m}, 2 \mathrm{H}, 2^{\prime}-\mathrm{H}_{\mathrm{a}}, 5^{\prime}-\mathrm{H}_{\mathrm{a}}\right)$, 2.14-2.20 (m, 1H, $\left.5^{\prime}-\mathrm{H}_{\mathrm{b}}\right), 2.22\left(\mathrm{ddd}, J=13.5,6.5,4.3 \mathrm{~Hz}, 1 \mathrm{H}, 2^{\prime}-\mathrm{H}_{\mathrm{b}}\right), 3.92-3.97\left(\mathrm{~m}, 1 \mathrm{H}, 4^{\prime}-\mathrm{H}\right), 4.07$ (ddd, $J$ $\left.=6.5,4.3,4.3 \mathrm{~Hz}, 1 \mathrm{H}, 3^{\prime}-\mathrm{H}\right), 4.42\left(\mathrm{dd}, J=11.8,7.1 \mathrm{~Hz}, 1 \mathrm{H}, 6^{\prime}-\mathrm{H}\right), 5.10\left(\mathrm{~s}, 2 \mathrm{H}, 1^{\prime \prime}-\mathrm{H}\right), 5.54(\mathrm{~d}, J=6.7 \mathrm{~Hz}$, $\left.1 \mathrm{H}, 6^{\prime}-\mathrm{NH}\right), 6.18\left(\mathrm{dd}, J=6.5,6.5 \mathrm{~Hz}, 1 \mathrm{H}, 1^{\prime}-\mathrm{H}\right), 7.29-7.36(\mathrm{~m}, 5 \mathrm{H}$, aryl-H), $7.37(\mathrm{~s}, 1 \mathrm{H}, 6-\mathrm{H}), 8.53$ (brs, $1 \mathrm{H}$, 3-NH). ${ }^{13} \mathrm{C} \mathrm{NMR}\left(126 \mathrm{MHz}, \mathrm{CDCl}_{3}\right): \delta[\mathrm{ppm}]=-4.71\left(\mathrm{Si}\left(\mathrm{CH}_{3}\right)_{2} \mathrm{C}\left(\mathrm{CH}_{3}\right)_{3}\right),-4.47\left(\mathrm{Si}\left(\mathrm{CH}_{3}\right)_{2} \mathrm{C}\left(\mathrm{CH}_{3}\right)_{3}\right)$, $12.46(\mathrm{C}-7), 18.05\left(\mathrm{Si}\left(\mathrm{CH}_{3}\right)_{2} \underline{\mathrm{C}}\left(\mathrm{CH}_{3}\right)_{3}\right), 25.18\left(\mathrm{Si}\left(\mathrm{CH}_{3}\right)_{2} \mathrm{C}\left(\mathrm{CH}_{3}\right)_{3}\right), 28.06\left(\mathrm{COOC}\left(\underline{C H}_{3}\right)_{3}\right), 36.26\left(\mathrm{C}-5^{\prime}\right), 40.39$ $\left(\mathrm{C}-2^{\prime}\right), 52.16\left(\mathrm{C}-6^{\prime}\right), 67.06\left(\mathrm{C}-1^{\prime \prime}\right), 75.11\left(\mathrm{C}-3^{\prime}\right), 82.89\left(\mathrm{COOC}^{\prime}\left(\mathrm{CH}_{3}\right)_{3}\right), 83.26\left(\mathrm{C}^{\prime} 4^{\prime}\right), 85.27\left(\mathrm{C}-1^{\prime}\right), 111.33$ (C-5), 128.26, 128.37, 128.68 (C-3", C-4", C-5", C-6", C-7"'), 136.00 (C-6), 136.41 (C-2"), 150.18 (C-2), 155.65 (Cbz-C=O), 163.74 (C-4), 170.65 (C-7'). HRMS (CI): calcd.: 604.3049 [M + H] $]^{+}$, found: 604.3029. TLC: $R_{\mathrm{f}}=0.30$ (1:1, petroleum ether-EtOAc).

$\left(6^{\prime} S\right)$-5,6-dihydrouridinyl amino acid tert-butyl ester (42): (6'S)-6'-N-Cbz-uridinyl amino acid tert-butyl ester 41 [31] (100 mg, $0.139 \mathrm{mmol})$ was dissolved in $i-\mathrm{PrOH}(20 \mathrm{~mL})$ and stirred over molecular sieve ( $3 \AA$ ) at rt for $15 \mathrm{~min}$. Pd black $(130 \mathrm{mg}, 1.22 \mathrm{mmol})$ was added and the reaction mixture was stirred under an $\mathrm{H}_{2}$ atmosphere $(\sim 1$ bar $)$ at $\mathrm{rt}$ for $4 \mathrm{~h}$. After filtration through a syringe filter and washing the filter with $i$-PrOH $\left(50{ }^{\circ} \mathrm{C}, 45 \mathrm{~mL}\right)$, the solvent of the combined filtrates was evaporated under reduced pressure to give 42 as a colorless foam $(82 \mathrm{mg}, 96 \%) .{ }^{1} \mathrm{H} \mathrm{NMR}\left(300 \mathrm{MHz}, \mathrm{CDCl}_{3}\right): \delta$ $[\mathrm{ppm}]=0.06\left(\mathrm{~s}, 3 \mathrm{H}, \mathrm{Si}\left(\mathrm{CH}_{3}\right)_{2} \mathrm{C}\left(\mathrm{CH}_{3}\right)_{3}\right), 0.07\left(\mathrm{~s}, 3 \mathrm{H}, \mathrm{Si}\left(\mathrm{C}_{3}\right)_{2} \mathrm{C}\left(\mathrm{CH}_{3}\right)_{3}\right), 0.08\left(\mathrm{~s}, 3 \mathrm{H}, \mathrm{Si}\left(\mathrm{CH}_{3}\right)_{2} \mathrm{C}\left(\mathrm{CH}_{3}\right)_{3}\right)$, $0.09\left(\mathrm{~s}, 3 \mathrm{H}, \mathrm{Si}\left(\mathrm{CH}_{3}\right)_{2} \mathrm{C}\left(\mathrm{CH}_{3}\right)_{3}\right), 0.90\left(\mathrm{~s}, 9 \mathrm{H}, \mathrm{Si}\left(\mathrm{CH}_{3}\right)_{2} \mathrm{C}\left(\underline{\mathrm{CH}}_{3}\right)_{3}\right), 0.91\left(\mathrm{~s}, 9 \mathrm{H}, \mathrm{Si}\left(\mathrm{CH}_{3}\right)_{2} \mathrm{C}\left(\overline{\mathrm{CH}}_{3}\right)_{3}\right), 1.46(\mathrm{~s}$, $\left.9 \mathrm{H}, \operatorname{COOC}\left(\mathrm{CH}_{3}\right)_{3}\right), 1.68\left(\mathrm{ddd}, J=13.9,9.4,7.1 \mathrm{~Hz}, 1 \mathrm{H}, 5^{\prime}-\mathrm{H}_{\mathrm{a}}\right), 2.12(\mathrm{ddd}, J=13.9,6.0,2.6 \mathrm{~Hz}, 1 \mathrm{H}$, $\left.5^{\prime}-\mathrm{H}_{\mathrm{b}}\right), 2.63-2.69(\mathrm{~m}, 2 \mathrm{H}, 5-\mathrm{H}), 3.29-3.40\left(\mathrm{~m}, 1 \mathrm{H}, 6-\mathrm{H}_{\mathrm{a}}\right), 3.49\left(\mathrm{dd}, J=6.3,6.3 \mathrm{~Hz}, 1 \mathrm{H}, 6-\mathrm{H}_{\mathrm{b}}\right), 3.56(\mathrm{dd}, J$ $\left.=7.1,7.0 \mathrm{~Hz}, 1 \mathrm{H}, 6^{\prime}-\mathrm{H}\right), 3.74\left(\mathrm{dd}, J=5.7,4.6 \mathrm{~Hz}, 1 \mathrm{H}, 3^{\prime}-\mathrm{H}\right), 4.01\left(\mathrm{ddd}, J=9.4,5.7,2.6 \mathrm{~Hz}, 1 \mathrm{H}, 4^{\prime}-\mathrm{H}\right)$, $4.14\left(\mathrm{dd}, J=4.6,4.0 \mathrm{~Hz}, 1 \mathrm{H}, 2^{\prime}-\mathrm{H}\right), 5.59$ (d, $\left.J=4.0 \mathrm{~Hz}, 1 \mathrm{H}, 1^{\prime}-\mathrm{H}\right), 7.61$ (brs, 1H, 3-NH). ${ }^{13} \mathrm{C} \mathrm{NMR}(126$ $\left.\mathrm{MHz}, \mathrm{CDCl}_{3}\right): \delta[\mathrm{ppm}]=-4.49\left(\mathrm{Si}\left(\mathrm{CH}_{3}\right)_{2} \mathrm{C}\left(\mathrm{CH}_{3}\right)_{3}\right),-4.40\left(\mathrm{Si}\left(\mathrm{CH}_{3}\right)_{2} \mathrm{C}\left(\mathrm{CH}_{3}\right)_{3}\right),-4.38\left(\mathrm{Si}\left(\mathrm{CH}_{3}\right)_{2} \mathrm{C}\left(\mathrm{CH}_{3}\right)_{3}\right)$, -4.00 $\left(\mathrm{Si}\left(\mathrm{CH}_{3}\right)_{2} \mathrm{C}\left(\mathrm{CH}_{3}\right)_{3}\right), 18.15\left(\mathrm{Si}\left(\mathrm{CH}_{3}\right)_{2} \underline{\mathrm{C}}\left(\mathrm{CH}_{3}\right)_{3}\right), 18.24\left(\mathrm{Si}\left(\mathrm{CH}_{3}\right)_{2} \underline{\mathrm{C}}\left(\mathrm{CH}_{3}\right)_{3}\right), 25.93\left(\mathrm{Si}\left(\mathrm{CH}_{3}\right)_{2} \mathrm{C}\left(\mathrm{CH}_{3}\right)_{3}\right)$, $26.02\left(\mathrm{Si}\left(\mathrm{CH}_{3}\right)_{2} \mathrm{C}\left(\underline{\mathrm{CH}}_{3}\right)_{3}\right), 28.16\left(\mathrm{COOC}\left(\underline{\mathrm{CH}}_{3}\right)_{3}\right), 31.29(\mathrm{C}-5), 38.47\left(\mathrm{C}-5^{\prime}\right), 38.70(\mathrm{C}-6), 53.62\left(\mathrm{C}-6^{\prime}\right), 73.52$ $\left(\mathrm{C}-2^{\prime}\right), 76.14\left(\mathrm{C}-3^{\prime}\right), 80.81\left(\mathrm{C}-4^{\prime}\right), 81.69\left(\mathrm{COOC}^{\prime}\left(\mathrm{CH}_{3}\right)_{3}\right), 91.64\left(\mathrm{C}-1^{\prime}\right), 152.17(\mathrm{C}-2), 169.44(\mathrm{C}-4), 173.97$ (C-7'). HRMS (CI): calcd.: $588.3495[\mathrm{M}+\mathrm{H}]^{+}$, found: 588.3488 .

$\mathrm{N}$-Cbz-protected 5,6-dihydrouridine derivative (44): Nucleosyl amino acid ester 42 (100 mg, $0.170 \mathrm{mmol})$ was dissolved in THF $(14 \mathrm{~mL})$ and aldehyde 43 [24,34] (70 $\mathrm{mg}, 0.22 \mathrm{mmol})$ was added. The reaction mixture was stirred over molecular sieve $(3 \AA)$ at $\mathrm{rt}$ for $23 \mathrm{~h}$. NaBH(OAc) ${ }_{3}(80 \mathrm{mg}, 0.39$ mmol) and Amberlyst $15^{\mathrm{TM}}(14 \mathrm{mg}, 44 \mu \mathrm{mol})$ were added and stirring was continued at $\mathrm{rt}$ for $22 \mathrm{~h}$. The reaction mixture was filtered and the residue was washed with EtOAc $(150 \mathrm{~mL})$. The combined filtrates were washed with sat. $\mathrm{NaHCO}_{3}$ solution $(100 \mathrm{~mL})$ and brine $(50 \mathrm{~mL})$. The aqueous layer was extracted with EtOAc $(3 \times 100 \mathrm{~mL})$. The combined organics were dried over $\mathrm{Na}_{2} \mathrm{SO}_{4}$ and the solvent was evaporated under reduced pressure. The resultant crude product was purified by column chromatography $\left(98: 2, \mathrm{CH}_{2} \mathrm{Cl}_{2}-\mathrm{MeOH}\right)$ to give 44 as a colorless solid (93 $\left.\mathrm{mg}, 58 \%\right)$. ${ }^{1} \mathrm{H} \mathrm{NMR}$ $\left(500 \mathrm{MHz}, \mathrm{CD}_{3} \mathrm{OD}\right): \delta[\mathrm{ppm}]=0.11\left(\mathrm{~s}, 3 \mathrm{H}, \mathrm{Si}\left(\mathrm{CH}_{3}\right)_{2} \mathrm{C}\left(\mathrm{CH}_{3}\right)_{3}\right), 0.12\left(\mathrm{~s}, 3 \mathrm{H}, \mathrm{Si}\left(\mathrm{CH}_{3}\right)_{2} \mathrm{C}\left(\mathrm{CH}_{3}\right)_{3}\right), 0.13$ (s, 3H, Si $\left.\left(\underline{\mathrm{CH}}_{3}\right)_{2} \mathrm{C}\left(\mathrm{CH}_{3}\right)_{3}\right), 0.14\left(\mathrm{~s}, 3 \mathrm{H}, \mathrm{Si}\left(\mathrm{CH}_{3}\right)_{2} \mathrm{C}\left(\mathrm{CH}_{3}\right)_{3}\right), 0.84-0.91(\mathrm{~m}, 6 \mathrm{H}, \mathrm{Leu}-5-\mathrm{H}), 0.92$ (s, 9H, $\left.\mathrm{Si}\left(\mathrm{CH}_{3}\right)_{2} \mathrm{C}\left(\mathrm{CH}_{3}\right)_{3}\right), 0.93\left(\mathrm{~s}, 9 \mathrm{H}, \mathrm{Si}\left(\mathrm{CH}_{3}\right)_{2} \mathrm{C}\left(\mathrm{C}_{3}\right)_{3}\right), 1.49\left(\mathrm{~s}, 9 \mathrm{H}, \mathrm{COOC}\left(\mathrm{CH}_{3}\right)_{3}\right), 1.53(\mathrm{dd}, J=7.2,7.2 \mathrm{~Hz}$,

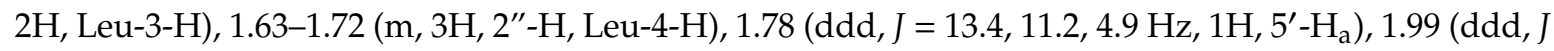
$\left.=13.4,9.6,2.7 \mathrm{~Hz}, 1 \mathrm{H}, 5^{\prime}-\mathrm{H}_{\mathrm{b}}\right), 2.51-2.58\left(\mathrm{~m}, 1 \mathrm{H}, 1^{\prime \prime}-\mathrm{H}_{\mathrm{a}}\right), 2.60-2.67\left(\mathrm{~m}, 3 \mathrm{H}, 1^{\prime \prime}-\mathrm{H}_{\mathrm{b}}, 5-\mathrm{H}\right), 3.18-3.36(\mathrm{~m}, 2 \mathrm{H}$, $\left.6^{\prime}-\mathrm{H}, 3^{\prime \prime}-\mathrm{H}_{\mathrm{a}}\right), 3.39\left(\mathrm{ddd}, J=12.9,6.6,6.6 \mathrm{~Hz}, 1 \mathrm{H}, 6-\mathrm{H}_{\mathrm{a}}\right), 3.47\left(\mathrm{ddd}, J=12.9,6.7,6.7 \mathrm{~Hz}, 1 \mathrm{H}, 6-\mathrm{H}_{\mathrm{b}}\right), 3.56$ $\left(\mathrm{ddd}, J=8.1,4.4,4.4 \mathrm{~Hz}, 1 \mathrm{H}, 3^{\prime \prime}-\mathrm{H}_{\mathrm{b}}\right), 3.85\left(\mathrm{dd}, J=4.8,4.8 \mathrm{~Hz}, 1 \mathrm{H}, 3^{\prime}-\mathrm{H}\right), 3.88-3.94\left(\mathrm{~m}, 1 \mathrm{H}, 4^{\prime}-\mathrm{H}\right), 4.04-4.14$ $\left(\mathrm{m}, 1 \mathrm{H}\right.$, Leu-2-H), 4.25 (dd, $\left.J=4.8,4.6 \mathrm{~Hz}, 1 \mathrm{H}, 2^{\prime}-\mathrm{H}\right), 5.09\left(\mathrm{~s}, 2 \mathrm{H}, 1^{\prime \prime \prime}-\mathrm{H}\right), 5.77\left(\mathrm{~d}, J=4.6 \mathrm{~Hz}, 1 \mathrm{H}, 1^{\prime}-\mathrm{H}\right)$, 7.25-7.39 (m, 5H, aryl-H). ${ }^{13} \mathrm{C}$ NMR $\left(126 \mathrm{MHz}, \mathrm{CD}_{3} \mathrm{OD}\right): \delta[\mathrm{ppm}]=-4.36\left(\mathrm{Si}\left(\mathrm{CH}_{3}\right)_{2} \mathrm{C}\left(\mathrm{CH}_{3}\right)_{3}\right),-4.34$ $\left(\mathrm{Si}\left(\underline{\mathrm{CH}_{3}}\right)_{2} \mathrm{C}\left(\mathrm{CH}_{3}\right)_{3}\right),-4.13\left(\mathrm{Si}\left(\underline{\mathrm{CH}}_{3}\right)_{2} \mathrm{C}\left(\mathrm{CH}_{3}\right)_{3}\right),-3.93\left(\mathrm{Si}\left(\underline{\mathrm{CH}}_{3}\right)_{2} \mathrm{C}\left(\mathrm{CH}_{3}\right)_{3}\right), 18.90\left(\mathrm{Si}\left(\mathrm{CH}_{3}\right)_{2} \underline{\mathrm{C}}\left(\mathrm{CH}_{3}\right)_{3}\right), 18.94$ 
$\left(\mathrm{Si}\left(\mathrm{CH}_{3}\right)_{2} \underline{\mathrm{C}}\left(\mathrm{CH}_{3}\right)_{3}\right), 23.37$ (Leu-C-5), 23.46 (Leu-C-5), 25.99 (Leu-C-4), $26.41\left(\mathrm{Si}\left(\mathrm{CH}_{3}\right)_{2} \mathrm{C}\left(\mathrm{CH}_{3}\right)_{3}\right), 26.48$ $\left(\mathrm{Si}\left(\mathrm{CH}_{3}\right)_{2} \mathrm{C}\left(\mathrm{CH}_{3}\right)_{3}\right), 28.44\left(\mathrm{COOC}\left(\underline{\mathrm{CH}}_{3}\right)_{3}\right), 29.97\left(\mathrm{C}-2^{\prime \prime}\right), 31.93(\mathrm{C}-5), 37.46\left(\mathrm{C}-5^{\prime}\right), 38.09(\mathrm{C}-6), 39.00\left(\mathrm{C}-3^{\prime \prime}\right)$, 42.22 (Leu-C-3), 46.02 (C-1"), 55.23 (Leu-C-2), 60.41 (C-6'), 67.71 (C-1'”'), $74.14\left(\mathrm{C}-2^{\prime}\right), 77.15\left(\mathrm{C}-3^{\prime}\right), 81.10$ $\left(\mathrm{C}-4^{\prime}\right), 83.24\left(\mathrm{COO} \underline{C}\left(\mathrm{CH}_{3}\right)_{3}\right), 91.77\left(\mathrm{C}-1^{\prime}\right), 128.85\left(\mathrm{C}-3^{\prime \prime \prime}, \mathrm{C}-7^{\prime \prime \prime}\right), 129.09\left(\mathrm{C}-5^{\prime \prime \prime}\right), 129.50\left(\mathrm{C}-4^{\prime \prime \prime}, \mathrm{C}-6^{\prime \prime \prime}\right)$, 138.20 (C-2"' ), 154.93 (C-2), 158.39 (Cbz-C=O), 172.49 (C-4), 175.67 (C-7'), 181.44 (Leu-C-1). HRMS $\left(\mathrm{ESI}^{+}\right)$: calcd.: $892.5282[\mathrm{M}+\mathrm{H}]^{+}$, found: 892.5261 .

5,6-Dihydrouridine derivative (45): N-Cbz-protected 5,6-dihydrouridine derivative 44 (51 mg, 57 $\mu \mathrm{mol})$ was dissolved in $\mathrm{MeOH}(10 \mathrm{~mL})$ and $\mathrm{Pd} / \mathrm{C}(10 \%, 3.6 \mathrm{mg}, 3.4 \mu \mathrm{mol} \mathrm{Pd})$ was added. The reaction mixture was stirred under an $\mathrm{H}_{2}$ atmosphere ( 1 bar) at $\mathrm{rt}$ for $2 \mathrm{~h}$. After filtration through a syringe filter and washing the filter with EtOAc $\left(50^{\circ} \mathrm{C}, 20 \mathrm{~mL}\right)$, the solvent of the combined filtrates was evaporated under reduced pressure to give 45 as a colorless solid (42 mg, quant.). ${ }^{1} \mathrm{H}$ NMR (500 MHz, CD $\left.30 D\right): \delta$ [ppm] $=0.11\left(\mathrm{~s}, 3 \mathrm{H}, \mathrm{Si}\left(\mathrm{CH}_{3}\right)_{2} \mathrm{C}\left(\mathrm{CH}_{3}\right)_{3}\right), 0.12\left(\mathrm{~s}, 3 \mathrm{H}, \mathrm{Si}\left(\mathrm{CH}_{3}\right)_{2} \mathrm{C}\left(\mathrm{CH}_{3}\right)_{3}\right), 0.13\left(\mathrm{~s}, 3 \mathrm{H}, \mathrm{Si}\left(\mathrm{CH}_{3}\right)_{2} \mathrm{C}\left(\mathrm{CH}_{3}\right)_{3}\right)$, $0.14\left(\mathrm{~s}, 3 \mathrm{H}, \mathrm{Si}\left(\mathrm{CH}_{3}\right)_{2} \mathrm{C}\left(\mathrm{CH}_{3}\right)_{3}\right), 0.89-0.96(\mathrm{~m}, 6 \mathrm{H}, \mathrm{Leu}-5-\mathrm{H}), 0.92\left(\mathrm{~s}, 9 \mathrm{H}, \mathrm{Si}\left(\mathrm{CH}_{3}\right)_{2} \mathrm{C}\left(\mathrm{CH}_{3}\right)_{3}\right), 0.94(\mathrm{~s}, 9 \mathrm{H}$, $\left.\mathrm{Si}\left(\mathrm{CH}_{3}\right)_{2} \mathrm{C}\left(\mathrm{CH}_{3}\right)_{3}\right), 1.41-1.55(\mathrm{~m}, 2 \mathrm{H}, \mathrm{Leu}-3-\mathrm{H}), 1.49$ (s, 9H, COOC $\left.\left(\mathrm{CH}_{3}\right)_{3}\right), 1.64-1.72\left(\mathrm{~m}, 3 \mathrm{H}, 2^{\prime \prime}-\mathrm{H}\right.$, Leu-4-H), $1.76\left(\mathrm{ddd}, J=13.9,10.8,4.9 \mathrm{~Hz}, 1 \mathrm{H}, 5^{\prime}-\mathrm{H}_{\mathrm{a}}\right), 1.96-2.02\left(\mathrm{~m}, 1 \mathrm{H}, 5^{\prime}-\mathrm{H}_{\mathrm{b}}\right), 2.52(\mathrm{ddd}, J=11.6,7.0$, 7.0 Hz, 1H, 1" $\left.-\mathrm{H}_{\mathrm{a}}\right), 2.59-2.68\left(\mathrm{~m}, 3 \mathrm{H}, 5-\mathrm{H}, 1^{\prime \prime}-\mathrm{H}_{\mathrm{b}}\right), 3.19-3.30\left(\mathrm{~m}, 2 \mathrm{H}, 6^{\prime}-\mathrm{H}, 3^{\prime \prime}-\mathrm{H}_{\mathrm{a}}\right), 3.41(\mathrm{ddd}, \mathrm{J}=13.6,6.8$, $\left.6.8 \mathrm{~Hz}, 1 \mathrm{H}, 6-\mathrm{H}_{\mathrm{a}}\right), 3.49\left(\mathrm{ddd}, J=13.6,6.8,6.8 \mathrm{~Hz}, 1 \mathrm{H}, 6-\mathrm{H}_{\mathrm{b}}\right), 3.85\left(\mathrm{dd}, J=4.8,4.8 \mathrm{~Hz}, 1 \mathrm{H}, 3^{\prime}-\mathrm{H}\right), 3.88-3.93$ $\left(\mathrm{m}, 1 \mathrm{H}, 4^{\prime}-\mathrm{H}\right), 4.04-4.14(\mathrm{~m}, 1 \mathrm{H}, \mathrm{Leu}-2-\mathrm{H}), 4.24\left(\mathrm{dd}, J=4.8,4.5 \mathrm{~Hz}, 1 \mathrm{H}, 2^{\prime}-\mathrm{H}\right), 5.76(\mathrm{~d}, J=4.5 \mathrm{~Hz}, 1 \mathrm{H}$, $\left.1^{\prime}-\mathrm{H}\right) .{ }^{13} \mathrm{C} \mathrm{NMR}\left(126 \mathrm{MHz}, \mathrm{CD}_{3} \mathrm{OD}\right): \delta[\mathrm{ppm}]=-4.36\left(\mathrm{Si}\left(\mathrm{CH}_{3}\right)_{2} \mathrm{C}\left(\mathrm{CH}_{3}\right)_{3}\right),-4.35\left(\mathrm{Si}\left(\mathrm{CH}_{3}\right)_{2} \mathrm{C}\left(\mathrm{CH}_{3}\right)_{3}\right)$, $-4.13\left(\mathrm{Si}\left(\mathrm{CH}_{3}\right)_{2} \mathrm{C}\left(\mathrm{CH}_{3}\right)_{3}\right),-3.92\left(\mathrm{Si}\left(\mathrm{CH}_{3}\right)_{2} \mathrm{C}\left(\mathrm{CH}_{3}\right)_{3}\right), 18.90\left(\mathrm{Si}\left(\mathrm{CH}_{3}\right)_{2} \underline{\mathrm{C}}\left(\mathrm{CH}_{3}\right)_{3}\right), 18.93\left(\mathrm{Si}\left(\mathrm{CH}_{3}\right)_{2} \underline{\mathrm{C}}\left(\mathrm{CH}_{3}\right)_{3}\right)$, 22.58 (Leu-C-5), 23.41 (Leu-C-5), 25.92 (Leu-C-4), $26.41\left(\mathrm{Si}\left(\mathrm{CH}_{3}\right)_{2} \mathrm{C}\left(\mathrm{CH}_{3}\right)_{3}\right), 26.48\left(\mathrm{Si}\left(\mathrm{CH}_{3}\right)_{2} \mathrm{C}\left(\underline{\mathrm{CH}}_{3}\right)_{3}\right)$, $28.46\left(\mathrm{COOC}\left(\mathrm{CH}_{3}\right)_{3}\right), 30.43\left(\mathrm{C}-2^{\prime \prime}\right), 31.95(\mathrm{C}-5), 38.17\left(\mathrm{C}-5^{\prime}\right), 38.25(\mathrm{C}-6), 38.85\left(\mathrm{C}-3^{\prime \prime}\right), 45.71$ (Leu-C-3), $46.16\left(\mathrm{C}-1^{\prime \prime}\right), 54.68$ (Leu-C-2), $60.94\left(\mathrm{C}-6^{\prime}\right), 74.24\left(\mathrm{C}-2^{\prime}\right), 77.16\left(\mathrm{C}-3^{\prime}\right), 81.13\left(\mathrm{C}-4^{\prime}\right), 82.77\left(\mathrm{COOC}\left(\mathrm{CH}_{3}\right)_{3}\right)$, $91.61\left(\mathrm{C}-1^{\prime}\right), 154.93(\mathrm{C}-2), 172.49(\mathrm{C}-4), 174.97\left(\mathrm{C}-7^{\prime}\right), 178.16$ (Leu-C-1). MS (ESI $\left.{ }^{+}\right)$: calcd.: 758.49 [M + $\mathrm{H}]^{+}$, found: 758.57 .

\subsection{Overexpression of MraY from S. Aureus}

The overexpression of MraY was performed as described before [39,41,49].

\subsection{Fluorescence Based MraY Assay}

The assay was performed as described before [39,41,49]. Measured data and inhibition curves are shown in the Supplementary Materials Figures S1-S4.

\section{Conclusions}

In summary, we report valuable new SAR insights for synthetic analogues of muraymycin antibiotics with structural variations in the nucleoside core unit. For this purpose, we have synthesized four novel muramycin analogues 13-16. The modular preparation of 13-15 demonstrated the efficiency of a recently established bipartite approach employing a solid phase-supported protocol for the construction of the peptide moiety [42]. Furthermore, it was shown that our previously reported route towards 5'-defunctionalized nucleosyl amino acids [31] is also applicable for structurally modified nucleosides.

By in vitro evaluation of $\mathbf{1 3 - 1 6}$ as inhibitors of the bacterial target protein MraY, it was found that the introduction of substituents in the 5-position of the pyrimidine nucleobase led to a drastic loss of inhibitory potency towards MraY. In contrast, the removal of nucleobase aromaticity (by reduction of the uracil C5-C6 double bond) only resulted in a ca. tenfold decrease in activity. The formal removal of the 2'-hydroxy group, however, led to a retention of inhibitory activity, thus demonstrating that modifications of the ribose moiety might be well-tolerated. These results were in good agreement with previous $X$-ray crystallographic studies on the interaction of naturally occurring muraymycin D2 7 with MraY. This indicates that such X-ray crystal structures of MraY-inhibitor complexes can be highly useful for the structure-based design of new MraY inhibitors. In this work, only four 
nucleoside-modified muraymycin analogues were studied, thus limiting the possibility to derive robust general instructions for the future design of muraymycin analogues from the reported data. Nevertheless, the obtained SAR insights strongly suggest that nucleobase modifications should be avoided, while the ribose moiety appears to be a good choice for the introduction of novel structural variations. This may even include lipophilic moieties in order to improve the bacterial cellular uptake of otherwise rather polar muraymycin analogues, thus providing congeners with improved activities in cellulo. Such development of synthetic muraymycin analogues towards potential antibacterial drug candidates is currently on the way in our laboratories.

Supplementary Materials: The following are available online, data from the MraY assays, copies of NMR spectra and Figures S1-S5.

Author Contributions: Conceptualization, C.D.; Formal analysis, A.H., G.N., S.C.W., S.K. and C.D.; Funding acquisition, C.D.; Investigation, A.H., G.N., S.C.W. and S.K.; Project administration, C.D.; Supervision, C.D.; Writing—original draft, A.H.; Writing-review and editing, A.H., G.N., S.C.W., S.K. and C.D. All authors have read and agreed to the published version of the manuscript.

Funding: This research was funded by the Deutsche Forschungsgemeinschaft (DFG, grant DU 1095/5-1).

Acknowledgments: We thank Matthias Engel (Saarland University) for his assistance in the preparation of Figure 2 and Jannine Ludwig (Saarland University) for technical assistance in the MraY assays.

Conflicts of Interest: The authors declare no conflict of interest.

\section{References}

1. Taubes, G. The bacteria fight back. Science 2008, 321, 356-361. [CrossRef] [PubMed]

2. Cooper, M.A.; Shlaes, D. Fix the antibiotics pipeline. Nature 2011, 472, 32. [CrossRef] [PubMed]

3. Walsh, C. Where will new antibiotics come from? Nat. Rev. Microbiol. 2003, 1, 65-70. [CrossRef] [PubMed]

4. Hamed, R.B.; Gomez-Castellanos, J.R.; Henry, L.; Ducho, C.; McDonough, M.A.; Schofield, C.J. The enzymes of $\beta$-lactam biosynthesis. Nat. Prod. Rep. 2013, 30, 21-107. [CrossRef] [PubMed]

5. Dini, C. MraY Inhibitors as novel antibacterial agents. Curr. Top. Med. Chem. 2005, 5, 1221-1236. [CrossRef] [PubMed]

6. Lloyd, A.J.; Brandish, P.E.; Gilbey, A.M.; Bugg, T.D.H. Phospho-N-acetyl-muramyl-pentapeptide translocase from Escherichia coli: catalytic role of conserved aspartic acid residues. J. Bacteriol. 2004, 186, 1747-1757. [CrossRef]

7. Struve, W.G.; Neuhaus, F.C. Evidence for an initial acceptor of UDP-NAc-muramyl-pentapeptide in the synthesis of bacterial mucopeptide. Biochem. Biophys. Res. Commun. 1965, 18, 6-12. [CrossRef]

8. Anderson, J.S.; Matsuhashi, M.; Haskin, M.A.; Strominger, J.L. Lipid-phosphoacetylmuramyl-pentapeptide and lipid-phosphodisaccharide-pentapeptide: presumed membrane transport intermediates in cell wall synthesis. Proc. Natl. Acad. Sci. USA 1965, 53, 881-889. [CrossRef]

9. Heydanek, M.G.; Struve, W.G.; Neuhaus, F.C. Initial state in peptidoglycan synthesis. III. Kinetics and uncoupling of phospho-N-acetylmuramyl-pentapeptide translocase (uridine $5^{\prime}$-phosphate). Biochemistry 1969, 8, 1214-1221. [CrossRef]

10. Ikeda, M.; Wachi, M.; Jung, H.K.; Ishino, F.; Matsuashi, M. The Escherichia coli mraY gene encoding UDP-Nacetylmuramoyl-acetylmuramoyl-pentapeptide transferase. J. Bacteriol. 1991, 173, 1021-1026. [CrossRef]

11. Boyle, D.S.; Donachie, W.D. mraY is an essential gene for cell growth in Escherichia coli. J. Bacteriol. 1998, 180, 6429-6432. [PubMed]

12. Vollmer, W.; Blanot, D.; De Pedro, M.A. Peptidoglycan structure and architecture. Fems Microbiol. Rev. 2008, 32, 149-167. [CrossRef] [PubMed]

13. Wiegmann, D.; Koppermann, S.; Wirth, M.; Niro, G.; Leyerer, K.; Ducho, C. Muraymycin nucleoside-peptide antibiotics: Uridine-derived natural products as lead structures for the development of novel antibacterial agents. Beilstein J. Org. Chem. 2016, 12, 769-795. [CrossRef] [PubMed]

14. Winn, M.; Goss, R.J.M.; Kimura, K.I.; Bugg, T.D.H. Antimicrobial nucleoside antibiotics targeting cell wall assembly: Recent advances in structure-function studies and nucleoside biosynthesis. Nat. Prod. Rep. 2010, 27, 279-304. [CrossRef] [PubMed] 
15. Ichikawa, S.; Yamaguchi, M.; Matsuda, A. Antibacterial nucleoside natural products inhibiting phospho-MurNAc-pentapeptide translocase; chemistry and structure-activity relationship. Curr. Med. Chem. 2015, 22, 3951-3979. [CrossRef] [PubMed]

16. Bugg, T.D.H.; Rodolis, M.T.; Mihalyi, A.; Jamshidi, S. Inhibition of phospho-MurNAc-pentapeptide translocase (MraY) by nucleoside natural product antibiotics, bacteriophage $\phi X 174$ lysis protein E, and cationic antibacterial peptides. Bioorg. Med. Chem. 2016, 24, 6340-6347. [CrossRef] [PubMed]

17. Lin, Y.; Li, Z.; Francisco, G.D.; Mcdonald, L.A.; Davis, R.A.; Singh, G.; Yang, Y.; Mansour, T.S. Muraymycins, Novel Peptidoglycan Biosynthesis Inhibitors: Semisynthesis and SAR of Their Derivatives. Bioorg. Med. Chem. Lett. 2002, 12, 2341-2344. [CrossRef]

18. Cui, Z.; Wang, X.; Koppermann, S.; Thorson, J.S.; Ducho, C.; Van Lanen, S.G. Antibacterial Muraymycins from Mutant Strains of Streptomyces sp. NRRL 30471. J. Nat. Prod. 2018, 81, 942-948. [CrossRef]

19. Carter, G.T.; Lotvin, J.A.; McDonald, L.A. (American Cyanamid Company) Antibiotics AA-896. Int. PCT Pub. No. WO02085310 A2, 31 October 2002.

20. McDonald, L.A.; Barbieri, L.R.; Carter, G.T.; Lenoy, E.; Lotvin, J.; Petersen, P.J.; Siegel, M.M.; Singh, G.; Williamson, R.T. Structures of the muraymycins, novel peptidoglycan biosynthesis inhibitors. J. Am. Chem. Soc. 2002, 124, 10260-10261. [CrossRef]

21. Tanino, T.; Al-Dabbagh, B.; Mengin-Lecreulx, D.; Bouhss, A.; Oyama, H.; Ichikawa, S.; Matsuda, A. Mechanistic analysis of muraymycin analogues: A guide to the design of MraY inhibitors. J. Med. Chem. 2011, 54, 8421-8439. [CrossRef]

22. Chung, B.C.; Mashalidis, E.H.; Tanino, T.; Kim, M.; Matsuda, A.; Hong, J.; Ichikawa, S.; Lee, S.Y. Structural insights into inhibition of lipid I production in bacterial cell wall synthesis. Nature 2016, 533, 557-560. [CrossRef] [PubMed]

23. Koppermann, S.; Ducho, C. Natural products at work: structural insights into inhibition of the bacterial membrane protein MraY. Angew. Chem. Int. Ed. 2016, 55, 11722-11724. [CrossRef] [PubMed]

24. Wiegmann, D.; Koppermann, S.; Ducho, C. Aminoribosylated Analogues of Muraymycin Nucleoside Antibiotics. Molecules 2018, 23, 3085. [CrossRef] [PubMed]

25. Chung, B.C.; Zhao, J.; Gillespie, R.A.; Kwon, D.-Y.; Guan, Z.; Hong, J.; Zhou, P.; Lee, S.-Y. Crystal structure of MraY, an essential membrane enzyme for bacterial cell wall synthesis. Science 2013, 341, 1012-1016. [CrossRef] [PubMed]

26. Mashalidis, E.H.; Kaeser, B.; Terasawa, Y.; Katsuyama, A.; Kwon, D.-Y.; Lee, K.; Hong, J.; Ichikawa, S.; Lee, S.-Y. Chemical logic of MraY inhibition by antibacterial nucleoside natural products. Nat. Commun. 2019, 10, 2917. [CrossRef]

27. Tanino, T.; Hirano, S.; Ichikawa, S.; Matsuda, A. Synthetic study of muraymycins using Ugi-four component reaction. Nucleic Acids Symp. Ser. 2008, 52, 557-558. [CrossRef]

28. Tanino, T.; Ichikawa, S.; Shiro, M.; Matsuda, A. Total Synthesis of (-)-Muraymycin D2 and Its Epimer. J. Org. Chem. 2010, 75, 1366-1377. [CrossRef]

29. Mitachi, K.; Aleiwi, B.A.; Schneider, C.M.; Siricilla, S.; Kurosu, M. Stereocontrolled Total Synthesis of Muraymycin D1 Having a Dual Mode of Action against Mycobacterium tuberculosis. J. Am. Chem. Soc. 2016, 138, 12975-12980. [CrossRef]

30. Ries, O.; Büschleb, M.; Granitzka, M.; Stalke, D.; Ducho, C. Amino acid motifs in natural products: Synthesis of $O$-acylated derivatives of (2S,3S)-3-hydroxyleucine. Beilstein J. Org. Chem. 2014, 10, 1135-1142. [CrossRef]

31. Spork, A.P.; Wiegmann, D.; Granitzka, M.; Stalke, D.; Ducho, C. Stereoselective synthesis of uridine-derived nucleosyl amino acids. J. Org. Chem. 2011, 76, 10083-10098. [CrossRef]

32. Büschleb, M.; Granitzka, M.; Stalke, D.; Ducho, C. A biomimetic domino reaction for the concise synthesis of capreomycidine and epicapreomycidine. Amino Acids 2012, 43, 2313-2328. [CrossRef] [PubMed]

33. Ries, O.; Ochmann, A.; Ducho, C. Synthesis of $N$-alkyl-N-hydroxyguanidines: A comparative study using different protecting group strategies. Synthesis 2011, 15, 2357-2368.

34. Yamashita, A.; Norton, E.; Petersen, P.J.; Rasmussen, B.A.; Singh, G.; Yang, Y.; Mansour, T.S.; Ho, D.M. Muraymycins, novel peptidoglycan biosynthesis inhibitors: Synthesis and SAR of their analogues. Bioorg. Med. Chem. Lett. 2003, 13, 3345-3350. [CrossRef]

35. Aleiwi, B.A.; Schneider, C.M.; Kurosu, M. Synthesis of Ureidomuraymycidine Derivatives for StructureActivity Relationship Studies of Muraymycins. J. Org. Chem. 2012, 77, 3859-3867. [CrossRef] [PubMed] 
36. Spork, A.P.; Koppermann, S.; Dittrich, B.; Herbst-Irmer, R.; Ducho, C. Efficient synthesis of the core structure of muraymycin and caprazamycin nucleoside antibiotics based on a stereochemically revised sulfur ylide reaction. Tetrahedron Asymmetry 2010, 21, 763-766. [CrossRef]

37. Spork, A.P.; Ducho, C. Stereocontrolled synthesis of $5^{\prime}$ - and $6^{\prime}$-epimeric analogues of muraymycin nucleoside antibiotics. Synlett 2013, 24, 343-346.

38. Spork, A.P.; Büschleb, M.; Ries, O.; Wiegmann, D.; Boettcher, S.; Mihalyi, A.; Bugg, T.D.H.; Ducho, C. Lead Structures for New Antibacterials: Stereocontrolled Synthesis of a Bioactive Muraymycin Analogue. Chem. Eur. J. 2014, 20, 15292-15297. [CrossRef]

39. Koppermann, S.; Cui, Z.; Fischer, P.D.; Wang, X.; Ludwig, J.; Thorson, J.S.; Van Lanen, S.G.; Ducho, C. Insights into the Target Interaction of Naturally Occurring Muraymycin Nucleoside Antibiotics. ChemMedChem 2018, 13, 779-784. [CrossRef]

40. Tanino, T.; Ichikawa, S.; Al-Dabbagh, B.; Bouhss, A.; Oyama, H.; Matsuda, A. Synthesis and biological evaluation of muraymycin analogues active against anti-drug-resistant bacteria. ACS Med. Chem. Lett. 2010, 1, 258-262. [CrossRef]

41. Spork, A.P.; Koppermann, S.; Schier, S.; Linder, R.; Ducho, C. Analogues of muraymycin nucleoside antibiotics with epimeric uridine-derived core structures. Molecules 2018, 23, 2868. [CrossRef]

42. Leyerer, K.; Koppermann, S.; Ducho, C. Solid Phase-Supported Synthesis of Muraymycin Analogues. Eur. J. Org. Chem. 2019, 2019, 7420. [CrossRef]

43. Zhu, X.-F.; Williams, H.J.; Scott, A.I. Facile and highly selective 5'-desilylation of multisilylated nucleosides. J. Chem. Soc. Perkin Trans. 1 2000, 2305-2306. [CrossRef]

44. Khan, A.T.; Mondal, E. A highly efficient and useful synthetic protocol for the cleavage of tert-Butyldimethylsilyl (TBS) ethers using a catalytic amount of acetyl chloride in dry methanol. Synlett 2003, 5, 694-698. [CrossRef]

45. Burk, M.J. C2-symmetric bis(phospholanes) and their use in highly enantioselective hydrogenation reactions. J. Am. Chem. Soc. 1991, 113, 8518-8519. [CrossRef]

46. Masquelin, T.; Broger, E.; Müller, K.; Schmid, R.; Obrecht, D. Synthesis of enantiomerically pure D- and L-(heteroaryl)alanines by asymmetric hydrogenation of (Z)- $\alpha$-amino- $\alpha \beta$-didehydro esters. Helv. Chim. Acta 1994, 77, 1395-1411. [CrossRef]

47. Ducho, C.; Hamed, R.B.; Batchelar, E.T.; Sorensen, J.L.; Odell, B.; Schofield, C.J. Synthesis of regio- and stereoselectively deuterium-labelled derivatives of L-glutamate semialdehyde for studies on carbapenem biosynthesis. Org. Biomol. Chem. 2009, 7, 2770-2779. [CrossRef]

48. Brandish, P.E.; Burnham, M.K.; Lonsdale, J.T.; Southgate, R.; Inukai, M.; Bugg, T.D.H. Slow binding inhibition of phospho-N-acetylmuramyl-pentapeptide-translocase (Escherichia coli) by mureidomycin A. J. Biol. Chem. 1996, 271, 7609-7614. [CrossRef]

49. Wohnig, S.; Spork, A.P.; Koppermann, S.; Mieskes, G.; Gisch, N.; Jahn, R.; Ducho, C. Total Synthesis of Dansylated Park's Nucleotide for High-Throughput MraY Assays. Chem. Eur. J. 2016, 22, 17813-17819. [CrossRef]

50. Brandish, P.E.; Kimura, K.I.; Inukai, M.; Southgate, R.; Lonsdale, J.T.; Bugg, T.D.H. Modes of action of tunicamycin, liposidomycin B, and mureidomycin A: Inhibition of phospho-N-acetylmuramyl-pentapeptide translocase from Escherichia coli. Antimicrob. Agents Chemother. 1996, 40, 1640-1644. [CrossRef]

51. Stachyra, T.; Dini, C.; Ferrari, P.; Bouhss, A.; van Heijenoort, J.; Mengin-Lecreulx, D.; Blanot, D.; Biton, J.; Le Beller, D. Fluorescence detection-based functional assay for high-throughput screening for MraY. Antimicrob. Agents Chemother. 2004, 48, 897-902. [CrossRef]

52. Bouhss, A.; Crouvoisier, M.; Blanot, D.; Mengin-Lecreulx, D. Purification and characterization of the bacterial MraY translocase catalyzing the first membrane step of peptidoglycan biosynthesis. J. Biol. Chem. 2004, 279, 29974-29980. [CrossRef] [PubMed]

Sample Availability: Samples of the target compounds are available from the authors.

(C) 2019 by the authors. Licensee MDPI, Basel, Switzerland. This article is an open access article distributed under the terms and conditions of the Creative Commons Attribution (CC BY) license (http://creativecommons.org/licenses/by/4.0/). 